Florida International University FIU Digital Commons

10-10-2016

\title{
Role of Students' Participation on Learning Physics in Active Learning Classes
}

Binod Nainabasti

Florida International University, bnain001@fiu.edu

DOI: $10.25148 /$ etd.FIDC001211

Follow this and additional works at: https://digitalcommons.fiu.edu/etd

Part of the Other Physics Commons, and the Special Education and Teaching Commons

\section{Recommended Citation}

Nainabasti, Binod, "Role of Students' Participation on Learning Physics in Active Learning Classes" (2016). FIU Electronic Theses and Dissertations. 3022.

https://digitalcommons.fiu.edu/etd/3022

This work is brought to you for free and open access by the University Graduate School at FIU Digital Commons. It has been accepted for inclusion in FIU Electronic Theses and Dissertations by an authorized administrator of FIU Digital Commons. For more information, please contact dcc@fiu.edu. 


\title{
FLORIDA INTERNATIONAL UNIVERSITY
}

Miami, Florida

\section{ROLE OF STUDENTS' PARTICIPATION ON LEARNING PHYSICS IN ACTIVE LEARNING CLASSES}

\author{
A dissertation submitted in partial fulfillment of the \\ requirements for the degree of \\ DOCTOR OF PHILOSOPHY \\ in \\ PHYSICS \\ by
}

Binod Nainabasti

2016 
To: Dean Michael R. Heithaus

College of Arts, Sciences, \& Education

This dissertation, written by Binod Nainabasti, and entitled Role of Students' Participation on Learning Physics in Active Learning Classes, having been approved in respect to style and intellectual content, is referred to you for judgment.

We have read this dissertation and recommend that it be approved.

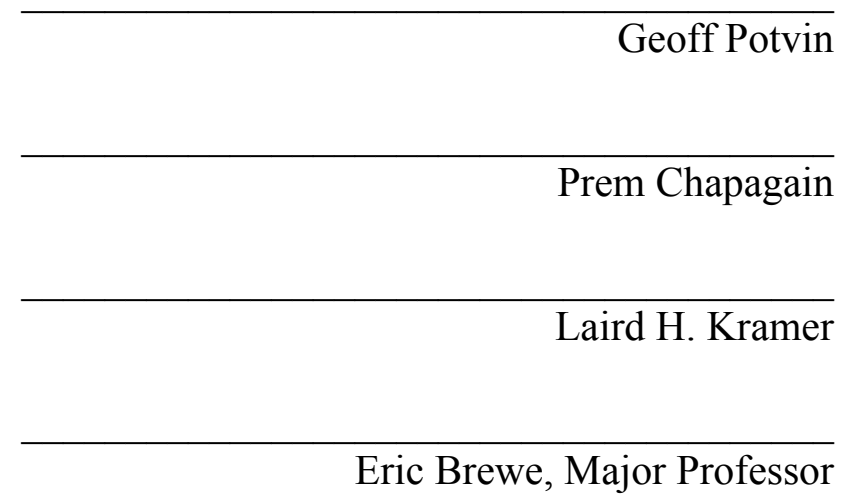

Date of Defense: October 10, 2016

The dissertation of Binod Nainabasti is approved.

Dean Michael R. Heithaus

College of Arts, Sciences and Education

Andres G. Gil

Vice President for Research and Economic Development and Dean of the University Graduate School

Florida International University, 2016 
(C) Copyright 2016 by Binod Nainabasti

All rights reserved. 


\section{DEDICATION}

This dissertation is dedicated to my father. 


\section{ACKNOWLEDGMENTS}

This dissertation research was supported by the National Science Foundation (Grant No. 0802184). Any findings, opinions, conclusions, or recommendations expressed in this material are those of the author and do not necessarily reflect the views of the National Science Foundation.

I do not have sufficient words to praise my dissertation advisor, Eric Brewe, who has rescued me from the middle of the ocean to a nice imaginative port. He is an amazing friendly mentor. I would like to recognize Laird H. Kramer for his support, encouragement, motivation, and guidance to complete this study. I am grateful to the other members of my committee: Prem Chapagain and Geoff Potvin for their feedback and support for this study.

I have been lucky to be a member of an admirable Physics Education Research Group at FIU while conducting this research. I have received great feedback and suggestions from hours of discussion in PER graduate students' weekly meetings, PER group meetings and research workshops. FIU PER folks have helped in the framing of ideas, and formulating thoughts. I am grateful to Zahra Hazari, Leanne Wells, David Jones, Vashti Sawtelle, Renee Michelle Goertzen, Geraldine Cochran, Adrienne Traxler, Hagit Kornreich-Leshem, Idaykis Rodriguez, Jianlan Wang, Rocio Benabentos, Justyna Zwolak, Seth Manthey, Natan Samuels, Remy Dou, Jessica Bartley, Daryl McPadden, Eric Williams, Feng Li, Jackie Doyle, Jonathan Mahadeo.

I am very grateful to David Brookes for his guidance for this research. I would also like to acknowledge Yuehai Yang for his help in coding the videos and developing coding scheme, Celestine William for her help in synchronizing the videos and audios. 
I would like to extend my great thanks to the FIU Physics Department for supporting me during my many years to finish this study. I would also like to acknowledge graduate writing consultants of Writing Center of FIU for their help in writing this dissertation.

Finally, a sincere thanks goes to: my mother, Punamaya; my wife, Shobha; my son, Biraj and all other family members and friends here in the USA and in Nepal for their support for this study. 


\section{ABSTRACT OF THE DISSERTATION \\ ROLE OF STUDENTS' PARTICIPATION ON LEARNING PHYSICS IN ACTIVE \\ LEARNING CLASSES}

by

Binod Nainabasti

Florida International University, 2016

Miami, Florida

Professor Eric Brewe, Major Professor

Students' interactions can be an influential component of students' success in an interactive learning environment. From a participation perspective, learning is viewed in terms of how students transform their participation. However, many of the seminal papers discussing the participationist framework are vague on specific details about what student participation really looks like on a fine-grained scale. As part of a large project to understand the role of student participation in learning, this study gathered data that quantified students' participation in three broad areas of two student-centered introductory calculus-based physics classes structured around the Investigative Science Learning Environment (ISLE) philosophy. These three broad areas of classes were inclass learning activities, class review sessions that happened at the beginning of every class, and the informal learning community that formed outside of class time. Using video data, classroom observations, and students' self-reported social network data, this study quantified students' participation in these three aspects of the class throughout two semesters. The relationship between behaviors of students' engagement in various 
settings of an active learning environment and (a) their conceptual understanding (measured by FCI gain) and (b) academic success in the courses as measured by exam scores and scores on out-of-class assignments were investigated. The results from the analysis of the student interaction in the learning process show that three class components, viz. the Review Session, Learning Activities, and Informal Learning Community, play distinct roles in learning. Students who come in the class with better content knowledge do not necessarily participate more in the learning activities of active learning classrooms. Learning Communities serve as a "support network" for students to finish assignments and help students to pass the course. Group discussions, which are facilitated by students themselves, better help students in gaining conceptual understanding. Since patterns of students' participation do not change significantly over time, instructors should try to ensure greater participation by incorporating different learning activities in the active learning classroom. 


\section{TABLE OF CONTENTS}

CHAPTER

PAGE

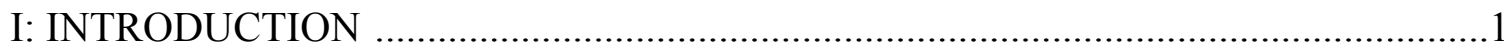

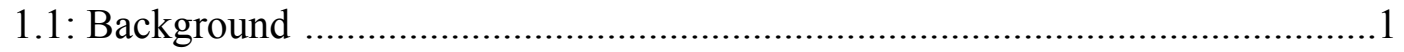

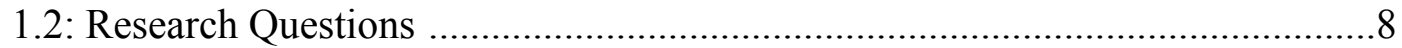

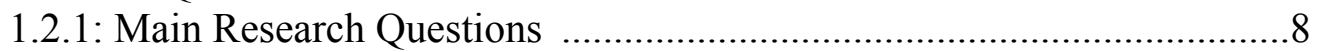

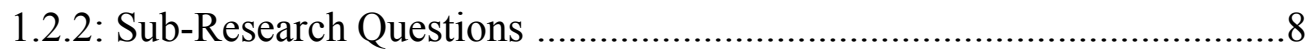

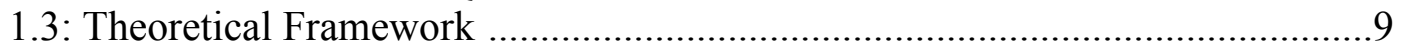

1.4: Definition of Important Terms....................................................................... 11

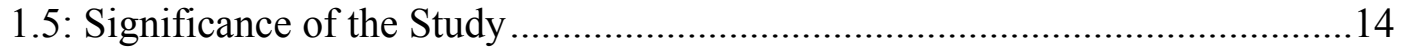

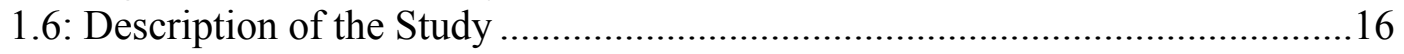

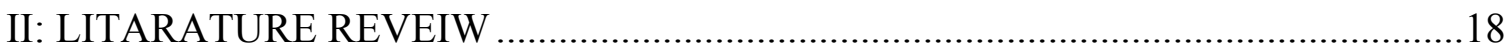

2.1: Active Learning Environments and Active Learning Pedagogies.................18

2.1.1: Commonly Used Science Education Reform Efforts.............................19

2.1.2: Effectiveness of Active Learning ........................................................22

2.2: Students' Participation in Active Learning Environment...............................27

2.3: The Role of Interaction in Learning .............................................................

2.4: Practices of Review Sessions in Active Learning Classroom ........................32

2.5: Out of Class Social Network and Its Impact on Learning ..............................35

2.5.1: Social Network and Learning Communities...........................................36

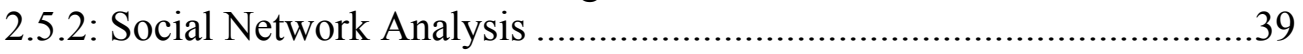

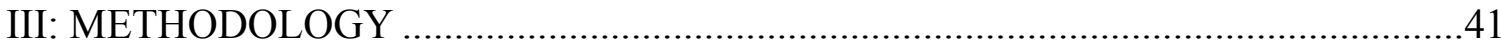

3.1: Features of ISLE Classes in this Study .....................................................4

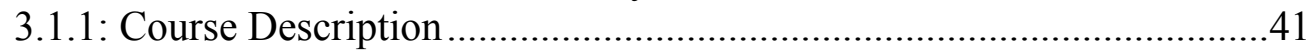

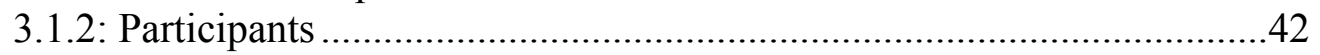

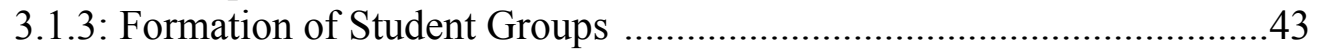

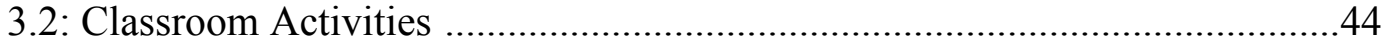

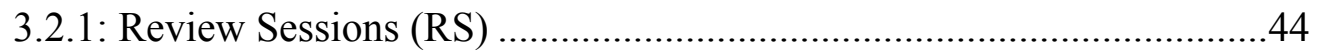

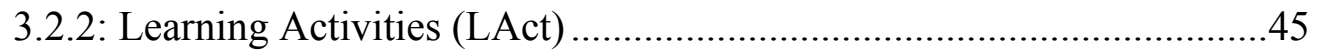

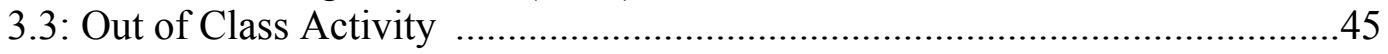

3.3.1: Informal Learning Communities (ILC) .............................................45

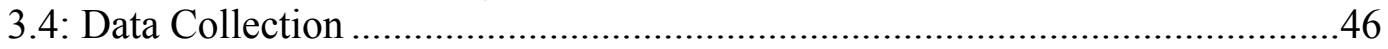

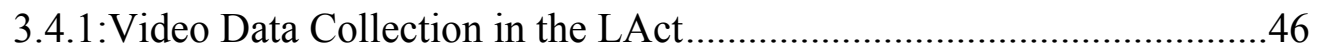

3.4.2: Quantifying Students' Participation in the LAct.....................................4

3.4.3: Quantifying Students' Participation in the RS ...................................50

3.4.4: Quantifying Students' Participation in the ILC...................................53

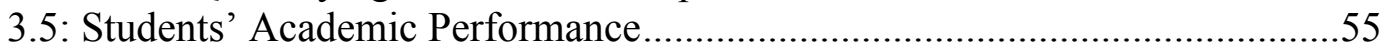

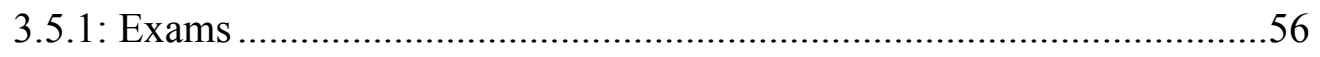

Group Component for Each Exam ……………………....................56

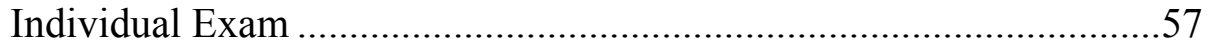

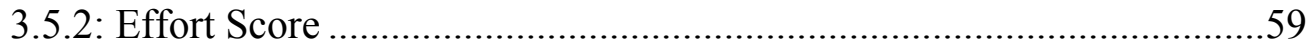




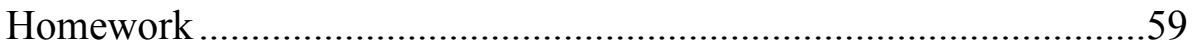

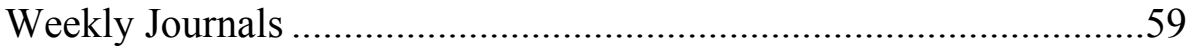

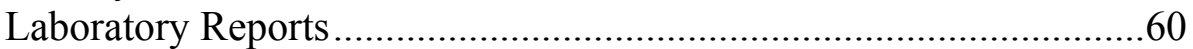

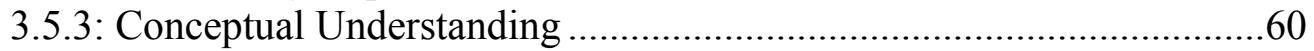

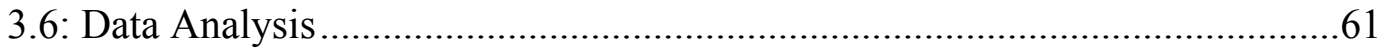

3.6.1: Main Research Question A .........................................................61

3.6.2: Main Research Question B .............................................................63

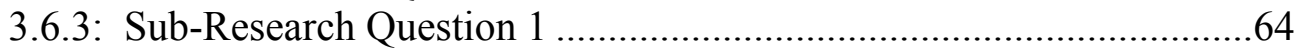

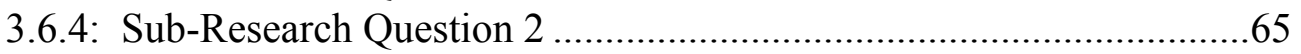

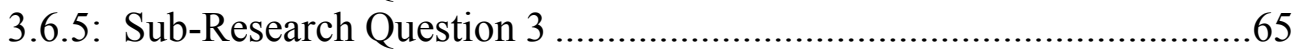

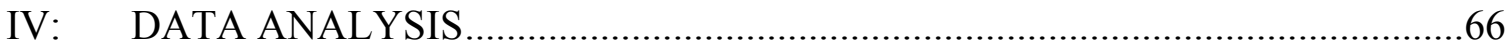

4.1: Relation Between Participation in LAct, RS and ILC, and Academic

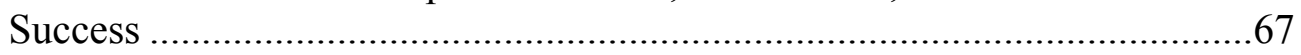

4.1.1: Relation Between Participation in LAct and Academic

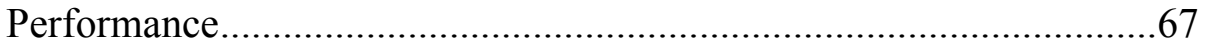

4.1.2: Relation Between Participation in the RS and Academic

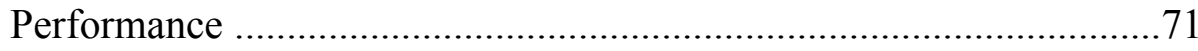

4.1.3: Relation Between Participation in the ILC and Academic Performance .............................................................................. 73

4.1.4: Relation Between PageRank Centrality and Students' Grades .............75

4.2: Pattern of Students' Participation in LAct, RS and ILC ...................................76

4.2.1: Pattern of Students' Participation in the ILC ……….............................77

4.2.2: Pattern of Students' Participation in the LAct .......................................8 80

4.2.3: Pattern of Students' Participation in the RS ..........................................83

4.2.4: Comparison of Students' Engagement in the Interaction in LAct,RS, and ILC Between the Fall and Spring Semesters ..................86

4.2.5: Comparison of Students' Participation in LAct, RS and ILC ...............88

4.3: Data Analysis Related to the Sub-Research Questions ....................................89

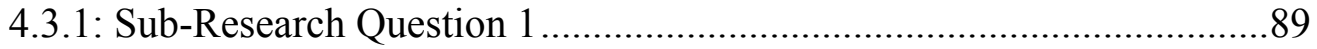

4.3.2: Sub-Research Question 2 ...............................................................90

4.3.3: Sub-Research Question 3 ................................................................93

V:RESULTS, DISCUSSIONS, IMPLICATIONS and FUTURE WORKS,

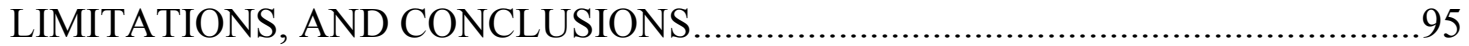

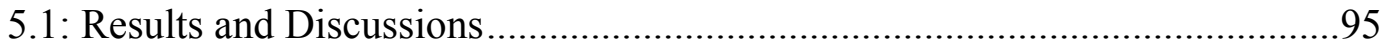

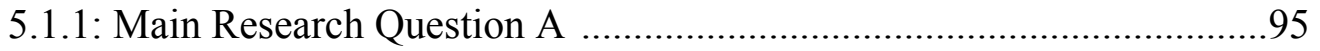

5.1.2: Main Research Question B ..................................................................99

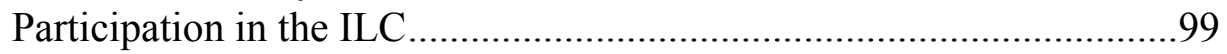

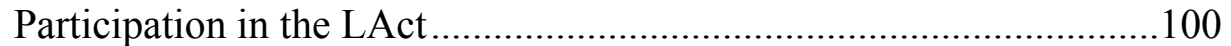

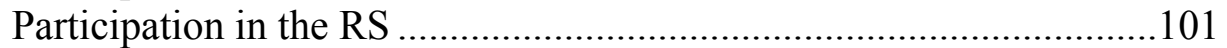

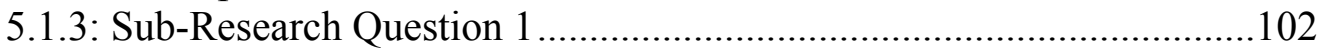

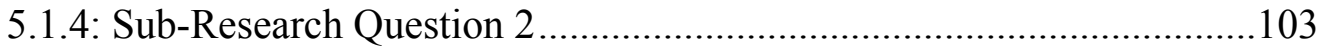

5.1.5: Sub-Research Question 3 ……….................................................104

5.2: Implications of this Research....................................................................105 


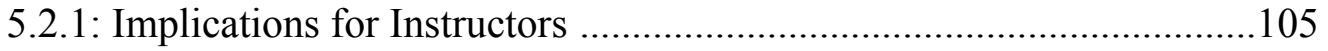

5.2.2: Implications for Students ..............................................................106

5.2.3: Implications for Researchers …....................................................106

5.3: Directions of Future Research ..................................................................107

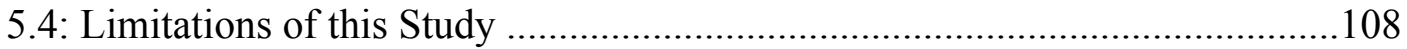

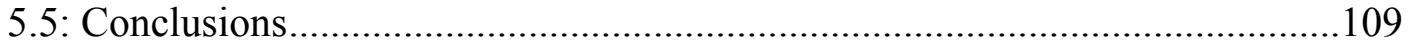

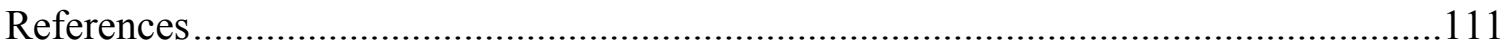

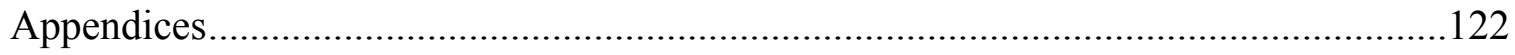

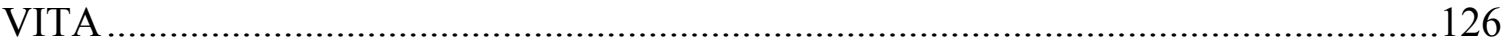




\section{LIST OF TABLES}

TABLE

PAGE

Table 1: Coding Scheme for Learning Activities ..........................................................

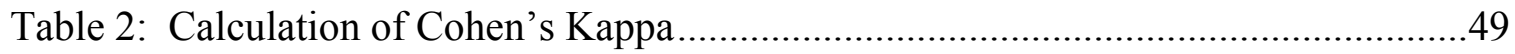

Table 3: Coding Scheme for Review Sessions ............................................................51

Table 4: Coding Example of One Review Session..........................................................52

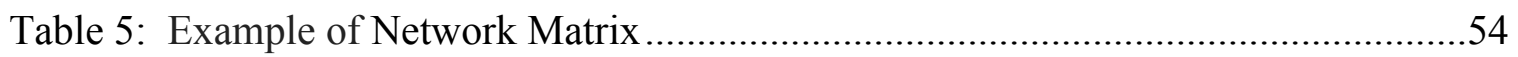

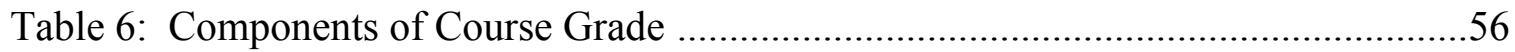

Table 7: Example of Group Exam and Related Individual Exam ..................................57

Table 8: Methods of Correlation for Students' Participation and Success .......................62

Table 9: Permutation Correlation Coefficient Between Coding Categories of LAct and Students' Performance in Fall 2013.

Table 10: Permutation Correlation Coefficient Between Coding Categories of LAct and Students' Performance in Spring 2014.

Table 11: Permutation Correlation Coefficient Between Participation in the RS and Students' Performance in the Fall and Spring Semesters

Table 12: Spearman's Correlation Coefficient Between PageRank Centrality and Students' Performance in the Fall and Spring Semesters .

Table 13: Characteristics of Social Network of ILC during Fall and Spring Semesters .75

Table 14: Wilcoxon Signed-Rank Test Between the PageRank Centrality of Three Time Segments of the Fall Semester....

Table 15: Paired t-test Between the Interaction Code Over the Three Time Segments of the Fall Semester

Table 16: Wilcoxon Signed-Rank Test Between the Interaction Code of RS in Three Time Segments of the Fall Semester 
Table 17: Model: Role of Participation on Conceptual Understanding

Table 18: Model: Role of Participation on Exam Score

Table 19: Model: Role of Participation on Effort Score in Fall

Table 20: Model: Role of Participation on Effort Score in Spring ................................93

Table 21: Correlation Coefficients Between Pre-FCI and Students' Participation .94 


\section{LIST OF FIGURES}

FIGURE

PAGE

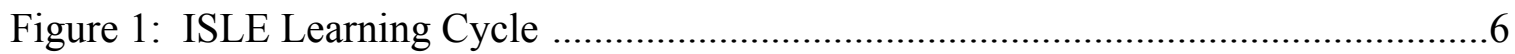

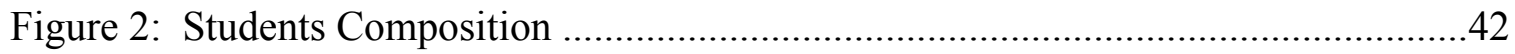

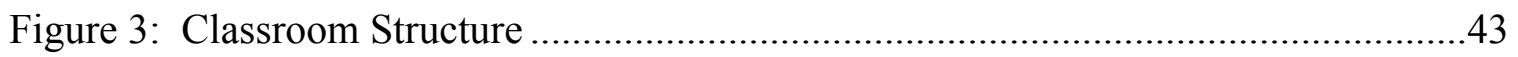

Figure 4: Average Distribution of Codes of Students' Behaviors in the LAct during the Fall and Spring Semesters ...............................................................6 68

Figure 5: Average Distribution of Codes of Students' Behaviors in the RS during the Fall and Spring Semesters

Figure 6: Average Course Grade Binned With PageRank Centrality in Tertile in the Fall and Spring semesters ............................................................. 76

Figure 7: Scatter Plot of PageRank in Three Time Segments of the Fall semester .79

Figure 8: Relation Between PageRank Centrality of Common Students in both Fall 2013 and Spring 2014

Figure 9: Scatter Plot of Interaction Code in the LAct in Three Time Segments of the Fall semester

Figure 10: Relation Between Each Category of Coding in the LAct for Common Students in the Fall and Spring Semester

Figure 11: Scatter Plot of the Interaction Code of RS in Three Time Segments of the Fall Semester

Figure 12: Relation Between Each Category of Coding in the RS for the Common Students in the Fall and Spring Semester .85

Figure 13: Scatterplot of Students' Participation in LAct, RS and ILC Between the Fall and Spring Semesters 


\section{CHAPTER I: INTRODUCTION}

\subsection{Background}

Considerable effort has gone into reforming introductory Science, Technology, Engineering, and Mathematics (STEM) courses under the assumption that traditional lecture-based instruction is ineffective and causes many STEM students to drop out from STEM majors (Mccray, Dehaan, \& Anne, 2003; Seymour, DeWelde, \& Fry, 2011). Reformers believe that STEM courses should help students to integrate basic concepts into conceptual frameworks, link prior learning to new knowledge, and develop scientific reasoning and problem-solving skills that support the application of concepts to new situations. They also believe that these goals are rarely realized for the majority of students in the traditional lecture model (Mccray et al., 2003). In order to overcome this situation, numerous researchers, government agencies and other stakeholders have called for the improvement of standard lecture delivery by incorporating active learning in the classroom (Marcey \& Brint, 2012; Freeman et al., 2014).

Active learning is a pedagogy in which students are encouraged to build up their learning independently (Eberlein et al., 2008). Active learning encourages students to interact/participate more in the learning process, which promotes positive attitudes toward learning, better affiliations among students, greater academic accomplishment and improved persistence level in STEM courses and programs (Freeman et al., 2014; Armbruster et al., 2009; Gleason et al., 2011; Hoellwarth et al., 2005; Felder, Felder, \& Dietz, 1998; Mikropoulos, Chalkidis, Katsikis, \& Kossivaki, 1997). The President's Council of Advisors on Science and Technology (PCAST) report (2012) has given substantial credit to active learning by saying "Classroom approaches that engage 
students in 'active learning' improve retention of information and critical thinking skills, compared with a sole reliance on lecturing, and increase persistence of students in STEM majors. STEM faculty need to adopt teaching methods supported by evidence derived from experimental learning research as well as from learning assessment in STEM courses" (Olson \& Riordan, 2012, p. iii). On the basis of these national reports, researchers and practitioners in STEM fields have developed and implemented reformed curricula in highly interactive and student-centered learning environments in formal settings, called active learning environments.

In addition to these national reports, numerous researchers have also discussed the benefit of active learning strategies in the classroom and highlighted the role of students' engagement in learning and retention. Education psychologist Svinicki (2013) mentions several benefits of active learning drawn from theory. They are: students are more likely to discover meaningful solutions or explanations, access their prior knowledge, receive more recurrent and instant feedback, increase self-reliance and self confidence, increase formation of knowledge that in the long run assists cognitive development, and acquire a knowledge of how to collaborate with others persons with different behaviors and attitudes. Similarly, Vygotsky (1962) emphasized the role of interaction in learning by stating that, “...differences in the condition of social interaction between children in different settings plays a decisive role in understanding" (p. 37).

There are some statements about the role of students' participation in learning that motivated this study. Bonwell and Eison (1991) cited "all genuine learning is active, not passive. It is a process of discovery in which the student is the main agent, not the teacher" (Adler, 1982, p. 3). In the widely cited book, Situated learning: Legitimate 
peripheral participation, Lave \& Wenger (1991) suggested that "the understanding to be gained from engagement ... can be extremely varied depending on the form of participation" (p. 173). To enhance and empower learning, active learning approaches are appropriate methods that support the development of skills and behaviors (Griffiths 2004). Therefore, researchers from different fields have been identifying the importance of students' involvement in the learning process.

As the number of proponents of active learning rises, educators in different arenas including STEM fields have started to develop and implement new curricula for active learning that require students' active participation in the learning process. Along with implementing active learning pedagogy, researchers have been developing various methodologies to examine its effectiveness over traditional methods of teaching. Results of these studies in STEM fields are summarized in a meta-analysis of 225 papers and it is concluded that when students are actively involved in their learning process, they are more likely to be successful and less likely to fail than in traditional learning settings (Freeman et al., 2014).

Active learning methods are consistently more successful than lecture instruction in science and engineering courses at all levels (Wieman \& Gilbert, 2015). In the field of physics, more efforts have been devoted to implementation of active learning pedagogy in introductory physics courses. Physics Education Researchers have developed several active learning methods to teach physics courses. For example, at Florida International University (FIU), physics faculty has been implementing two types of active learning curricula for introductory physics courses: Modeling Instruction (MI), guided by the 
modeling theory of instruction (Hestenes, 1987) and Investigative Science Learning Environment (ISLE), directed by the ISLE learning cycle (Etkina et. al., 2007).

Several studies have been done on active learning physics classes to investigate the effectiveness of active learning strategies over traditional methods of teaching. A large study that integrated more than 6,000 physics students of several introductory physics courses from different universities and colleges found that students in classes that utilized active learning and interactive engagement strategies in the learning process remarkably enhance their conceptual understanding and problem-solving ability (Hake, 1998). Along with improved conceptual understanding and problem-solving ability, active learning settings provide students with opportunities to learn, to negotiate meaning, and to become members of a learning community (Brewe et. al., 2010).

Previous research on active learning strategies has focused on the relation between students' engagement and their performance by either analyzing students' engagement from one activity or investigating performance at the macro level. Most research measured students' success on the basis of their grades and conceptual inventory. However, a university classroom that is primarily student centered, where students co-construct their knowledge through the process of empirical investigations and reach consensus through scientific argumentation, is not a common practice in the research literature. Researchers should go further to measure students' success beyond conceptual inventory and grades (Goertzen, Brewe, \& Kramer, 2012) to find the effectiveness of active-learning in learning and teaching. None of the available studies conducted in-depth longitudinal research on how different types of engagement in an active learning environment affects their academic performance and how students 
transform or change their participation through the course as they learn how to learn in an interactive student-centered learning environment.

This study will analyze the varying forms of students' engagement across two semesters in different settings of mostly student-centered active learning introductory physics classes that implemented the Investigative Science Learning Environment (ISLE) philosophy. The benefit of the longitudinal study is that it is able to identify productive and unproductive characteristics of students' behavior in active learning environments and how they transform their participatory behavior over the semesters when they are involved in a student-centered learning environments. The present study will also investigate how these characteristics are associated with their success through the courses.

The chosen classes for this study were active learning introductory physics classes that implemented the ISLE philosophy. Most of the learning activities were taken from the active learning guide by Van Heuvelen (Van Heuvelen, 2005). Details about these classes are presented in the methodology section of this study. A brief description of ISLE is presented in the following section.

\section{Investigative science learning environment (ISLE)}

Investigative Science Learning Environment (ISLE) is an approach to teaching that suggests students should learn physics by engaging in processes that reflect the activities of physicists when they construct and apply knowledge (Etkina et al., 2006). Developers of ISLE created a series of activities in which students repeatedly engage while learning physics. They put these activities in a cycle, called the ISLE cycle, Fig 1. 


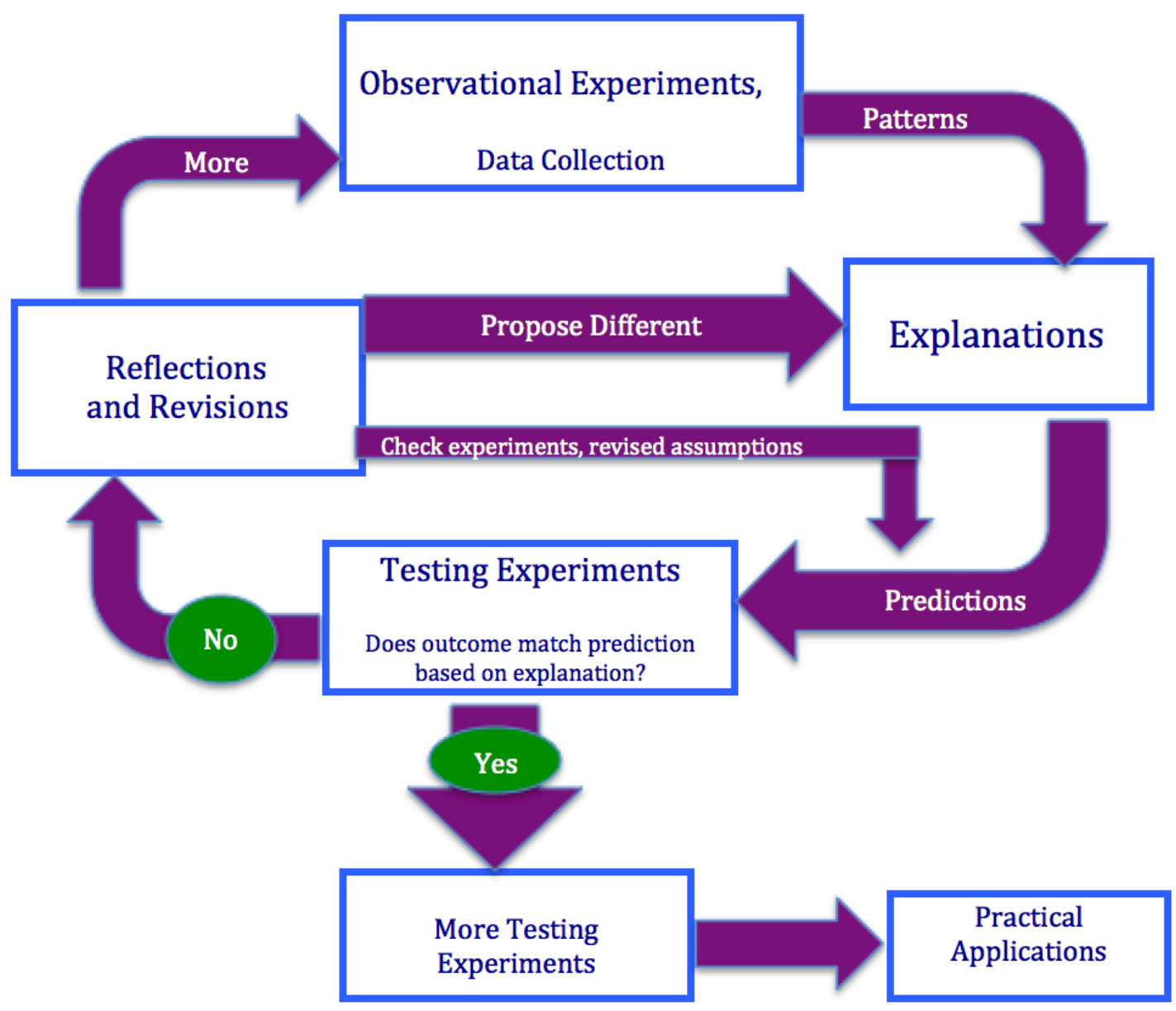

Figure 1. ISLE Learning Cycle (Etkina \& Van Heuvelen, 2006; Cancula et al. 2015)

There are two main features of the ISLE approach. The first feature involves development of students' ideas by “(a) observing phenomena and looking for patterns, (b) developing explanations for these patterns, (c) using these explanations to make predictions about the outcomes of testing experiments, (d) deciding if the outcomes of the testing experiments are consistent with the predictions, and (e) revising the explanations if necessary" (Etkina \& Heuvelen, 2007, p.4). The second main feature is "inspiring students to represent physical processes in various ways, thus helping them develop 
productive representations for problem solving and for reasoning" (Etkina \& Heuvelen, 2007, p.4). The combination of these features can be applied to every conceptual unit in the ISLE philosophy.

According to the developers of ISLE, it is a comprehensive learning system that provides a general philosophy and specific activities that can be used in a variety of settings, ranging from a fully student-centered studio-like setting to lectures (interactive meetings where students construct and test ideas), recitations (where students learn to represent them in multiple ways while solving problems) and labs (where students learn to design their own experiments to test hypotheses and solve practical problems). Details of the ISLE methodology are provided in "Investigative Science Learning Environment A Science Process Approach to Learning Physics" (Etkina \& Heuvelen, 2007). Using this approach to learning, extensive curriculum materials have been developed for different student populations, from middle school to advanced physics courses. Learning physics through ISLE produces substantial learning gains on standardized tests, such as the CSEM (Maloney, O'Kuma, Hieggelke, \& Van Heuvelen, 2001), FCI (Hestenes, Wells, \& Swackhamer, 1992) and on the assessments of science practices (Etkina et al., 2010).

Several research reform curricula, including ISLE, are trying to implement highly interactive and student-centered learning environments in formal teaching. The core elements of active learning are student activity and engagement in the learning process (Prince, 2004). However, not much research has been done on the interaction behavior that students should excercise to excel in an active learning environment. The present study will address the following research questions. 


\subsection{Research Questions}

The research questions investigated in this study can be classified as the main research questions and the sub- research questions.

\subsubsection{Main Research Questions}

The main research questions of the study are:

A. What are the different ways in which students participate in learning both inside and outside of the classroom and what kind of relationships exist between how they participate and their success in the class?

B. How do students transform or change their participation through the course as they learn how to learn in an interactive student-centered learning environment?

In addition to these main questions, the following sub-questions are also investigated.

\subsubsection{Sub-Research Questions}

1. What is the relation between students' participation in various aspects of an interactive learning physics class and their conceptual understanding?

2.Which aspects of the interactive learning class play the greatest role in students' success?

3. Does students' prior physics knowledge of conceptual understanding bias their participation in an interactive learning environment? 


\subsection{Theoretical Framework}

The present study is motivated by three theoretical approaches to learning. They are the participationist framework, constructivist learning theory, and social cognitive theory. Students' participation in an active learning environment is influenced by three factors (behavioral, environmental and personal) of social cognitive theory (Zimmerman, 1989). Characteristics of these factors direct students' participation in the learning process, which is associated with constructivism that promotes active learning (Bandura, 1986; Mayer, 2004).

In the participationist framework, learning is an ongoing process of transformation of participation in which people contribute knowledge in shared endeavors (Rogoff, 1990). Participation theory helps us recognize the bidirectional interaction between learning and students' identity. Researchers believe that transformation of knowledge occurs through participation as "the idea that learning and development occur as people participate in the socio-cultural activities of their community, transforming their understanding, roles and responsibilities as they participate" (Rogoff, Matusov, \& White, 1996, p. 390). Students' knowledge acquisition through engagement and collaboration depends on several factors, such as their knowledge, attitude, skills, self-efficacy and the environment around them (Bandura, 1977, 1986). Engagement also provides opportunities for students to learn to negotiate meaning and to become members of a learning community (Brewe et al., 2010; Zhu \& Baylen, 2005), and their inherent and external factors will influence their leaning. These 
factors are classified in three groups in social cognitive theory; behavioral, environmental and personal (Schunk \& Zimmerman, 1998).

These three factors of social cognitive theory are interrelated and may assist in better learning. Personal experience can converge with behavioral determinants and environmental factors (Zimmerman, 1989). Flower (1994) emphasizes the role of social cognitive theory in learning through interaction. The author argues that participants have to engage to make the interaction meaningful by responding, negotiating internally and socially, adding to evolving ideas, and offering complementary perspectives with one another, while doing allocated assignments. These are the essential factors in the classroom environment to influence students' participation for meaningful interaction (Flower, 1994; Wade, 1994). Therefore, the theoretical foundation for relationships between students' participative behaviors in different aspects of the interactive learning classes and their learning comes from emphasizing the social and contextual nature of learning and development with constructivism theory (Bandura, 1971; Lave \& Wenger, 1991; Rogoff, 1990; Vygotsky, 1962; Vygotsky, 1978; Wertsch, 1991).

In social constructivist learning theory, educators need to understand clearly the nature of students' engagement to increase the effectiveness of interactions in learning (Vygotsky, 1978). Active learning is identified as an important principle of constructivist approach to learning. A constructivist approach in teaching and learning requires one to change various habitual ways for thinking and participating in active learning (Gulati, 2008). Participative, social cognitive, and constructive theories consider the different aspects of students' engagement when the students are involved in an active learning environment by focusing on the relationships between individual, social, and 
environmental factors to meet the goal of the activity in the learning communities. Therefore, it is appropriate to take these theories as the guiding theoretical approach for this study. Studying the nature and importance of student interactions will be the primary focus of this study.

\subsection{Definition of Important Terms}

\section{Investigative Science Learning Environment (ISLE): Investigative Science} Learning Environment (ISLE) is a instruction approach that involves students' development of their own ideas by "observing phenomena and looking for patterns, developing explanations for these patterns, using these explanations to make predictions about the outcomes of testing experiments, deciding if the outcomes of the testing experiments are consistent with the predictions, revising the explanations if necessary, and encouraging students to represent physical processes in multiple ways" (Etkina \& Van Heuvelen, 2007, p. 4).

2. Modeling Instruction (MI): Modeling Instruction (MI) is a reformed pedagogical approach where lecture, recitation, and lab are merged in a studio format. The MI approach focuses on model development and testing in a collaborative learning environment, in which a model is the conceptual representation of a real thing. Modeling Instruction helps students in developing student abilities to understand scientific claims, make sense of physical experience, communicative coherent opinions of their own and support them with convincing arguments, assess evidence in support of acceptable belief (Brewe, 2008; Hestenes, 1987; Wells, Hestenes, \& Swackhamer, 1995). 
3. Diagnostic test: "A test with items in a multiple- choice or short answer format that has been designed with common misconceptions in mind" (Rollnick \& Mahooana, 1999).

4. Force Concept Inventory (FCI): Force Concept Inventory is a multiple-choice diagnostic test for Newtonian Mechanics that focuses on the conceptual understanding. It has 30 multiple-choice questions, given in paper/pencil format (Hestenes et al., 1992). When it is administered in the beginning of the semester, then it is called PRE FCI score and for the end of the semester, POST FCI score.

5. FCI Gain: Force Concept Inventory (FCI) gain is calculated by using the formula [(POST-PRE)/(100-PRE)]. This gain is called Hake gain (Hake, 1998). For this study, PRE FCI score is considered as a measurement of students' conceptual understanding prior to the course.

6. Learning Activities (LAct): The instructor ran the class according to the basic sequence of the ISLE learning cycle, using a set of worksheets based on the Active Learning Guide (Van Heuvelen, \& Etkina, 2005). The contents of these worksheets are what this study refered to as "Learning Activities" (LAct). On a particular physics topic, learning activities typically began with experimentation to explore physical phenomena, finding patterns in the data and developing physical relations and hypotheses to explain observational data.

7. Review Session (RS): Each class started with a review session where the entire class worked together and anyone could participate. Review sessions were structured around two questions "what did we learn last class?" and "did anything remain unclear?" 
Sessions usually lasted 15-20 minutes and were largely student-directed with minimal intervention from the instructors. The instructor needed some facilitators to lead the review session. Therefore, the instructor assigned one group (three students) to lead each review session each class (Nainabasti, Brookes, \& Yang, 2015).

8. Informal Learning Community (ILC): Self-reported learning communities of students outside the class are referred to as informal learning communities (ILCs) in this study. The researcher asked students to self-report every week "who they worked with" outside of class. The "who worked with whom" data allowed the researcher to build up a social network diagram of the ILC that formed outside of class time.

9. Journal: Students were required to write a report on their learning every week by answering these three questions: (a) Write a paragraph about what you learned this week, (b) Is there anything that remains unclear from this week? (c) If you were the instructor, what question would you ask to determine whether your students had learned this week's material? (Etkina, 2000; May \& Etkina, 2002). This report was called "Journal" for this study.

10. Group Exam: The group exam was designed to assess students' ability to learn by themselves with the collaboration of their classmates (Lin \& Brookes, 2013). A problem was given to students that needed to be solved using physics they have not yet learned. Generally, the group exam problem was too difficult to solve individually. Therefore, ingroup exams, students were allowed to work together as a whole class to answer the given problem and they could use all the available resources (text book, notes, homework, internet, etc). 
11. PageRank Centrality: PageRank is a link analysis algorithm with the purpose of quantifying the importance of a node within the network. In a simple definition, the value of PageRank Centrality of a node is the probability of arriving at a particular node from any other in the entire network (Bruun \& Brewe, 2013). The mathematical theory behind the PageRank Centrality is presented in Page et al. (1999).

12. Active Learning: In simple terms, an instructional method that requires students' engagement in the learning process is called active learning. Several researchers and educators have defined active learning differently. The definition of active learning used in this dissertation is from Greenwood Dictionary of Education,

\footnotetext{
"The process of having students engage in some activity that forces them to reflect upon ideas and how they are using those ideas. Requiring students to regularly assess their own degree of understanding and skill at handling concepts or problems in a particular discipline. The attainment of knowledge by participating or contributing. The process of keeping students mentally, and often physically, active in their learning through activities that involve them in gathering information, thinking, and problem solving" (Collins, \& O'Brien, 2011, p.6)
}

\subsection{Significance of the Study}

The present study will attempt to fill the gap of micro (Jung \& Choi, 2002; Rashidi \& Naderi, 2012; Swing \& Peterson, 1982; Webb \& Mastergeorge, 2010, 2013; Webb, 1982, 1984, 1991) and macro-level study (Freeman et al., 2014; Hake, 1998; McKeachie et al., 1986) of the role of the engagement of students in learning in the active 
learning environment by analyzing the students' engagement in various settings of active learning classrooms across two semesters. The research has significance to students, instructors, and researchers because it explores the characteristics of active learning classes. The study will introduce students with a typical example of an interactive learning class and its features. It will provide the information about productive and unproductive behaviors that students pose in different aspects of the active learning environment, such as interaction among students in a small group, interaction in a whole class and participation in the informal learning community outside the class. Findings from the research will illustrate the ways that students can benefit in learning when they choose to take active learning classes for college physics.

The research will also help instructors in many ways. First, it will provide information about various aspects of the active learning classrooms and general patterns of students' engagement in each classroom setting. Second, once instructors identify students' productive and unproductive behavior in the interactive learning classes, they can create a situation that minimizes the chances of unproductive behavior. It is very important to keep the learning environment friendly by maximizing productive behavior. Third, it will help the instructor create strategies to make the class more effective and interactive so that every student will have opportunities to share and transfer the knowledge.

Education researchers, who are mainly involved in the curriculum design and practices for active learning environment, will also benefit from this research. There have been no studies evaluating the association between students' behaviors in active learning 
reform classes and their success through courses so far. If the researchers know the association between the students' behavior in different aspects of an active learning class and their success through the course, they may be able to provide a different insight on the reform process of teaching, learning, and curriculum development.

\subsection{Description of the Study}

This section describes a short overview of remaining chapters of this study. Chapter 2 presents the literature review from the foundations of active learning to the most recent research. On the basis of the research questions, the literature review is divided into five sub-sections. Chapter 3 describes the methodology. It begins with the description of an active learning class at its component where the study was conducted, and how I quantified students' engagement/participation/interaction in different settings of two active learning introductory physics classes that implemented ISLE curriculum. Chapter 3 also presents how I measured the students' success through the course. Lastly, the statistical methods used to identify and quantify associations between students' interactions and their successes in the courses are described.

Chapter 4 describes the data analysis used to address the research questions.. Chapter 5 presents the results and discussion for each of the research questions of this study. Chapter 5 summarizes the results of the data analysis that identifies patterns of student interaction and collaboration, both inside and outside of the classroom and recaps the findings on how students' interaction contributes when they were engaged in different aspects of the interactive learning class to their success. Chapter 5 also describes the

implication of the research results on its stakeholders: students, instructors and 
researchers who are involved in education research and policy. Meanwhile, this research not only tries to address the role of students' engagement in different settings of active learning classes, but also presents potential future research in this area. Some limitations of this study are also disclosed in this chapter before conclusion. 


\section{CHAPTER II: LITERATURE REVIEW}

This review of literature analyzes student participation in and out of the active learning classroom by examining the relation between student engagements in different settings of active learning classes and their performance. The literature review is divided into the following five sections: (1) Active learning environment and active learning pedagogies (2) Students participation in active learning environment. (3) Role of interaction in learning (4) Practices of review sessions in active learning classroom, and (5) Out of class social network and the impact on learning. The purpose of exploring these five strategies is to create a foundation for my study in order to show the necessity of investigating specific ways students participate within different learning settings of active learning environment classrooms.

\subsection{Active Learning Environments and Active Learning Pedagogies}

The active learning environment, also known as the interactive or studentcentered learning environment, is a type of learning setting in which students are encouraged to interact in the process of building their own mental models from the knowledge they are acquiring (Modell \& Michael, 1993; Machemer and Crawford, 2007). Student-centered learning is an approach to teaching that focuses attention on the activities, ideas, and conceptions of the learner. Active learning promotes student engagement in the learning process. It is developed from the idea that student passivity does not support or enhance learning (Machemer \& Crawford, 2007). Active Learning is defined as a method of teaching that employs "instructional activities involving students in doing things and thinking about what they are doing" (Bonwell \& Eison, 1991, p.2). 
Most of the reform-oriented science educators believe that learning and retention improve when the learning process happens in an active learning environment (Prince, 2004). Summarizing the effectiveness of active learning pedagogies, Micheal (2006) described a conclusion about why active learning classes should be implemented:

"There is evidence that active learning, student-centered approaches to teaching physiology work, and they work better than more passive approaches. There is no single definitive experiment to prove this, nor can there be given the nature of the phenomena at work, but the very multiplicity of sources of evidence makes the argument compelling. Therefore, we should all begin to reform our teaching, employing those particular approaches to fostering active learning that match the needs of our students, our particular courses, and our own teaching styles and personalities. There are plenty of options from which we can choose, so there is no reason not to start. This will mean that we too become learners in the classroom"(Michael, 2006, p. 165 ).

\subsubsection{Commonly Used Science Education Reform Efforts}

Science education researchers strive to transform conventional science education by introducing different reform efforts that mainly focus on active learning (Bybee, 1997). There are several types of reform classes that implement an interactive learning environment. Therefore, several researchers formulated different active learning environments, each with some differences of modalities in teaching and learning. In all formats, active learning requires students' active and collaborative participation in the learning process. For example, some commonly used active learning strategies and philosophy include Peer Instruction (PI) (Mazur, 1997), Process-oriented Guided Inquiry Learning (POGIL) (Eberlein et al., 2008), Problem-based Learning (PBL) (Hmelo-Silver, 
2004), Peer-led Team Learning (PLTL) (Gosser \& Roth, 1998), Modeling Instruction (MI) (Hestenes, 1987; Jackson, Dukerich, \& Hestenes, 2005), Investigative Science Learning Environment (ISLE), (Etkina et al., 2006), Student-Centered Activities for Large Enrollment Undergraduate Programs (SCALE-UP) (Beichner et al., 2007) among others.

The main goal of these instructional strategies and philosophies is to help students learn more effectively within student-centered learning settings and activities. However, what these studies take for granted is how different levels of participation influence the learning process. There has been no research on how students engage in an active learning classroom or what the relationship is between the different ways students choose to participate and how these choices impact their success in the active learning environment. Nevertheless, these studies have contributed significantly to educational reforms and have made subsequent research possible, like the one presented here. Thus, describing such significant studies will be useful to my own efforts.

One such study is POGIL, which is a group learning, student-centered instructional philosophy first implemented in general chemistry in 1994. Currently, it is employed in various subjects in many colleges. POGIL was built with the idea that students learn best when they are actively engaged and thinking about the learning process (Hanson, 2006). Another study is problem-based learning (PBL), a studentcentered instructional method in which students work collaboratively in groups to find what problem requires solving and then resolve it together. In this method, the instructor does not provide knowledge, but rather facilitates the learning process (Hmelo-Silver, 
2004). In Peer-Led Team Learning (PLTL), students also have to work collaboratively with their peers to solve challenging problems. Additionally, PLTL encourages students to work in groups on a given topic (Gosser and Roth, 1998). Another widely used strategy is Modeling Instruction (MI), which also focuses on collaborative learning to develop and test models of conceptual representations of real world problems (Hestenes, 1987).

A more recent active learning approach is Investigative Science Learning Environment (ISLE). It requires student involvement in each step of the learning process. As presented in the Figure 1 (page 6), ISLE involves student development of ideas through observing, finding patterns, developing hypotheses for these patterns, testing hypotheses based on these explanations, deciding if the outcomes of the testing experiments are consistent with the predictions, and changing the hypothesis if necessary (Etkina \& Van Heuvelen, 2007).

Student-Centered Activities for Large Enrollment Undergraduate Programs (SCALE-UP) is another common type of active learning environment specifically designed for collaborative learning in a studio-like setting. The classroom settings are structured to facilitate interactions among students in a team and between teams of students who work on learning activities. It has been practiced in many colleges and universities all over the world and research has found significant improvements in student learning from implementation of SCALE-UP (Beichner et al., 2007, Goertzen et al. (2012). 
In the literature of these reform efforts, different philosophies stressed different methodologies of teaching. These reform efforts need students' active engagement in learning: PI expects argumentation development (Mazur, 1997); PBL focuses on thinking strategies and domain knowledge; PLTL emphasizes leadership development; SCALE-UP centers on collaboration in computer-rich environments (Beichner et al. 2007); MI encourages students to "make sense of physical experience, understand scientific claims, articulate coherent opinions of their own and defend them with cogent arguments, evaluate evidence in support of justified belief" (Lucas, 2014, p. 5); and POGIL and ISLE claim that learning happens in a cycle that consists of exploration, concept invention, testing and application (Eberlein et al., 2008; Etkina \& Van Heuvelen, 2007). Therefore, although there were some differences in wording, all reform efforts agreed that students' active participation in the learning process requires students to construct knowledge.

\subsubsection{Effectiveness of Active Learning}

To promote active learning environments, researchers established and implemented the above student-centered approaches. The primary goal of these approaches is to establish a hands-on, highly collaborative interactive learning environment in which the instructor acts as a facilitator rather than the source of knowledge. There is a great deal of research that has demonstrated improvements in conceptual understanding from these active learning instructional approaches in comparison to traditional lecture-laboratory classes. Brewe et al. (2010) investigated the conceptual understanding of students enrolled in introductory physics classes of both studio format active learning classes that implemented university Modeling Instruction 
(MI) curriculum and traditional lecture classes that have been taught for several years at Florida International University. In MI, students performed better in post instruction Force Concept Inventory than students taught in lecture-format classes. (FCI; Hestenes \& Wells, 1992). In a sample size of around 1000 students (258 MI students and 758 Lecture students), MI students scored $61.9 \%$ correct on the post-FCI versus students in traditional lecture scoring $47.9 \%$ correct. The difference was statistically significant (Brewe et al., 2010).

Burrowes (2003) compared learning performance in two sections of the same general biology I course taught by the same instructor. One section was taught in an active learning setting that followed constructivist ideas (the experimental group of 104 students), whereas the other was taught in the traditional teacher-centered manner (control group of 100 students). The results of this experiment were remarkable: the mean exam score of the experimental section was significantly higher than that of students in the control section, and students in the experimental section performed better on problems that specifically tested their skill to "think like a scientist." In the study, students' were tested in three stages of the semester: after six weeks of instruction, after 12 weeks of instruction and at the end of the semester (Burrowes, 2003). In all exams, the average scores of students in the experimental groups were significantly better than in the control section. The study contributes to the evidence that teaching in a constructivist, active learning environment is more effective to increase conceptual understanding than traditional instruction, fostering academic success, increasing higher level thinking abilities, and enhancing students' interest in the subject (Burrowes, 2003). 
Additionally, SCALE-UP classes demonstrated improvement in conceptual understanding as compared with traditional lecture-laboratory classes by getting higher normalized gains in the mechanics pre/post force and motion concept tests at North Carolina State University (NCSU), University of Central Florida (UCF), University of New Hampshire (UNH), Rochester Institute of Technology (RIT), and Coastal Carolina University (CCU) (Beichner et al., 2007). In the same study, researchers found a two to three times increase in normalized gain on pre/post conceptual learning assessments: the Force Concept Inventory (FCI) (Hestenes \& Wells, 1992), the Conceptual Survey of Electricity and Magnetism (Maloney et al., 2001), the Force and Motion Conceptual Evaluation (FMCE) (Thornton \& Sokoloff, 1998), and the Electric Circuit Conceptual Evaluation (ECCE) (Sokoloff, 1996). They also mentioned that failure rates are drastically reduced by fifty percent when students take active learning classes (Beichner et al., 2007).

In an effort to reduce the failure rate in an entry course for biology majors in the traditional lecture settings, Freeman et al. (2007) tested five-course designs that varied in the structure of daily and weekly active learning exercises. The study was organized in three phases. First, to better comprehend and explain the previous failure and to forecast students' performance, they analyzed students' characteristics on the basis of whether they took those courses earlier or not. Second, they designed and implemented four different courses. Third, they picked one of these four and compared it to a new course design in the following semester (Freeman et al., 2007). When researchers compared students' academic performance in earlier versions of the identical course taught by the 
same teachers to the students' performance in the new course design that implemented active-learning exercises, students in the newly designed course had better performance, higher total exam points, significantly lower failure rates, and higher scores on an identical midterm (Freeman et al., 2007).

Before Freeman et al. (2007), Knight \& Wood (2005) also uncovered a compelling support for the superiority of the interactive approach over traditional lecture setting by comparing normalized learning gains calculated from the difference between post-test and pre-test scores. They performed an examination to test whether studentlearning enhancements in a large, traditionally taught upper-level biology course changing to a more interactive classroom format could enhance lecture courses. This study was carried out in two successive semesters. They used an identical course syllabus in both semesters, but implemented different teaching styles: in spring 2004, they made the class more interactive by integrating some active learning strategies, whereas the traditional lecture format was used in fall 2003. They investigated the normalization gain in these two consecutive semesters and found a significant $16 \%$ difference $(p=.001)$ in average learning gains and a 33\% improvement in performance by students in the active learning setting course of spring 2004. Students in the interactive class achieved greater than $60 \%$ learning gain compared to the traditional class (Knight \& Wood, 2005).

Similarly, two decades earlier, Hake (1998) studied more than six-thousand physics students of several introductory physics courses from different universities and colleges. He found that, in a Newtonian diagnostic test (Force Concept Inventory), students in classes that utilized active learning and interactive engagement techniques 
improved $25 \%$ with an average gain of $48 \%$ compared to a gain of $23 \%$ for students in traditional, lecture-based courses,. Once instructors switched their physics classes from traditional instruction to active learning, students' learning was enhanced by $38 \%$, from around $12 \%$ to over $50 \%$ on the same diagnostic test (Hoellwarth \& Moelter, 2005).

More importantly, Freeman et al. (2014) compared students' performance in active learning versus traditional lecture settings by meta-analyzing 225 studies (they claimed that this was the largest and most comprehensive meta-analysis of undergraduate STEM education published to date). They found that average exam scores improved by $\sim 6 \%$ in active learning sections. They also revealed that students were 1.5 times less likely to pass in traditional classes than in classes with active learning settings.

In contrast to the above studies, using data collected from three different quarters over the course of 2 years, Hoellwarth, Moelter, and Knight (2005) found two conflicting results. The normalized learning gain in conceptual understanding that was measured by using the Force Concept Inventory (FCI) (Hestenes \& Wells, 1992) and the Force and Motion Conceptual Evaluation (FMCE) (Thornton \& Sokoloff, 1998)) was significantly larger for students in the studio sections that implemented an active learning environment. At the same time, students in the active learning studio format classrooms performed the same, or slightly worse, on quantitative final exam problems (Hoellwarth et al., 2005).

All of these active learning approaches have focused on student engagement/participation in their knowledge acquisition. Active and collaborative teaching together with various means to encourage student engagement led to better 
academic achievement, regardless of academic discipline (Kuh et al., 2005). Therefore, students' participation in the learning process is one of the major parts in the implementation of active learning. None of the research investigated how students are involved in the learning process in active learning environments. Therefore, further research on how students participate in active learning environments has become essential to validate the active learning methods in teaching and learning.

\subsection{Students' Participation in Active Learning Environment}

All these different active learning methods have one thing in common: they emphasize the role of students' participation in their learning. Many research studies found that when students are involved more actively in learning activities, they learn better and improve critical thinking (Smith 1977; Webb 1982, 1984). Therefore, examination of students' level of participation in the active learning environment is important to understand its effectiveness in the learning process.

Dancer and Kamvounias (2005) assessed students' classroom participation using both instructors' and students' feedback. In the first step of this research, students were asked to explain why class participation could be an important component of the course and how they thought it should be graded. Using student responses and instructors' opinions, they came up with five criteria of measurement for classroom participation. They were: preparation (e.g., understanding and analyzing of material), contribution (e.g., expressing an opinion and asking a question), group skills (e.g., assisting others), communication skills (e.g., quality of expression), and attendance (e.g., punctuality). They used these criteria to measure students' level of participation in the classroom with 
a five-point rating scale: very good, good, average, fair, and poor. They claimed that students had the opportunity to improve the quality of participation through peer and instructors feedback. However, they did not discuss the association between students' ways of participation and their academic performance in the course. They also did not examine the students' participation in off-topic and disengagement while they were engaging in the learning process. They admitted that measurement of student participation is very difficult.

Participation contains many activities that range in duration from a few seconds to an extended period of time - it is very subjective and difficult to measure (Rocca, 2010). Handelsman et al. (2005) mentioned: "Student engagement is considered an important predictor of student achievement, but few researchers have attempted to derive a valid and reliable measure of college student engagement in particular courses" (p. 184). Even faculty who achieve student success can find it to be a challenge to document which specific classroom practices are the most successful in engaging student learning (Savory, 2012).

Despite the difficulties of quantifying students' participation, there are numerous benefits. Rocca (2010) cited that "Students are more motivated (Junn, 1994), learn better (Daggett, 1997; Garard, Hunt, Lippert, \& Paynton, 1998; Weaver \& Qi, 2005), become better critical thinkers (Crone, 1997; Garside, 1996), and have self-reported gains in character (Kuh \& Umbach, 2004) when they are prepared for class and participate in discussions" (p.188). Additionally, less memorization is needed when students participate more, which also helps in higher levels of cognition, analysis, comprehension and 
synthesis (Smith, 1977). There are many other benefits of student participation. For example, students who participate also show enhancement in their communication abilities (Dancer \& Kamvounias, 2005), better grades as their participation rises (Handelsman et al., 2005), and learners thought involvement is "essential" to their own learning (Fritschner, 2000).

A number of studies pointed out that participation/engagement in the learning process has an important role in academic success. However, at the same time, scholars have also found that only a small percentage of students in the classroom like to participate. Karp and Yoels (1976) found that only 30\% of students in any given classroom tend to participate. Similarly, around two decades later, Howard and Henney (1998) found that about $90 \%$ of interactions were made by a handful of students and only around $33 \%$ were regular participators, while $50 \%$ of the students observed and did not participate at all (Howard \& Henney, 1998). According to Rocca (2010), several earlier studies (Crombie, Pyke, Silverthorn, Jones, \& Piccinin, 2003; Fritschner, 2000; Howard et al., 1996; Nunn, 1996) have confirmed this finding, that is only a low percentage of students are involved in participation in the class.

Most of the studies took place in regular lecture classes that integrated some active learning techniques. These investigations have shown that more than half of the students did not participate at all (Howard \& Henney, 1998; Karp \& Yoels, 1976; Rocca, 2010). However, I have not seen any study about the investigation of the frequency of student participation and the way in which they participate in an active learning classroom that implemented reform curricula. 


\subsection{The Role of Interaction in Learning}

The literature refers to students' interaction and students' participation or engagement interchangeably. However, as will be shown in the current study, interaction is one characteristic within the larger category of participation. That is, participation is broken down into several categories, such as off-topic, disengagement, writing/drawing, and interaction (interaction being defined as Communicating with other students or instructors in audible words regarding the subject). As such, interaction has become an integral part of students' behavior in an active learning environment. In a 2012 White House report titled "Engage to Excel", the United States President's Council of Advisors on Science and Technology (PCAST) described the importance of students' engagement in learning. Engaging students in active learning will increase student retention and improve performance in STEM courses. The PCAST report made a reference to a study that mentioned: "students in traditional lecture courses were twice as likely to leave engineering and three times as likely to drop out of college entirely compared with students taught using active learning techniques" (Olson \& Riordan, 2012, p.6).

Anderson (2003) referred to John Dewey $(1933,1916)$ and mentioned that education should focus on more than merely knowledge retention and should include an emphasis on interaction. As Anderson cited, Dewey stated that interaction is a major factor of the learning process that happens when students change the inert information passed to them from someone else and construct this information into knowledge with its own value and function (Anderson, 2003). Smith (1977) designed an exploratory study to examine the connection between critical thinking and students' classroom behaviors. 
Those students' behaviors were: peer-to-peer interaction, student participation, questions from instructor, and faculty encouragement and use of student ideas. The "Watson-Glaser Critical Thinking Appraisal and the Chickering behavioral self-report index" was used to assess students' critical thinking. Twelve classes from different disciplines were covered in the study and found that critical thinking was significantly and positively associated with students' peer-to-peer interaction. Moreover, Vygotsky (1978) realized the importance of interaction and stated that interaction in the learning process has been recognized as one of the most significant constituents of students' behavior in learning.

Swing and Peterson (1982) examined students' abilities and behaviors during small-group interactions. Results indicated that task-related collaboration in the small group enhanced the achievement and retention of high and low ability students, but impeded the success of medium ability students (Swing \& Peterson, 1982). Webb (1984, 2010) also found similar results from the help giving and taking perspective. In her study, she identified a different level of interaction on the basis of students' ability while they were engaging in the learning process in small groups. She also revealed some significant associations between student interaction and achievement and identified that individual ability and group composition are the major predictors of students' interaction in the learning process (Webb, 1991, 2010, 2013).

In more recent active learning teaching approaches, such as MI, ISLE, SCALEUP, POGIL, PLP, interaction has been accepted as one of the vital and critical components of the education process in active learning settings. However, none of the available studies examined the role of students' interaction in an active learning 
environment longitudinally. More importantly, current theories or suggestions for enhancing student learning do not focus broadly on their engagement in effective educational practices (Rabourn, Shoup, \& Brckalorenz, 2015). Therefore, longitudinal study of students' interactive behavior in active learning settings is very important.

\subsection{Practices of Review Session in Active Learning Classroom}

Generally, review sessions are known as preparation meetings to help students before exams and are mostly intended to support students' learning for imminent assessments. In a normal review session in problem-based courses, mentors make a set of problems from the content of the course that they have covered in a certain segment to test students. The mentors normally answer problems for the students, focusing on the vital concepts needed to review for the test (Grady, 2014). Reviews are also done in a question and answer manner. These meetings are not intended to help students learn new material; instead, they focus on gaps in the previously learned subject material. However, reviews help students to identify significant ideas and better prepare for solving subject related problems if instructors incorporate active or cooperative learning approaches during review sessions (Favero, 2011). To help students in their learning, some educators have implemented some active learning techniques in review settings.

Favero (2011) implemented two different types of review sessions during the class time. He implemented open-ended strategies in one type and close-ended strategies in the other. In both types of the review session, active learning and peer instruction approaches were utilized. In review sessions that implemented closed-ended strategies, he 
gave problems taken from the past exams and students worked individually first and then in-group to know more about the given problems. However, the open-ended approach was unique. He used overhead transparencies for this approach in the class. He began the review session using a "think/write, pair, share" strategy. In this activity, each student was asked to write down the five main concepts or facts from the current section of the course. And then students were asked to compare their results in the group of three. Finally, all the facts and concepts that students brought up in the class were presented via overhead projector. He found that open-ended strategies in the review session helped him comprehend students' existing level of thinking and it provided students a chance to know the key topics and concepts from the course and to reflect on their learning.

Grady (2014) practiced a different kind of review session that she called an "inverted" review session. In this inverted review session, the whole class was divided into small groups of 3-5 students, and each group was assigned to choose a problem from different review topics. Students had to prepare a solution for the assigned problems in 15 minutes, and then each group was asked to present its problem and solution to the class for the rest of the class time. Usually, these review sessions were conducted before the exam. From these review sessions, she expected to promote students' intrinsic motivation and help better their academic performance. Unfortunately, Grady did not examine the students' participation in the review session with their academic achievement.

Blazer's (2014) teaching tactics of classroom review expanded on other types of review by including a three to five minutes summary of the main ideas discussed in the previous class. Each class began with someone asking the question "What did we do last 
time". The researcher pointed out several achievements that result from this practice. First, it assists students with concentration by recapping what they covered in the previous class. Second, it provides students with a way to give a presentation without much pressure while receiving feedback from peers and instructors. Participation in the review process might be beneficial if there is a larger stakes presentation assignment later in their academic career. And lastly, participation in classroom review requires students to use their skills of "summarizing, condensing, and prioritizing information"(Blazer, 2014, p. 344).

Giving students opportunities to share in front of the class what they did not understand in the previous class creates opportunities for peer-to-peer teaching. Such a collaborative and active learning technique increased retention of information and improved student attitudes (Chickering \& Gameson, 1987; Prince, 2004). Blazer's classroom review happened during the regular class time. However, there are practices of conducting optional help sessions outside of class time to help students in their success on the exam. For example, in a study of "how do help sessions accomplish in introductory science courses", Jensen and Moore (2009) examined students' participation in traditional help sessions in a large introductory biology course. They found that students who joined help sessions earned better grades than those who did not attend.

All of the studies about the review session have looked at overall performance between the control and experimental group, but none of them looked at how students engaged in the review session or how they improved their academic performance. However, in this study, review sessions are introduced as a part of everyday class activity 
by incorporating active and cooperative learning approaches in an active learning environment, just like the review practices conducted by Blazer (2014). The benefits of review sessions of what students learned in their earlier classes have not been thoroughly investigated in active learning environments. Although according to Bruner, (1983) "True learning involves figuring out how to use what you already know in order to go beyond what you already think" (as quoted by Lundy, 2007 p. 20). The current study tries to identify the benefits of review sessions that happened in the beginning of the class by examining the association between the frequency of student participation and their success throughout the course and how they change their participatory behavior across the semesters.

Most of the active learning approaches have focused on students' engagement/participation and its impact on their knowledge acquisition. Active and collaborative teachings, together with various approaches, are used to encourage student participation in and out of the class for better academic achievement, regardless of academic discipline (Kuh et al., 2005). However, how students transform their participation through the course as they learn how to learn in an interactive studentcentered learning environment has not yet been investigated longitudinally.

\subsection{Out of Class Social Network and Its Impact on Learning}

Interaction not only occurs inside, but it also takes place outside of the classroom. Students' engagement in educational settings outside of the classroom is a foundation for high levels of students learning and personal development, as well as an indicator of educational effectiveness (Kuh, 1996). One way that students participate out of the classroom is social networking. Social networks of learning communities have become a 
fundamental part in the learning process when learners are associated with the active learning classroom (Traxler, 2015; Gleason et al., 2011).

\subsubsection{Social Network and Learning Communities}

The social network is a structure comprised of a set of actors, some of whose members are linked by a set of one or more relations. A relation is a specific kind of connection or tie between a pair of actors. These kinds of relations might be either directed or undirected. The connection where one actor initiates and the second actor receives is called directed. Connections are treated as undirected if either actor indicates a tie without considering who connected whom (Knoke and Yang, 2008). Social networks play an important function in learning communities as essential channels for knowledge sharing and as foundations of social support (Cadima, Ojeda, \& Monguet, 2012).

The importance of student interactions and participation in a learning community are established as the foundation of sociocultural learning theory (Vygotsky, 1978). Learning communities are receiving substantial attention by higher education researchers and practitioners. Although the concept of learning communities in teaching and learning started in the 1920s (Smith, 2001), a current version of the learning community surfaced in the late 1980s (Zhao \& Kuh, 2004). The goal of the learning community is to advance the collective knowledge and use it to support the growth of individual knowledge (Scardamalia \& Bereiter, 1994). Learning communities incorporate collaborative and active learning activities and encourage involvement in academic and social activities that spread outside the classroom (Brewe, Kramer, \& Sawtelle, 2012). The connections 
between actors of learning communities play an important role in transferring knowledge and information.

Although the network of learning communities are receiving significant consideration by higher education researchers and experts (Zhao \& Kuh, 2004), there has not been a great deal of research on this regarding undergraduate education (Grunspan, Wiggins, \& Goodreau, 2014). Grunspan et al. (2014) mentioned that the nature of social networks in the academic arena and its impact on learning outcomes can inform educators in unique ways and improve educational reform. Depending on the topic of interest, characteristics of social networks have been utilized differently: sociologists have investigated how acquaintances assist people in finding employment (Granovetter, 1983), computer search engines, for example Google, are sorting out the web page based on frequency of connections between links and its users (Lunt et al., 2015), and educators have investigated how academic achievement is affected when students are part of a social network (Bruun \& Brewe, 2013). Moreover, social networks have been effectively used to examine and create models in academic performance, GPA, conceptual understanding, classroom behaviors (William et al., 2015; Bruun \& Brewe, 2013; Grunspan, Wiggins, \& Goodreau, 2014), and scientific collaboration (Newman, 2001).

Williams et al. (2015) studied a social network of who received help from whom inside the class. They asked students who interacted with whom during a specific week five-times during a semester in an active learning physics classroom that implemented Modeling Interaction curriculum. They examined the association between network centrality and students' conceptual understanding, measured by a diagnostic test FMCE. They found a statistically significant association between students' interactions in the 
classroom with the learning gain. Similarly, Bruun and Brewe (2013) examined the students' centrality in different social networks associated with three different interaction categories: (1) Students' interaction about how to solve physics problems in the active learning physics classes (2) Students' interactions on conceptual learning and (3) social interactions among students not related to the content of the classes. They found significant connections between centrality measures and students' future grades. Grunspan et al. (2014) examined impact of in-class study network on students' academic performance. They also found a significant association between the students' centrality in the study network and their exam scores over the semester.

All these studies mainly focused on in-class student networks that formed in the classroom. Some researchers even investigated out of class learning networks, as this research has done; however, those studies only examined virtual networks. For example, Yang and Chen (2008) investigated virtual social networks formed from peer-to-peer collaboration and found that cooperation through a virtual social network helps in sharing knowledge and assists community members in finding content and cooperative, knowledgeable colleagues who are ready to share their information. Cadima et al. (2012) conducted a study of two different distributed virtual learning communities. They found that there were significant correlations between the social network and students' performance (Cadima et al., 2012). Although Kuh's (1996) idea of students' engagement in educational settings outside of the classroom is a foundation of educational effectiveness, which included students' learning and personal development, it is hard to find a study that examines the ways in which students form their learning networks. Despite its importance, the structure of student learning communities outside the class is 
not typically studied in detail or in combination with other measurements of student outcomes, such as conceptual gains and students' academic achievement. The current study utilized social network analysis tools to study the connection between students' engagement in the learning communities that form outside the class and their academic success in the course.

\subsubsection{Social Network Analysis}

The process of examining social structure by using network and graph theories is called Social Network Analysis (SNA) (Otte and Rousseau, 2002). To study social networks, SNA tools have been used since the mid-1930s to advance research in the social, educational and behavioral science to understand the nature and consequences of connections or ties between individuals or groups (Carrington, Scott, \& Wasserman, 2005). Social Network Analysis is a distinctive method with its specific version of data gathering, numerical analysis, and presentation of the outcomes. The main idea of SNA is that it enables educators, researchers, and practitioners to see how an actor is connected or embedded in the network (Hanneman, Riddle, \& Robert, 2005). Social Network Analysis can also be used to identify configurations of interaction in groups, measure the interaction of group members, and evaluate the influence of the flow of knowledge during the interaction (Scott et al., 2005). Social Network Analysis is also useful in finding mechanisms of social change (Rice \& Yoshioka-Maxwell, 2015).

As education reformers are increasingly adopting collaborative teaching methods, the use of SNA tools can provide them with additional techniques to assess the effectiveness and methods of their teaching (Kapucu et al., 2010). To visualize and 
quantify students interactions and students' role within a social network, SNA can be used (Brewe et al., 2012). Kapucu et al. (2010) suggested that use of network analysis delivers a means of assessing student-learning habits through collaboration. They pointed out that SNA tools allow educators to (a) categorize patterns of interaction among students, (b) identify features of student relationships and advice networks, (c) plan to teach approaches and interventions to help student interaction, and (d) develop students' interpersonal skills so they can learn in active learning environments.

By using the SNA tool, researchers found a complex weighted picture of student interaction in a study of who interacted with whom in class while students were involved in the learning process. (Bruun \& Brewe, 2013). Cadima et al., (2012) claimed: "Social networks play an essential role in learning environments as a key channel for knowledge sharing and students' support” (p. 297). By using SNA tools, this study tried to identify and understand the relation between the students' engagement outside the class learning communities and their performance in the courses, and, then, investigated the students' collaborative patterns across two semesters. 


\section{CHAPTER III: METHODOLOGY}

This chapter describes the methodology that was used to conduct this study. Accordingly, the following is discussed: class descriptions, participant description, classroom structure, classroom activities, methods of data collection, procedures and statistical techniques for data analysis.

\subsection{Features of ISLE Classes in this Study}

\subsubsection{Course Description}

This research was conducted in two introductory physics classes, implementing the Investigative Science Learning Environment (ISLE) curriculum that focused explicitly on helping students to develop abilities used in the practice of science (Karelina \& Etkina, 2007). These classes integrated the lecture and lab course components with little formal lecturing and operated as a collaborative learning environment. The lab portion of the course was integrated into the class activities since experimentation is an integral part of how physicists generate their knowledge and understanding of real-world problems. The classes had thirty students in a studio-format, with a focus on conceptual reasoning and development of scientific habits of mind (Etkina et al., 2006). The course was required for STEM majors. It was also the first required course of the physics majors, and thus could be regarded as an entry point on the pathway to becoming a physicist.

In the physics class, students were expected to participate in activities designed to engage the student in similar activities as research physicists. Students were expected to

connect theories and experiments like researchers. Students spent time investigating 
phenomena, developing models that explain those phenomena, and learning to apply the physics ideas they have developed to real world situations. The investigative process involved observing phenomena, proposing hypotheses, testing hypotheses by predicting the outcome of a suggested testing experiment using the proposed hypothesis to make the prediction, and applying established knowledge to solve real-world problems. Students performed hands-on tasks during class and reasoned about physical situations. The instructors guided students through those activities and provided them with constructive feedback to help students learn according to ISLE cycle (E Etkina \& Heuvelen, 2007), presented in Figure 1.

\subsubsection{Participants}

Participants for this study were drawn from students enrolled in Introductory Physics I and II with Calculus at Florida International University during Fall 2013 and Spring 2014 semesters.

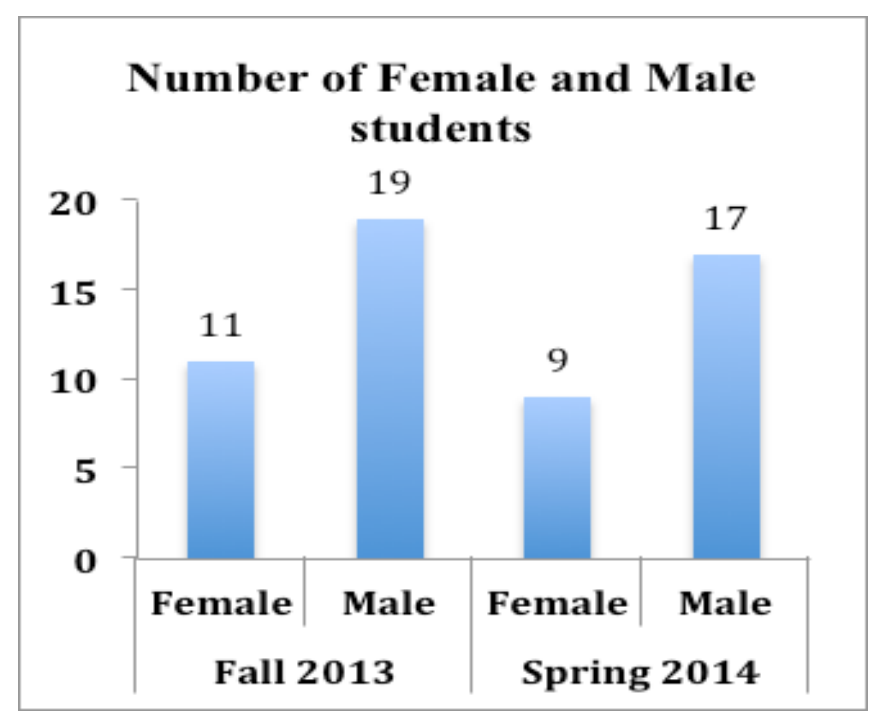

Figure 2. Students Composition 
There were thirty students (11 females and 19 males) during Fall 2013 and twenty-six (9 females and 17 males) in Spring 2014. Twenty students that were enrolled the Fall 2013 class, were also in Spring 2014 class. Of these 20 students 6 were females and the remaining 14 were males.

\subsubsection{Formation of Student Groups}

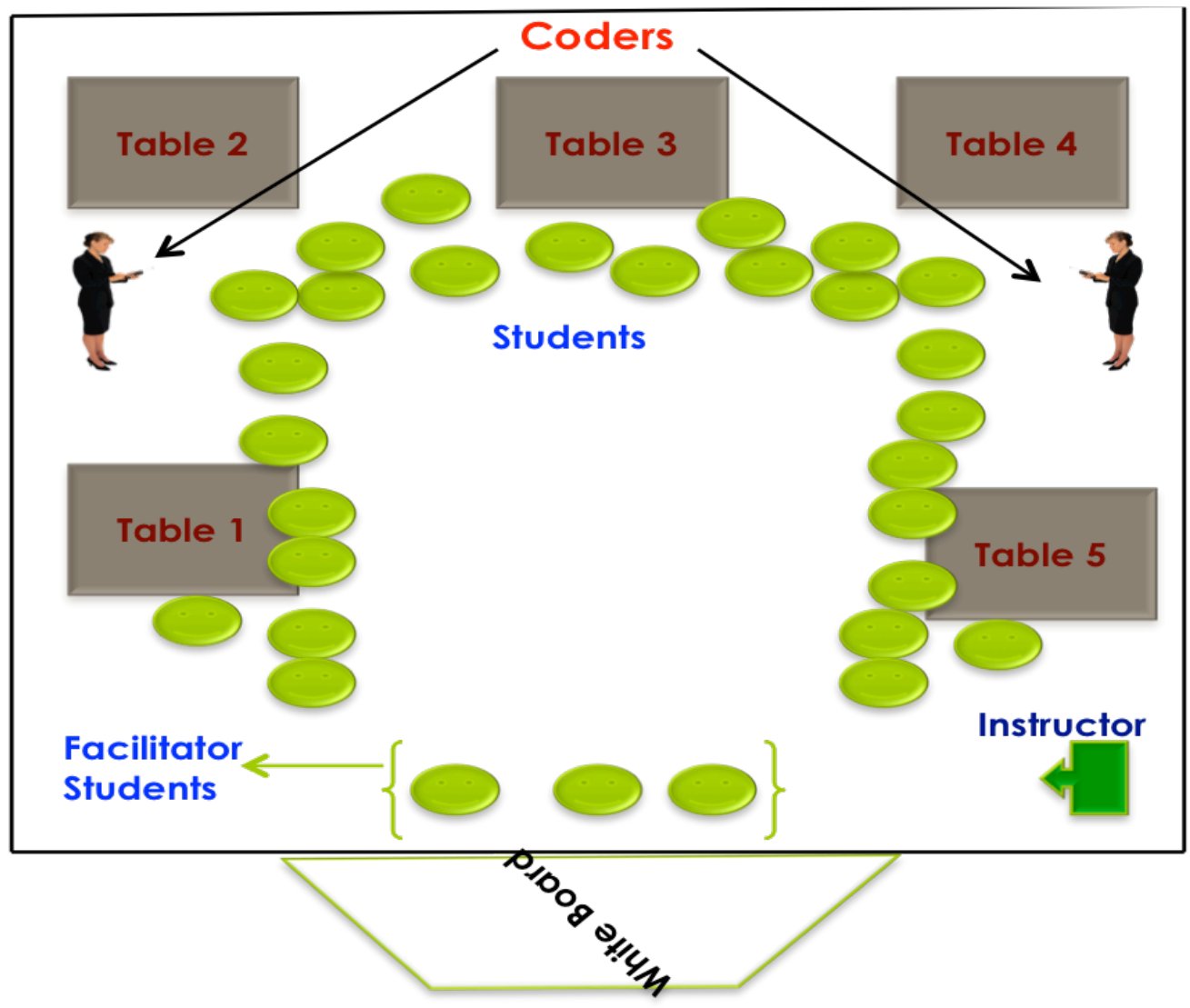

Figure 3. Classroom Structure

During most of the activities, students worked in groups of three. The seating arrangement in the classroom consisted of five tables, each seating two groups of three students. All tables were arranged in a circle so that there was a big space available in the 
center for presentations. The layout of the classroom is shown in Figure 3. Students were assigned to groups randomly on the first day of class. Instructors changed the groups every two weeks prior to the first exam by random selection. The first exam was held during $6^{\text {th }}$ week. After the first exam, students were allowed to form their own groups and they did not change groups for the rest of the semester. However, these intact groups were reshuffled between tables throughout the semester.

\section{2 Classroom Activities}

Class meetings consisted of three main activities. These activities were Review Sessions, Learning Activities, and Whiteboard Circle Meetings. For the study, students' participation data in Whiteboard Circle Meetings was not collected. Each of these activities is described subsequently.

\subsubsection{Review Sessions (RS)}

Each class meeting started with a review session where the entire class worked together and anyone could participate. Review sessions were structured around two questions "What did we learn last class?" and "Did anything remain unclear?" Sessions usually lasted 15-20 minutes and were largely student-directed with minimal intervention from the instructors. The instructors assigned one group of three students per review session to serve as facilitators and lead the review session. Normally, two students noted questions, concerns and ideas on the whiteboard that were brought up by the rest of the

class, and one student managed the students' turns to talk. Once the class had come up with questions, concerns, and ideas, students started addressing those questions, concerns, and ideas one by one. The instructor and teaching assistant only intervened 
when students were stuck or headed off in a tangential direction. Intervention from the instructor frequently took the form of constraining a problem or issue to keep the students on track rather than giving a direct answer to a specific question.

\subsubsection{Learning Activities (LAct)}

The instructor ran the class according to the basic sequence of the ISLE learning cycle using a set of worksheets based on the Active Learning Guide (Van Heuvelen, 2005). An example of one day lesson plan is presented in Appendix 1. Students working on these worksheets are referred to as "Learning Activities" (LAct) in this dissertation. The LAct typically began with experimentation to explore physical phenomena using Investigative Science Learning Environment (ISLE) learning cycle. Exploration of physics phenomena included: finding patterns in the given data, developing physical relations, identifying ways to represent phenomena, and generating hypotheses to explain observational data. Next, students designed and conducted experiments to test their hypotheses. Once they understood the phenomena, students practiced using the representations and applying them to solve real-world problems. Throughout the Learning Activities (LAct) students were expected to work together in groups and summarize their work on small portable whiteboards to the whole class.

\subsection{Out of Class Activity}

\subsubsection{Informal Learning Community (ILC)}

Participation in learning not only happened inside the class, but also outside the class. The instructor did not require students to work outside the class in groups. However, out of class group work was common in these courses. Thus, their participation 
in learning physics outside of the class was also captured. The students working outside the class are referred to as the "Informal Learning Community" (ILC).

\subsection{Data Collection}

Data were collected to study the relation between interaction among students in different areas of the physics class and their academic success in the courses. Inside the classroom participation data were collected during learning activities (LAct) and Review Sessions (RS). In addition, we collected student outcome data including Exam Score, Effort Score (score on out of class assignment), and FCI scores to evaluate student success in the course. Combination of exam score and effort score represented students' grade for the course. Finally, we solicited student self-reports of out-of-class interactions and self-reported students' hours of study outside of class time. To collect these data, students were asked every week, "who worked with whom", throughout the two semesters" and "how many hours did you study physics outside the class every week".

\subsubsection{Video Data Collection in the LAct}

The majority of the learning activities episodes were videotaped and recorded separately throughout the two semesters. Five video cameras (GE DV1 from General Imaging Company) were mounted and aimed one camera at each table, generating 5 separate videos for one episode. A single audio recorder (Olympus Digital Voice Recorder VN-702PC) was placed as close to the middle of each table as possible to capture students' voices. Each audio recorder was positioned at some height on the table with the help of some books underneath it, so that the recorders could collect the students' voices with fewer obstacles. Students were aware of the recording, but it 
happened each class for two semesters, making it less obtrusive. The audio and video for each episode were synchronized using Final Cut Pro software (Brenneis, 2002).

From pilot work, it was found that easy or non-controversial activities did not yield as much student-student interaction and discussion. Thus, six LActs episodes from the fall and three episodes from the spring semester were selected because of the level of difficulty of the learning activity. An example of worksheet of these learning activities is presented in Appendix 2.

\subsubsection{Quantifying Students' Participation in the LAct}

Videos of LActs were analyzed using a grounded theory approach utilizing a constant comparative methodology (Kolb, 2012). Glaser and Strauss (1967, p. 2) defined grounded theory as "the discovery of theory from data systematically obtained from social research" In grounded theory, multiple stages of gathering, refining, and classifying the data are used to establish a model. First, two coders watched videos together to get the idea of possible categories of students' involvement in LAct. Following the observation of several videos, they came up with possible coding categories and started coding differently. After finishing coding of first video, they met to verify their coding and discussed the differences. They then modified coding descriptions until they reached an agreement on their differences. This coding process went on for several videos until they achieved substantial agreement $(0.62<$ Cohen's Kappa $<0.8)$ (McHugh, 2012) on their coding.

Video data were analyzed by classifying students' behavior during learning activities using a coding scheme devised for the current project. The coding scheme includes four categories, Interacting, Off-topic, Writing/Drawing, and Uncodable, The 
categories and definitions for each category are presented in Table 1. Students' interactions were coded into these four categories in 30 -second time intervals. A single code was given for each student during each 30-second time segment based on a superseding policy. If a student was involved in interaction related to the assigned activity, the student was coded as 'Interacting' no matter how much time he/she spent interacting during that 30 -second time interval. A student was coded as 'Off-topic' for a time interval if there were no audible words related to the physics topic, but the student was involved in an off-topic conversation. A student was coded as 'Writing/Drawing' if there were no audible words related to physics or off-topic conversations, but the student was writing or drawing on paper or on whiteboards. When behaviors of students did not fit any of these first three categories, then they were coded as 'Uncodable'.

Table 1. Coding Scheme for Learning Activities

\begin{tabular}{c|c|c}
\hline Code & Categories & Description \\
\hline 1 & Interacting & $\begin{array}{l}\text { Communicating with other students or instructors } \\
\text { in audible words regarding the physics subject. }\end{array}$ \\
\hline 2 & Off-topic & $\begin{array}{l}\text { Communicating with other students or instructors } \\
\text { in audible words about anything but the subject. }\end{array}$ \\
\hline 3 & $\begin{array}{l}\text { Writing/ } \\
\text { Drawing }\end{array}$ & $\begin{array}{l}\text { Writing or drawing on papers or whiteboards } \\
\text { without speaking to others. } \\
\text { Behaviors/activities that do not fit any of the } \\
\text { three specific categories above. }\end{array}$ \\
\hline
\end{tabular}

Thirty videos from Fall Semester (six episodes * five tables) were coded; videos were on average 20 minutes long. Two coders coded each video of LAct. Randomly 
selected samples were chosen to evaluate inter-rater reliability. On these samples a Cohen's Kappa (Cantor, 1996) of 0.78 was achieved.

Table 2. Calculation of Cohen's Kappa

\begin{tabular}{|c|c|c|c|c|c|c|}
\hline \multirow{10}{*}{ Coder 2} & \multicolumn{6}{|c|}{ Coder 1} \\
\hline & & Ineracting & $\begin{array}{l}\text { Off- } \\
\text { topic }\end{array}$ & Writing & Uncodable & Total \\
\hline & Interacting & 89.00 & 1.00 & 4.00 & 1.00 & 95.00 \\
\hline & Off-topic & 2.00 & 11.00 & 0.00 & 2.00 & 15.00 \\
\hline & Writing & 3.00 & 1.00 & 14.00 & 4.00 & 22.00 \\
\hline & Uncodable & 3.00 & 3.00 & 1.00 & 41.00 & 48.00 \\
\hline & Total & 97 & 16 & 19 & 48 & 180 \\
\hline & Consensus & 89.00 & 11.00 & 14.00 & 41.00 & 155.00 \\
\hline & By chance & 51.19 & 1.33 & 2.32 & 12.80 & 67.65 \\
\hline & \multicolumn{6}{|c|}{ Cohen's Kappa $=0.77$} \\
\hline
\end{tabular}

Note: Numeric values with green color were agreements between two coders and red color were disagreements

Cohen's Kappa was calculated by

$$
\mathrm{K}=\frac{p_{0}-p_{c}}{1-p_{c}}
$$

Where $p_{0}$ is the probability of agreement between two coders, $p_{c}$ is the probability of getting agreement by chance. Two coders coded independently. Therefore, the probability of agreement from chance for a coding category is equal to the product of probability of coding for that category from two coders. 
For example, in Table 2, for the Interacting code, the probability of coding a single instance of the Interacting code by Coder 1 is 95/180 and by Coder 2 is 97/180. The total instances of coding are 180 . Therefore, the probability of coding the Interacting code by chance is $\left(\frac{95}{180} * \frac{97}{180}\right)$ times 180 , which is 51.19 . Therefore, the probability of agreement between two coders is 0.86 (total agreements/total possibilities) and the probability of getting agreement by chance is $0.37\left(p_{0}=155 / 180\right.$ and $p_{c}=67.65 /$ 180) (Cantor, 1996).

\subsubsection{Quantifying Students' Participation in the RS}

Two researchers coded the review sessions in real time without videotaping according to the coding scheme described in Table 3. Unlike in the coding videos of LAct, the coding scheme for RS was straightforward and two coders had around 95\% agreement from the very beginning because a single code was given to each student for the entire review session The class was set up in such a way that two coders stood unobtrusively behind the students' circle in RS. The physical structure of the RS was shown in the Figure 3 (page 43). Coders could observe directly what the students were doing during RS without obstruction. Therefore, they could easily see whether students were involved in disengagement (texting, surfing online, doing any homework, etc). Coders were very familiar with the students' names so they did not have problems going continuously without stopping up and down the list of students to assign codes in real time. In this way coders were able to gather almost all of the data about the students' behavior in RS. 
Each student was assigned a single code for the entire review session based on the same superseding policy that was applied to the LAct. The superseding policy was: if students were involved and engaged in the review session activities in different ways (as seen in table 3), code 'Interacting' was given to them no matter how much time they spent on interacting during that day of entire review session. The Disengagement code was assigned for that day if they were not interacting at all, but they displayed evidence of being disengaged. The 'Uncodable' code was allocated if students were neither interacting nor disengaged in the RS. An example of coding of one-day review session is presented in the Table 4.

Table 3. Coding scheme for Review Sessions

\begin{tabular}{l|l|l}
\hline Code & \multicolumn{1}{|l}{ Categories } & Description \\
\hline 1 & Interacting & $\begin{array}{l}\text { Engaging in review activities in different ways. } \\
\text { E.g.: Reminding what they did in the last class, } \\
\text { answering and explaining questions, presenting } \\
\text { and challenging ideas, and facilitating the RS. }\end{array}$ \\
\hline \multirow{3}{*}{3} & Disengagement & $\begin{array}{l}\text { Engaging in activities not related to the review } \\
\text { session with clear evidence of not paying } \\
\text { attention to the review session. For example: } \\
\text { texting, surfing online, doing homework for any } \\
\text { class, etc. }\end{array}$ \\
\hline \multirow{3}{*}{ Uncodable } & $\begin{array}{l}\text { Taking notes about the subject under review, } \\
\text { sitting silently, apparently paying attention } \\
\text { without speaking, sitting with no evidence of any } \\
\text { active involvement in the review session, without } \\
\text { participation and disengagement }\end{array}$ \\
\hline
\end{tabular}


Table 4. Coding Example of One Review Session.

\begin{tabular}{|c|c|c|c|}
\hline & Name of Students & $\begin{array}{l}\text { Code given to the } \\
\text { students }\end{array}$ & $\begin{array}{c}\text { Agree/ } \\
\text { Disagreement between } \\
\text { two coders }\end{array}$ \\
\hline 1 & Malori & 3 & Agree \\
\hline 2 & Anthony & 3 & Agree \\
\hline 3 & Jose & 1 & Agree \\
\hline 4 & Nancy & 1 & Agree \\
\hline 5 & Amy & 3 & Agree \\
\hline 6 & Gary & 1 & Agree \\
\hline 7 & Jason & NA & Agree \\
\hline 8 & John & 2 & Agree \\
\hline 9 & Barbara & 3 & Agree \\
\hline 10 & Cathy & NA & Agree \\
\hline 11 & Mary & 3 & Agree \\
\hline 12 & Paul & 1 & Agree \\
\hline 13 & Robert & 1 & Agree \\
\hline 14 & Chris & 3 & Agree \\
\hline 15 & Nick & 1 & Agree \\
\hline 16 & Thomas & 1 & Agree \\
\hline 17 & Casey & 1 & Agree \\
\hline 18 & Donald & 3 & Agree \\
\hline 19 & Zia & 3 & Agree \\
\hline 20 & Melissa & 3 & Agree \\
\hline 21 & Joseph & 2 & Agree \\
\hline 22 & Steven & 3 & Agree \\
\hline 23 & Richard & 3 & Agree \\
\hline 24 & Edward & 1 & Agree \\
\hline 25 & Laura & 3 & Agree \\
\hline 26 & Karen & 1 & Disagree \\
\hline 27 & Brian & 1 & Agree \\
\hline
\end{tabular}

Note: If there were disagreements in coding between two coders, the same superseding policy would be used to choose a code for conflicted one. NA: Absent on that day 
The joint probability of agreement method was utilized to calculate intercoder reliability. It is the probability of agreement between two coders (total number of agreement between two coders in total coding; for example, in Table 4, percentage of agreement in coding was $\frac{26}{27} * 100 \sim 96 \%$ ). Randomly selected samples were chosen to evaluate inter-coder reliability. On these samples, the average joint probability of agreement was $96 \%$.

\subsubsection{Quantifying Students' Participation in the ILC}

Participation in learning not only happened inside the class, but also outside the class. The instructor did not require students to work outside the class in groups. However, out of class group work was common in these courses. Thus, their participation in learning physics outside of the class was also captured. The students working outside the class are referred to as the "Informal Learning Community" (ILC). Students were asked as part of their weekly homework to self-report every week "who they worked with" and "how much time they spent working on physics" outside of class. Responses were collected through Blackboard (electronic classroom management system) The "who worked with whom" data allowed to build up a social network of the ILC that formed outside of class-time. The social network includes students as nodes and reported interactions as links.

For example, suppose there were 5 students: Malori, Anthony, Nancy, Jose and Amy. One week students' self-reported data "who worked with whom" and corresponding network matrix is presented in Table 5. Because in this example there are 5 students, the network matrix becomes $\left(\begin{array}{lll}5 & X & 5\end{array}\right)$ and each element represents either 
' 0 ' or ' 1 '. Elements with a ' 0 ' represents two connecting students who did not work together and ' 1 ' represents two connecting students who worked together during that week and reported at least by one. Therefore, the network matrix was undirected meaning it did not matter who reported whom. For example, the element $\mathrm{a}_{12}=1$ (first row and second column element) represents either Malori reported she worked with Anthony or Anthony reported he worked with Malori or both reported working with each other. The element $\mathrm{a}_{41}=0$ represents that both Jose and Malori did not report they worked together.

A sample of one-week network matrix of "who worked with whom" is presented in the Appendix 3. The social network matrix for the above example is shown in Table 5. The matrices for each of the weeks were then summed to create an aggregate, weighted network of the whole semester.

Table 5. Example of Network Matrix

\begin{tabular}{llllll}
\hline Students & Malori & Anthony & Nancy & Jose & Amy \\
\hline Malori & 0 & 1 & 1 & 0 & 0 \\
\hline Anthony & 0 & 0 & 1 & 1 & 0 \\
\hline Nancy & 1 & 0 & 0 & 0 & 1 \\
\hline Jose & 0 & 0 & 0 & 0 & 1 \\
\hline Amy & 1 & 0 & 1 & 0 & 0 \\
\hline
\end{tabular}

The networks of students' interactions were analyzed to quantify their participation in the ILC. The PageRank centrality (Brin \& Page, 1999) measure was 
utilized on the aggregated student network data. PageRank is a link analysis algorithm with the purpose of quantifying the importance of a node within the network. In our study, each node represented a student. So, a student could acquire a high PageRank by having many students from the class naming him/her as part of their group or by having even a few students from the class with high PageRank name him/her as part of their group (Bruun \& Brewe, 2013). The network analysis package igraph of the R statistical programming language (Csardi \& Nepusz, 2006) was used to calculate PageRank Centrality. The mathematical description behind the calculation of PageRank Centrality and how the PageRank of each student was calculated can be found in the $7^{\text {th }}$ chapter of "Experiments with MATLAB" book (Moler, 2011) and in Page et.al. (1998).

To understand the nature and characteristics of the social network of ILC in the fall and spring semesters, several network measures were used. They were: Average Degree, Average Weighted Degree, and Network Density. Average Degree is an average number of edge incidents to each node. Average Weighted Degree is the average weight of connections for each node in the network. Network density "is a measure of how close the network is to complete. A complete graph has all possible edges and density equal to one" (Heymann, 2013, p. 15).

\subsection{Students' Academic Performance}

In addition, data that showed evidence of student success in the course were collected. These student outcome data included: Exams Score (Group Exam and Individual Exams), and Effort Score (Homework, Journal and Lab Report). FCI gain was used to measure conceptual understanding. To address some research problems, overall 
course grade (combination of exam score and effort score) was also utilized. Table 6 shows the grade breakdown for the courses.

Table 6: Components of Course Grade

\begin{tabular}{|l|c|c|}
\hline Components of Grading & Max Score & $\begin{array}{c}\text { Weight for the } \\
\text { final grade }\end{array}$ \\
\hline $\begin{array}{l}\text { Two, midterm exams (group and } \\
\text { individual)* }\end{array}$ & 100 & $15 \%$ each \\
\hline Final Exam (group and individual)* & 100 & $20 \%$ total \\
\hline Homework & 10 & $20 \%$ total \\
\hline Weekly Journals & 10 & $20 \%$ total \\
\hline Laboratory Report & 20 & $10 \%$ tal \\
\hline
\end{tabular}

*Weightage of group exam was $40 \%$ and individual exam was $60 \%$

\subsubsection{Exams}

There were two midterms and one final. Each was broken into two separate parts (Group Exam and Individual Exam) and both lasted approximately 2 hours in length.

Group Component for Each Exam: The group component of each exam was designed to assess student's skill at learning in collaboration with their classmates. A problem was given to students that needed to be solved using physics they had not yet learned. Generally, the group exam problem was too difficult to solve individually. Thus, for the group component of each exam, group members were also allowed to work with the class as a whole to answer the given problem. They could use all the available resources (text book, notes, homework, internet, etc). Each group of three handed in their own write-up and group members received the same grade for the group exam. Write-ups 
were graded using the scientific abilities rubric (Etkina et al. 2006). One example group exam, and the corresponding individual exam question, is presented in the Table 7.

Individual Exam: Students took the individual component of the exam two days after the group component. All individual exams included conceptual, application and open-ended problems. Some questions required students to describe how they might design an experiment to achieve a certain goal. The first two individual exams only covered the material in those respective time periods, whereas the final exam was cumulative. Individual exams were closed book and students were only allowed to use an attached formula sheet. There was always a question on the individual portion of the exam related to the topic students worked on in the group exam.

Table 7. Example of Group Exam and Related Individual Exam

\begin{tabular}{|l|l|}
\hline Group Exam & $\begin{array}{l}\text { You are expected to learning something completely new using any } \\
\text { resources at your disposal. } \\
\text { Your goal is to understand constant rate circular motion and } \\
\text { whether you can describe and explain it mathematically with } \\
\text { Newton's second law. } \\
\text { The actual parts of the question are below the line. } \\
\text { 1) Consider an object traveling in a circle at a constant speed. Find } \\
\text { the direction of the object's acceleration at any point on its circular } \\
\text { path. Explain how an object can have acceleration if the speed is } \\
\text { constant. } \\
\text { 2) Starting from what you already know, } \vec{a}=\frac{\Delta \vec{v}}{\Delta t}, \text { what you found } \\
\text { in part a), and anything else you can find, find an algebraic } \\
\text { expression for the acceleration of an object traveling in a circle of } \\
\text { radius } r \text { with a constant speed } v \text {. }\end{array}$ \\
$\begin{array}{l}\text { 3) Come up with three everyday examples of an object traveling in } \\
\text { a circle at a constant rate. Perform the actual experiments or watch } \\
\text { videos. (A rollerblading instructor is at your disposal if you require }\end{array}$ \\
\hline
\end{tabular}




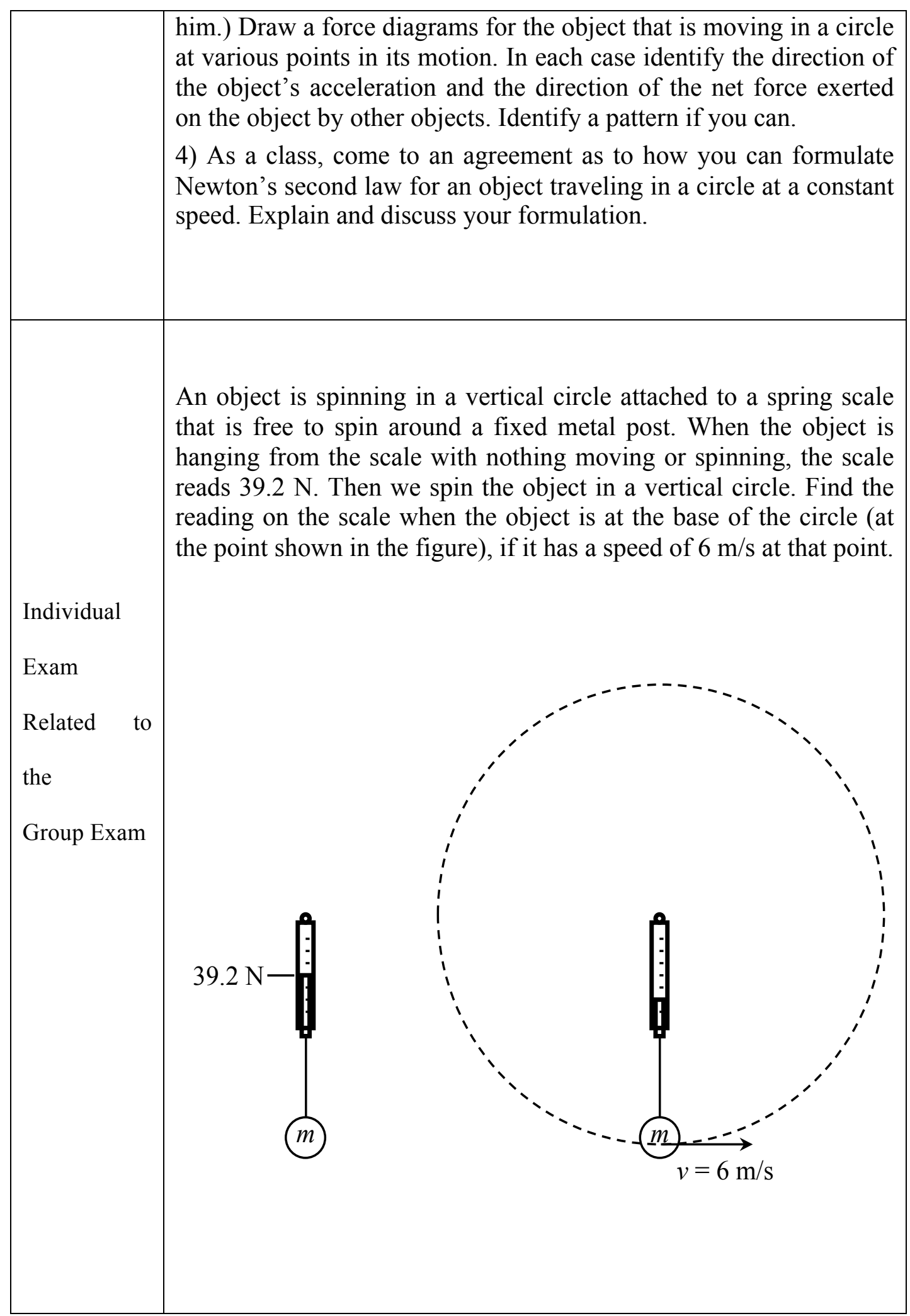




\subsubsection{Effort Score}

Students' effort score was calculated based on three types of assignments completed outside of class time. They were homework, weekly journals, and laboratory reports. Their contributions to effort score were $40 \%, 20 \%$, and $40 \%$ respectively. Detailed descriptions of each component of effort score are described below.

Homework: Every week students were assigned 7-9 homework problems. The instructor encouraged students to discuss the problems with each other. However, students were not allowed to copy homework from each other. Usually, 3-4 selected homework problems were graded on three criteria: Clarity, Consistency, and Evaluation. All these three criteria may not be applicable to some questions, and so they were selectively chosen as appropriate.

Weekly Journals: Students maintained a journal on their learning every week by answering the following three questions (Etkina, 2000; Harper, Etkina \& Lin, 2003; May \& Etkina, 2002). For this study, instructor also solicited "who worked with whom" and "how many hours did you study physics outside the class every week" in the weekly journal.

1. Write a paragraph about what you learned this week. Include in your paragraph a discussion about how, if your friend questioned the truth of what you learned, you would convince your friend that what you learned is true.

2. Is there anything that remains unclear from this week?

3. If you were the instructor, what question would you ask to determine whether your students had learned this week's material? 
The purpose of the weekly journal was two-fold. It allowed students to reflect on what they had learned every week, embedded in the context of "how do I know what I know," and gave them an opportunity to ask questions about the things they had not understood yet. The weekly journal allowed the instructor to assess students' learning progress and helped to adjust the pace of classroom activities. Students submitted their journals through Blackboard.

\section{Laboratory Reports}

There was approximately one laboratory every week. While experimentation was fully integrated into the course, and happened continuously throughout the learning process, students were required to write up one lab reports each week. The resulting reports were worth $20 \%$ of the final grade and were graded out of 20 points. Each group of three students handed in one report and obtained the same grade for the report. The lab report was graded based on 5 preselected rubric items that were shared a priori with students and were worth 3 points each. Additional 5 points came from the overall completeness of the report; the quality of the writing, and how well students communicated the key ideas of their experiments.

\subsubsection{Conceptual Understanding}

The Force Concept Inventory (FCI) was utilized to measure students' conceptual understanding (Hestenes et al., 1992). It is a 30-item multiple-choice diagnostic test that emphasizes the conceptual understanding of Newtonian Mechanics, administered in a paper/pencil format. The FCI gain is calculated by using the formula [(POST-PRE)/(100PRE)]. This gain is called Hake gain (Hake, 1998). For this study, PRE FCI score was 
considered as a measurement of students' conceptual understanding prior to the course and FCI Gain is considered as a measurement of conceptual understandings.

\subsection{Data Analysis}

This section presents the methodology for each main and sub-research problem.

\subsubsection{Main Research Question A}

What are the different ways in which students participate both inside and outside of the classroom and what sort of relationships exist between how they participate and their success in the class?

Permutation correlation tests were used to identify relationships between students' participation in in-class activities and student outcome variables. Permutation method is a non-parametric test. It is a common method to test statistical hypotheses. In a standard correlation method, two variables from each participant are linked to one another. However, in permutation correlation, the various participant score of a variable are randomly associated with the scores of another variable to generate a distribution of correlation based on this random association. Therefore, the method of permutation is also called randomization method. This occurs many times. In this study, I generated 10,000 permutations. For example, the various participant scores on learning activities are randomly associated with the exam scores to generate an $r$-value based on this random association. A null distribution of correlation coefficient is created for the correlation between exam score and students' level of participation for the set of exam score in the class (Winkler, et al., 2014). 
Permutation correlation offers an efficient methodology when the data do not follow the distributional assumptions, for example normality. It is also suitable for the dependence assumption. (Grunspan et al., 2014; Winkler, et al., 2014). Moreover, permutation testing is appropriate to investigate the association between two variables for small samples. Spearman Rank Correlation was adopted for the analysis when one of the variables was calculated in rank basis. Therefore, to analyze the correlation between PageRank centrality and students' success in the course (FCI gain, Effort Score, Exam Scores), Spearman Rank correlation method was utilized. Table 8 summarizes the types of correlation between dependent and independent variables.

Table 8. Methods of Correlation for the Students' Participation and Success

\begin{tabular}{|c|c|c|c|}
\hline & Exam Score & Effort Score & FCI gain \\
\hline \multicolumn{4}{|c|}{ In Class Participation } \\
\hline All Categories of & Permutation & Permutation & Permutation \\
LAct & Correlation & Correlation & Correlation \\
\hline All Categories of & Permutation & Permutation & Permutation \\
RS & Correlation & Correlation & Correlation \\
\hline \multicolumn{4}{|c|}{ Out of Class Participation } \\
\hline PageRank Centrality & Spearman's Rank & Spearman's Rank & Spearman's Rank \\
& Correlation & Correlation & Correlation \\
\hline
\end{tabular}

It is important to be aware of the increased likelihood of encountering Type I error when multiple pair-wise tests are implemented on a single data set. Type I error occurs when a significant difference was found while there was actually none. Running multiple t-tests and calculating numerous correlations increases the likelihood of type I 
error. According to Armstrong (2014) Bonferroni correction should be considered if a large number of tests are carried out without preplanned hypotheses on a single data set to avoid a type I error. Bonferroni correction is commonly used in numerous studies that investigate the relationship between variables. Therefore, Bonferroni correction is very important to consider in making conclusion of this study.

The Bonferroni correction helps to avoid the type I error which rises as the number of tests increases. If a null hypothesis under the $5 \%$ significance level is true, a probability of 0.95 is coming to a not significant. For two independent null hypothesis, the probability of neither test will be significant is 0.9 . When 20 independent tests are performed, the probability that none will be significant is 0.36 (i.e the chance of at least one test being significant is 0.64$)$. So, in general the error rate will be $1-(1-\alpha) / T$. Where $\alpha$ is the critical $\mathrm{p}$ level and $\mathrm{T}$ is the number of tests performed. Therefore, a $\alpha / \mathrm{T}$ can be used like an adjusted significance level as an approximation for the error rate. (Armstrong, 2014; Perneger, 1998; Curtin \&Schulz, 1998).

\subsubsection{Main Research Question B}

How do student's transform or change their participation through the course as they learn how to learn in an interactive student centered learning environment?

Students' transformation of participation was investigated in two ways; did they develop over the course of the fall semester and did they change from fall to spring semesters? In order to determine if students' pattern of participation change over the fall semester, the fall semester was divided into three time segments. The first segment lasted from the beginning to the first mid-term, the second segment included the time between 
the first and the second mid-term, and the third segment took place between the second mid-term and the final.

'Interaction' codes in LAct and RS, and PageRank centrality data were utilized to investigate the participation pattern within the fall and between the two semesters. When these data were tested by the Shapiro-Wilk Normality test, only the data from the Interaction code of the LAct were normally distributed. Therefore, for the LAct data, the two tail paired t-test was used to analyze how students' change their participation patterns over the semester between three time segments. For the Interaction in RS and out of class participation data (PageRank Centrality) the Wilcoxon Signed-Ranks Test was utilized. The Wilcoxon Signed-ranks test is a non-parametric, alternative to the paired t-test, which ranks the differences of students' participation in two time segment data, overlooking the signs, and relates the ranks for the negative and positive differences (Demšar, 2006). According to Demšar (2006), "When the assumptions of the paired ttest are met, the Wilcoxon signed-ranks test is less powerful than the paired t-test. On the other hand, when the assumptions are violated, the Wilcoxon test can be even more powerful than the t-test" (Demšar, 2006, p-8).

To investigate the pattern of students' participation throughout two semesters, the common students in both semesters were taken into account and pair t-test was utilized for the analysis along with scatters plots between the fall and spring semesters.

3.6.3 Sub-Research Question 1: What is the relation between students' participation in various aspects of an interactive learning physics class and their conceptual understanding? 
Multiple linear regressions was used to develop a model for predicting conceptual understanding (quantified by FCI Gain) from interaction in Review Sessions, interaction in Learning Activities, and PageRank Centrality of Informal Learning Community. In order to accomplish this, data from the Fall semester was used.

3.6.4 Sub-Research Question 2: Which aspects of the interactive learning class play the greatest role in students' success?

To answer this research question, multiple linear regression method was utilized to develop a model for predicting students' success (quantified by Exam Scores and Effort Scores) from Interaction in RS, Interaction in LActs, and PageRank Centrality of ILC. Separate models for each dependent variable were investigated for the fall and spring semesters.

3.6.5 Sub-Research Question 3: Does students' prior conceptual understandings bias their participation in an interactive learning environment?

Pre-FCI scores were used to measure students' prior physics knowledge. To examine whether or not prior students' physics knowledge makes students biased in their participation in an interactive learning environment, permutation correlation coefficients were used between the Pre-FCI scores, and students' 'Interaction' in LAct and in RS. For the PageRank centrality the Spearman's rank correlation was utilized. 


\section{CHAPTER IV: DATA ANALYSIS}

This chapter presents the results of the data analysis. The data were collected and then processed in response to the problems posed in chapter one of this study. The data analysis focuses on finding the relation between participation and students' success in the course and how students change their pattern of participation throughout two semesters in an active learning environment.

This chapter is divided into three sections. The first section establishes the associations between students' engagement in three areas of physics class - Learning Activities (LAct), Review Sessions (RSs) and Informal Learning Community (ILC) and their success in the course to address the first main research question: "What are the different ways in which students participate both inside and outside of the classroom and what sort of relationships exist between how they participate and their success in the class?" The second section analyzes how students transformed their participation over the first semester and then across two semesters. Finally, the third section presents data analysis for each sub-problem research question.

The first section is divided into three sub-sections. (1) Data from the LAct and students' performance are analyzed separately for the fall and spring semesters in order to find consistent results over two semesters. (2) The RS data are analyzed to find the relation between students' participation in the RS and their success in the courses. (3) Data from the ILC are investigated to identify the relation between students' PageRank Centrality (measurement of participation outside the class) and performance in the fall and spring semesters. 
The second section analyzes how students transformed their participation in different areas of physics class (the LAct, RS, ILC) during the fall semester. In order to conduct the analysis, data from three time segments of the fall semester are compared. To investigate the change in participation pattern between the fall and spring semesters, the data associated with the students common to both semesters are compared. Finally, in the third section, data analysis related to each sub-problem is presented serially according to the research questions written in the first chapter.

\subsection{Relation Between Participation in the LAct, RS and ILC, and Academic Success}

This section investigates the relations between various types of coding categories in the LAct, RS, and PageRank centrality of the ILC with the students' measure of success in both semesters. FCI Gain, Exam Score, Effort Score (out-of-class assignment score) were the measures of success for the fall semester. The measures of success for the spring semester were Exam Score and Effort Score. Students' course grade was assigned based on the combination of the exam score and effort score. Each score counted as fifty percent for the course grade.

\subsubsection{Relation Between Participation in LAct and Academic Performance}

Thirty videos were coded in total (10 videos per time segment, two from each table in each time segment) from the fall Semester; on average, each video was 20 minutes long. An average of 102 minutes of video per student group throughout the fall semester with a standard deviation of 15 minutes were coded. The standard deviation of average coding time per student was four minutes. Three videos from the spring 
semester were also coded, and those videos were selected from the middle of that semester (first from January 30, second from March 3, and third from March 20). Those videos were 9 minutes long on average. The average time spent coding per student was around 25 minutes, with a standard deviation of six minutes. The reason behind the high standard deviation in both semesters was that not all students appeared in all learning activity videos.

Fall 2013

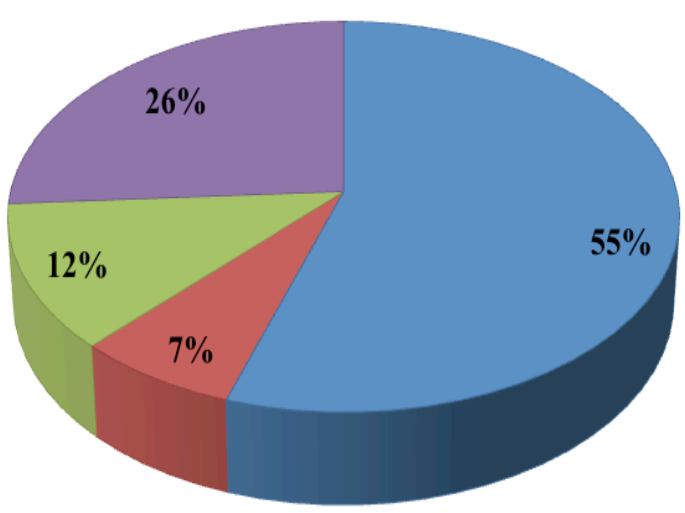

Interacting ${ }^{-}$Off-topic ${ }^{-}$Writing/Drawing ${ }^{-}$Uncodable

Figure 4. Average Distribution of Codes of Students' Behaviors in the LAct during the Fall and Spring Semesters.

The average distribution of codes of students' behaviors in the LAct in fall 2013 and spring 2014 was found to have the same pattern in both semesters in the Interacting, Off-topic and Uncodable coding categories. However, there was a noticeable difference 
in the Writing/Drawing category, as seen in Figure 4. Even though the instructor encouraged students from the very beginning to use social network tools (such as whatsApp, Facebook, and GoogleDocs) to share their final work of the class activities with each other, it was doubtful whether this could have been as frequent in the first semester as opposed to the second semester because students were not as familiar with each other during the first semester. As they became more familiar, they probably started sharing more classwork through pictures, which might have made them take less notes and write less on their notebooks during the LActs in the spring 2014.

Table 9. Permutation Correlation Coefficient Between Coding Categories of LAct and Students' Performance in Fall 2013

\begin{tabular}{c|c|c|c|c}
\hline Performance & Interacting & Off-topic & Writing & Uncodable \\
\hline $\begin{array}{c}\text { Pre FCI } \\
\text { Score }\end{array}$ & -0.12 & -0.07 & 0.26 & 0.05 \\
\hline Effort Score & 0.27 & $-0.47^{*}$ & 0.07 & -0.12 \\
\hline Exam Score & 0.43 & -0.33 & 0.02 & 0.36 \\
\hline FCI Gain & 0.38 & -0.21 & 0.01 & 0.44 \\
\hline
\end{tabular}

Note: Using Bonferroni adjusted alpha levels .0125 per test (.05/4)

${ }^{*} \mathrm{p}<0.012$, Number of observation, $\mathrm{N}=30$ and $\mathrm{N}=24$ (for FCI data)

Number of permutation $=10,000$

Table 9 shows the permutation correlation coefficient between students' participation in the LAct and their success as quantified by FCI gain (Hake, 1998), exam score and effort score in the fall semester. Whether prior physics knowledge (quantified by students' FCI pre-score (Hestenes, M. Wells, G. Swackhamer, 1992)) would bias students' participation in the LAct was an additional consideration. The weakly negative 
correlation between Pre FCI and Interacting suggests that students who came to the class with better conceptual understanding did not necessarily participate more than others during the LActs. Four hypotheses were tested with the same participation categories of LAct in the fall semester, with the consideration of Bonferroni Correction alpha value for the significance level set to 0.012 .

The relationship between students' different coding categories in the LAct in the spring semester and their academic performance, measured by effort score and exam score, are presented in Table 10. The correlation between Interacting and Exam Score $(\mathrm{r}=0.67, \mathrm{p}<0.012)$ indicates that 'Interacting' code in the LAct in the spring semester had significant association with the exam score.

Table 10. Permutation Correlation Coefficient Between Coding Categories of LAct and Students' Performance in Spring 2014

\begin{tabular}{c|c|c|c|c}
\hline Performance & Interacting & Off-topic & Writing & Uncodable \\
\hline Effort Score & 0.10 & -0.34 & -0.15 & -0.07 \\
\hline Exam Score & $0.67^{*}$ & $-0.63^{*}$ & 0.14 & $-0.51^{*}$ \\
\hline
\end{tabular}

Note: Using Bonferroni adjusted alpha levels .0125 per test $(.05 / 4) * \mathrm{p}<0.012, \mathrm{~N}=26$

As in the fall semester, students who were involved in off-topic conversation had a significantly negative correlation $(r=-0.63, p<0.0125)$ with their exam scores in the spring semester. Being uncodable during the LActs also had a significant negative association with exam scores in the spring semester. Weak correlations between different coding categories of the LAct and effort score suggest that students' levels of participation in LAct did not associate with the performance in out-of-class assignments. 
The Interacting code in the LAct in the spring semesters had a significant, positive correlation with the exam score at alpha level 0.0125 . The Interactive code in the fall semester was not significant in corrected alpha level, but significant at the alpha level 0.05. A stronger positive correlation between the exam score and the Interacting code in the spring semester suggests that a collaborative habit in small groups helps students to become better learners over time. The stronger negative correlation between the off-topic code and exam score in the spring semester in comparison with the results in the fall semester supports the claim.

\subsubsection{Relation Between Participation in the RS and Academic Performance}

As described in the methodology chapter, each class started with a review session where the entire class worked together and anyone could participate. The RS was structured around two questions: "What did we learn last class?" and "Did anything remain unclear?" Sessions usually lasted the first 15-20 minutes of the class and were largely student-directed with minimal intervention from the instructors. Two coders coded 29 days of the RS during the fall semester and 32 days in the spring semester, according to the coding scheme that was presented in Table 3 of methodology chapter. Two coders established around 96\% inter-rater agreement in coding RS.

Upon analyzing the average distribution of codes of students' behaviors in the RS, similar percentages of total coded instances in the Interacting and Uncodable coding categories were found in both semesters, as seen in Figure 5. The average amount of students' participation in the Interaction and Uncodable coding categories (43\% and $41 \%$ in fall and $46 \%$ and $43 \%$ in the spring semester) in both semesters were around the same. 
There was a small increase in the Disengagement code (11\% in fall and $16 \%$ in the spring semesters); however, the change was not significantly different from Wilcoxon Rank ttest $(\mathrm{z}=-1.538, \mathrm{p}=0.123)$.

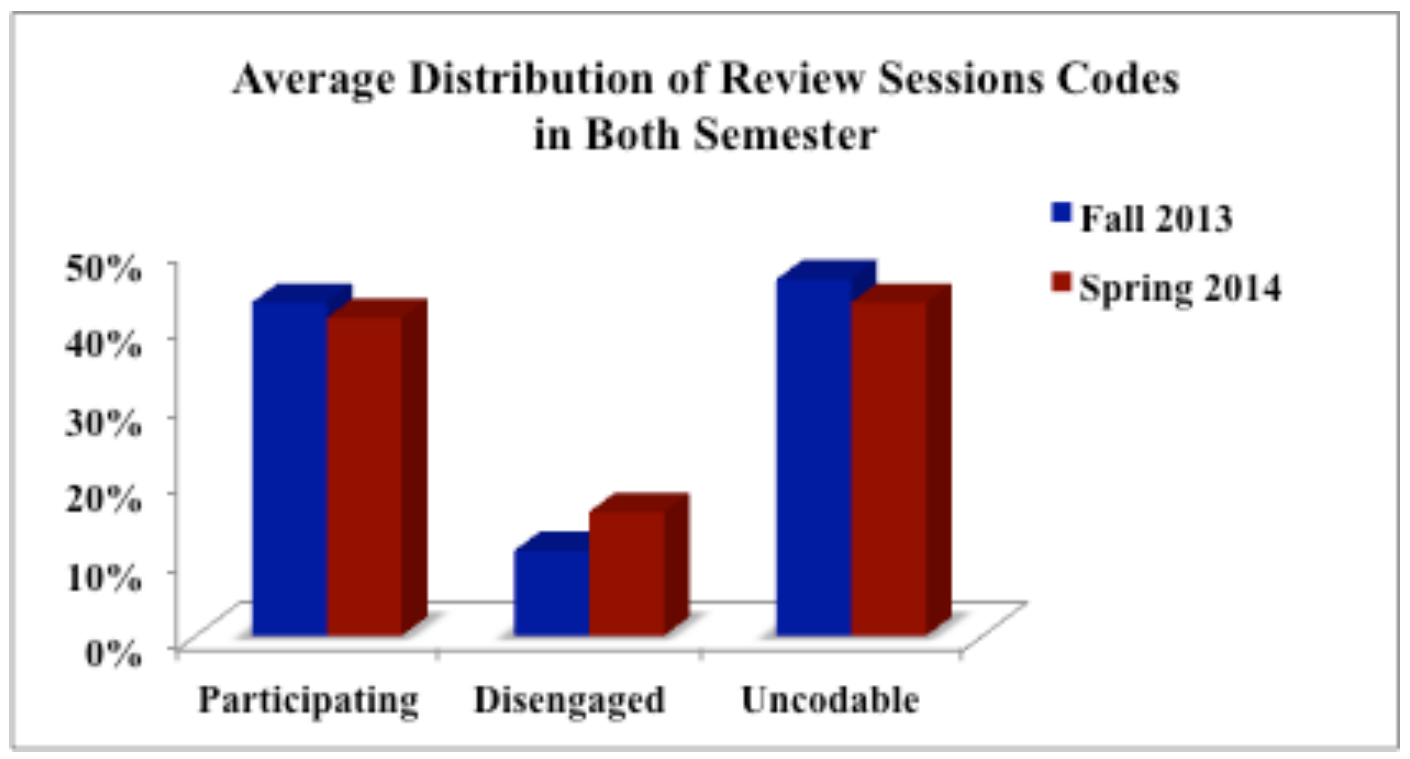

Figure 5. Average Distribution of Codes of Students' Behaviors in RS during the Fall and Spring Semesters.

Table 11 shows the permutation correlation coefficient between students' participation in the RS and their success as quantified by FCI gain, exam score and effort score in the fall and spring semesters. The correlations between Interaction and Exam Score $(r=0.31, p=0.09$ in fall; $r=0.46, p=0.01$ in the spring semester $)$ indicate that Interaction code in the RS was not consistently significant across two semesters. The association between the participating code and effort score did not have significant relation in both semesters. As in LAct, the weak correlations between Pre FCI and participation in RS suggest that students who came to the class with better conceptual understanding did not necessarily participate more than others in the RS. 
Table 11. Permutation Correlation Coefficient Between Participation in the RS and Students' Performance in the Fall and Spring Semesters.

\begin{tabular}{l|c|c}
\hline \multirow{4}{*}{ Fall 2013 } & Performance & Participation \\
\hline & Pre FCI Score & 0.12 \\
\cline { 2 - 3 } & Effort Score & -0.38 \\
\cline { 2 - 3 } & Exam Score & 0.31 \\
\hline \multirow{3}{*}{ Spring 2014 } & FCI Gain & $0.57 *$ \\
\cline { 2 - 3 } & Effort Score & -0.20 \\
\hline
\end{tabular}

Note: Using Bonferroni adjusted alpha levels .0125 per test $(.05 / 4) \quad * p<0.012$, number of observation $\mathrm{N}_{\text {fall }}=30, \mathrm{~N}_{\text {spring }}=26$

\subsubsection{Relation Between Participation in the ILC and Academic Performance}

In this section, students' study network in ILC is analyzed in order to understand how characteristics of the social structure could enhance students' academic performance. The contribution of this study is twofold. First, I have introduced an innovative study of the relationship between students' networks outside the class and students' performance on the overall exam score and effort score. Second, I have provided basic analysis of correlations between Social Network Analysis (SNA) measures and student individual performance.

In both fall and spring semesters, students were asked to self-report every week "who they worked with" outside of the class. The "who they worked with" data were allowed for the construction of the social network of the ILC that formed outside of the class time. Upon analyzing the connection between PageRank Centrality and different 
measures of students' success (Exam and Effort score), consistent significant associations were found in both semesters.

Table 12. Spearman's Correlation Coefficient Between PageRank Centrality and Students' Performance in the Fall and Spring Semesters

\begin{tabular}{l|l|l}
\hline Performance Measures & PageRank in Fall 2013 & PageRank in Spring 2014 \\
\hline Pre FCI & -0.28 & \\
\hline Effort Score & $0.45^{*}$ & $0.54^{*}$ \\
\hline Exam Score & 0.38 & 0.40 \\
\hline FCI Gain & -0.004 & \\
\hline
\end{tabular}

Note: Using Bonferroni adjusted alpha levels 0.0125 per test $(.05 / 4) \quad * \mathrm{p}<0.012$, number of observation $\mathrm{N}_{\text {fall }}=30, \mathrm{~N}_{\text {spring }}=26$

The characteristics of students' aggregated networks in ILC during the fall 2013 and spring 2014 semesters is summarized in Table 13. These characteristics include: Average Degree, Average Weighted Degree, and Network Density of the aggregated networks. The average number of edge incidents to each node is called Average Degree. Average weight of connections for each node in the network is Average Weighted Degree. Network density is the fraction of possible connections that occur. The total number of possible connection is $\mathrm{N}(\mathrm{N}-1) / 2$ for an undirected network. In both semesters, average number of connection to each student is same that is around 18. Average weighted degree is also same in both semesters. Therefore, we don't see changes from fall to spring semester in students' network in ILC. 
Table 13. Characteristics of Social Network of ILC during Fall and Spring Semesters

\begin{tabular}{l|l|l}
\hline Network Metric & Fall 2013 & Spring 2014 \\
\hline Average Degree & 18.13 & 18.308 \\
\hline Average Weighted Degree & 76.47 & 77.385 \\
\hline Network Density & 0.625 & 0.732 \\
\hline \multicolumn{2}{c}{ Number of students: $\mathrm{N}_{\text {fall }}=30, \mathrm{~N}_{\text {spring }}=26$} &
\end{tabular}

\subsubsection{Relation Between PageRank Centrality and Students' Grade}

The relations between the PageRank centrality and students' success in the courses based on exam score, effort score and FCI gain were examined. A strong positive significant correlation between students' effort score (which included all out-of-class assignment scores) and PageRank centrality was found in both fall and spring semesters. The Spearman correlation coefficients for the fall and spring semesters were 0.45 ( $p$ $=0.01)$ and $0.54(\mathrm{p}=0.004)$, respectively. However, PageRank centralities were marginally associated with exam scores in both semesters. In the fall semester, correlation coefficients were $0.38(\mathrm{p}=0.04)$ and in spring $0.40(\mathrm{p}=0.04)$. To examine how less central students were different than high central ones in their success through the course, the average course grade was binned with PageRank in tertile in both semesters and was investigated. [Tertile: each of three equal groups into which a population can be divided according to the distribution of values of a particular variable. There were 10 students in each tertile in Fall and 9,9,8 students in spring] 


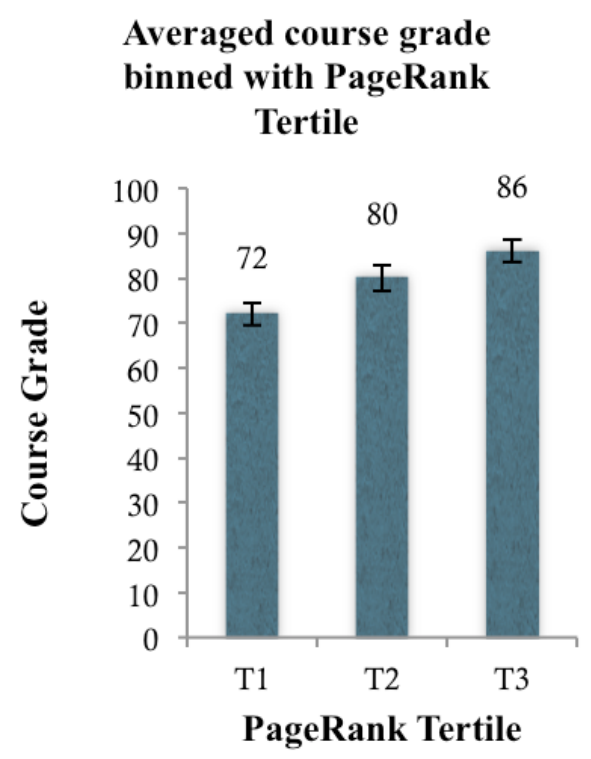

Fall 2013
Averaged course grade binned with PageRank

Tertile

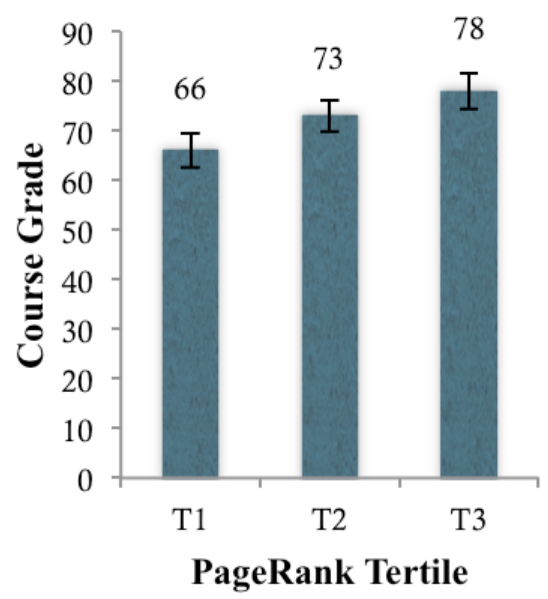

Spring 2014

Figure 6. Average Course Grade Binned with PageRank Centrality in Tertile in the Fall and Spring Semesters.

The average course grade score (combination of exam score and effort score) of the lowest PageRank tertile in both semesters was significantly lower than the average course grade score of the highest PageRank tertile groups. This implies that students who were more central in the learning community formed by themselves outside the class remained less likely to fail in the course. Similarly, less central students from the learning community were more likely to fail in the course. The second and third tertiles in both semesters were not significantly different. Therefore, students did not need to be highly central to achieve success in the course.

\subsection{Pattern of Students' Participation in LAct, RS and ILC}

This section analyzes how students transformed their participation through the course during the fall semester. In order to conduct this analysis, the fall semester is 
divided into three time segments. Participation data (Interaction in the LAct and RS, and PageRank centrality of the ILC) between those segments are compared. The data associated with the students common to both semesters are considered and compared using paired t-test and Wilcoxon Signed-Rank Test to examine the change in pattern of participation between the fall and spring semesters.

\subsubsection{Pattern of Students' Participation in the ILC}

Comparison of PageRank centrality among the three segments of the Fall Semester

The Spearman's rank correlation coefficients between students' participation in the ILC, which was quantified by PageRank centrality, in the three time segments of the fall semester were investigated. There was a 0.92 rank correlation coefficient between the first and second segments, 0.87 between the second and third segments, and 0.80 between the first and third segments, respectively. In order to understand whether change in participation pattern was significant or not, the Wilcoxon Rank-Test was used and the results are presented in Table 14.

Both W-value and Z-value were calculated by using Wilcoxon Signed-Rank Test between the PageRank centrality of three time segments of the fall semester. "If the pair sample size $\mathrm{N}$ was at least 20 , then the distribution of the Wilcoxon $\mathrm{W}$ statistics tends to form a normal distribution, which implies that Z-value can be used to evaluate our hypothesis" (Demšar, 2006). Both results are presented in Table 14. With $\alpha=0.05$, the null-hypothesis can be rejected if $z$ is smaller than -1.96 (Demšar, 2006). To give a clear picture of the distribution of data points, the scatter plot between the three time segments is also presented in Figure 7. Students who were less central during the first time segment still remained less central during the second and third time segments of the fall semester. 
Table 14. Wilcoxon Signed-Rank Test Between the PageRank Centrality of Three Time Segments of the Fall Semester

\begin{tabular}{|l|c|c|c|}
\hline & Segment I II & Segment I III & Segment II III \\
\hline W-value & 181.5 & 199.5 & 216 \\
\hline Mean Difference & -0.03 & -0.04 & -0.04 \\
\hline Sum of pos. Ranks & 196.5 & 199.5 & 219 \\
\hline Sum of neg. Ranks & 181.5 & 206.5 & 216 \\
\hline Z- value & -0.180 & -0.079 & -0.032 \\
\hline Mean (W) & 189 & 203 & 217.5 \\
\hline Standard Deviation (W) & 41.62 & 43.91 & 46.25 \\
& & & \\
\hline
\end{tabular}

To analyze the students' behavior shift over time in the ILC, the relation between PageRank Centrality among those students who took both courses in fall 2013 and spring 2014 is analyzed. Twenty students were common in the fall and spring semesters. Figure 8 shows a scatterplot of PageRank Centrality in fall and spring for the common students. The Wilcoxon Rank-Test (two-tailed) was utilized to test the difference of students' PageRank centrality between the two semesters, and found W-value: 103.5, Z-value: $0.056(\mathrm{p}=0.952)$. Therefore, the difference was not significant. 


\section{$0.01 \quad 0.03 \quad 0.05$}
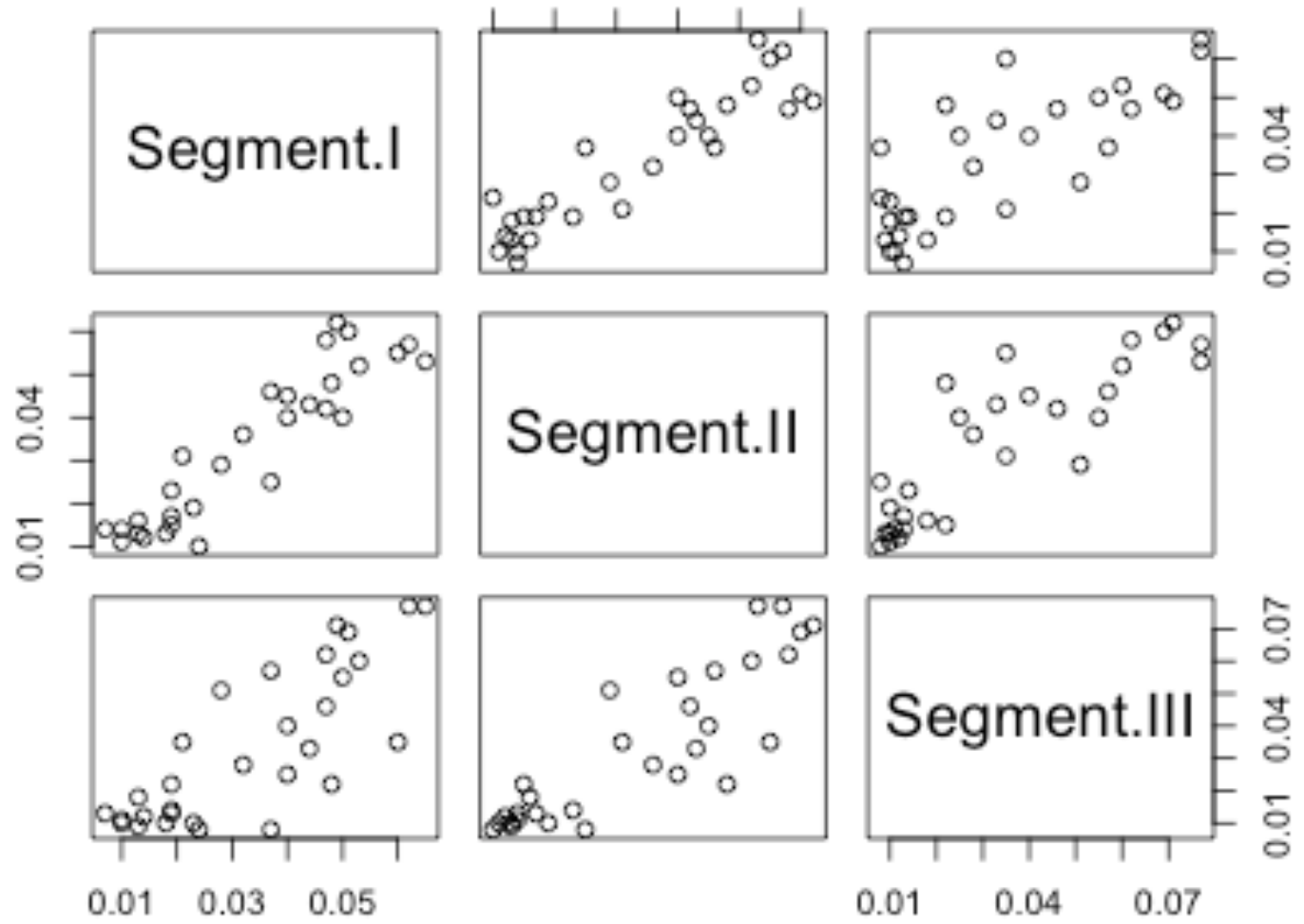

Figure 7. Scatter Plot of PageRank in Three Time Segments of the Fall Semester

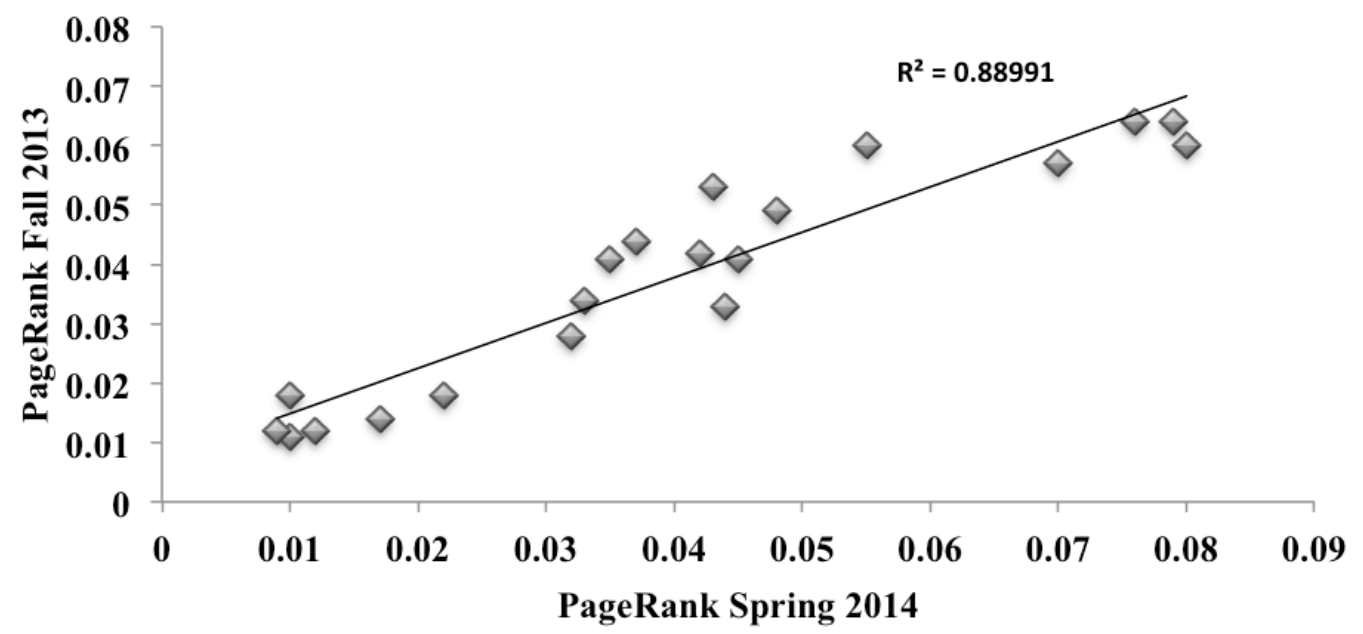

Figure 8. Relation Between PageRank Centrality of Common Students in both Fall 2013 and Spring 2014 


\subsubsection{Pattern of Students' Participation in the LAct}

This sub-section analyzes how students transformed their participation in the LAct during the fall semester. In order to conduct this analysis, the fall semester was divided into three time segments and the participation data in the Interaction code between the three time segments was compared. Data from the Interaction code of LActs turned out to be normally distributed when it was tested by the Shapiro-Wilk Normality Test. Results from normality tests were: for Segment I $(n=30, M=0.554, S D=0.190$, $\mathrm{W}=0.988)$, for Segment II $(\mathrm{n}=30, \mathrm{M}=0.536, \mathrm{SD}=0.213, \mathrm{~W}=0.956)$, for Segment III $(\mathrm{n}=30, \mathrm{M}=0.537, \mathrm{SD}=0.203, \mathrm{~W}=0.951)$. The threshold value of $\mathrm{W}$ for $\mathrm{n}=30$ is 0.927 for $\mathrm{p}=0.05$. Therefore, the two tail paired t-test was used to investigate the students' pattern of participation change over the fall semester. Table 15 presents results of the paired t-test between the Interaction codes of each time segment of the fall semester. There were no significant changes in the Interaction code over the three time segments of the fall semester.

Table 15. Paired t-test Between the Interaction Code Over the Three Time Segments of the Fall Semester

\begin{tabular}{l|c|c|c|c|c}
\hline Segments & $\begin{array}{c}95 \% \text { con. } \\
\text { Interval }\end{array}$ & t-value & $\begin{array}{c}\text { Degree of } \\
\text { Freedom }\end{array}$ & -value & $\begin{array}{l}\text { Mean } \\
\text { Differences }\end{array}$ \\
\hline Segment I $\sim$ II & $-0.081-0.117$ & 0.362 & 29 & 0.719 & 0.018 \\
\hline Segment I $\sim$ III & $-0.070-0.104$ & 0.393 & 29 & 0.697 & 0.017 \\
\hline Segment II $\sim$ III & $-0.037-0.036$ & -0.044 & 29 & 0.965 & -0.0007 \\
\hline
\end{tabular}



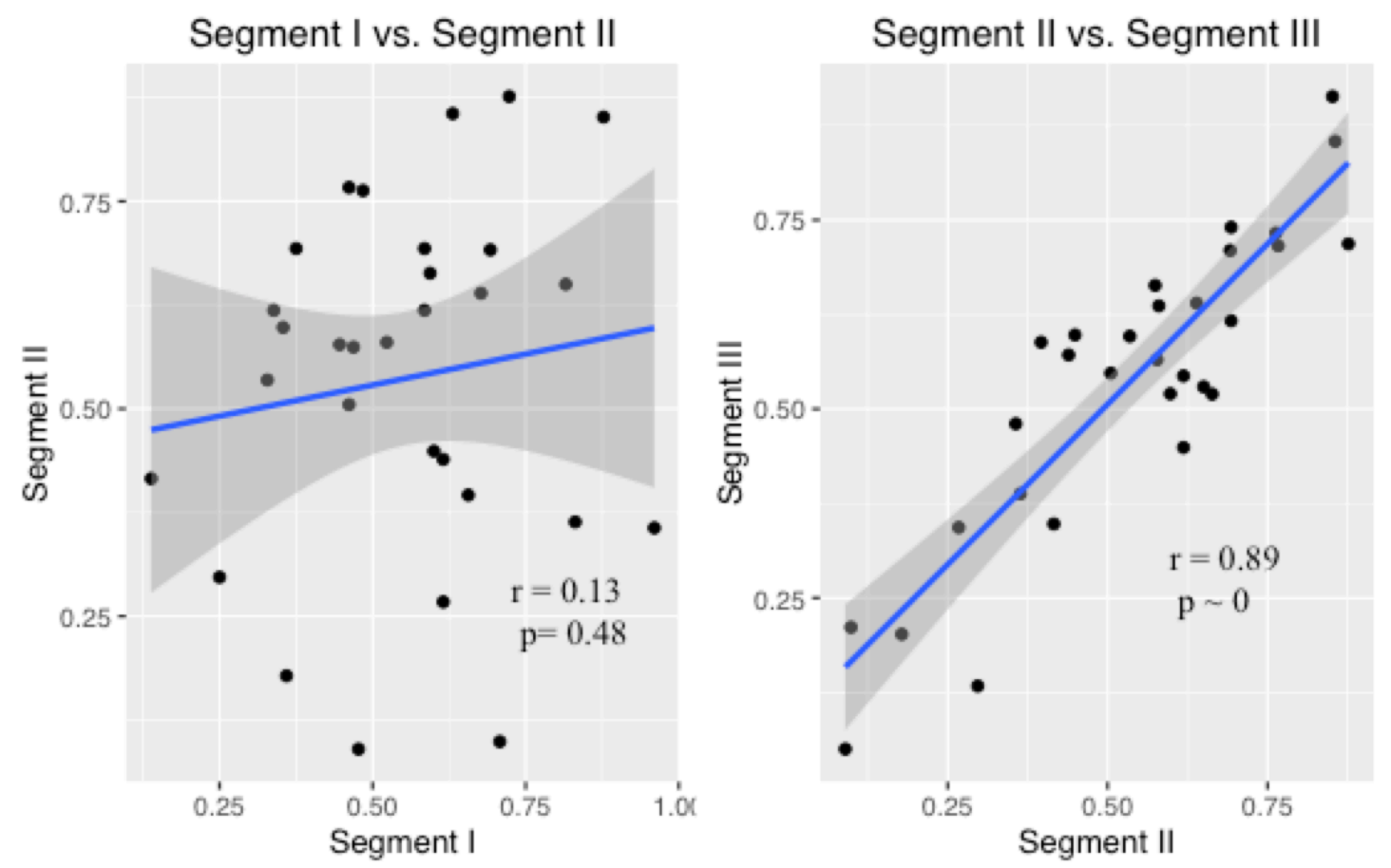

Figure 9. Scatter Plot of Interaction Code in the LAct in Three Time Segments of the Fall Semester.

Figure 9 shows the distribution of Interaction codes- in two scatter plots, between the time segments of the fall semester of the LAct. There was a strong, significant correlation between the Interaction code in the second and third segments (permutation correlation coefficient - 0.89, p-value 0 with 95 percent confidence interval: $0.76-0.94$ ). However, there was no significant correlation between the segments: first and second, and first and third. The reason behind this might be the formation of groups that the instructor adopted in the class. Before the first exam, group members were changed every other week and, after that, group members were fixed for the rest of the semester. This might have happened because the level of interactivity remained constant if a student collaborated with the same group members and changed if he/she worked with different 
group members. Therefore, interaction in groups would have changed if an instructor changed members of the group frequently in an active learning classroom.
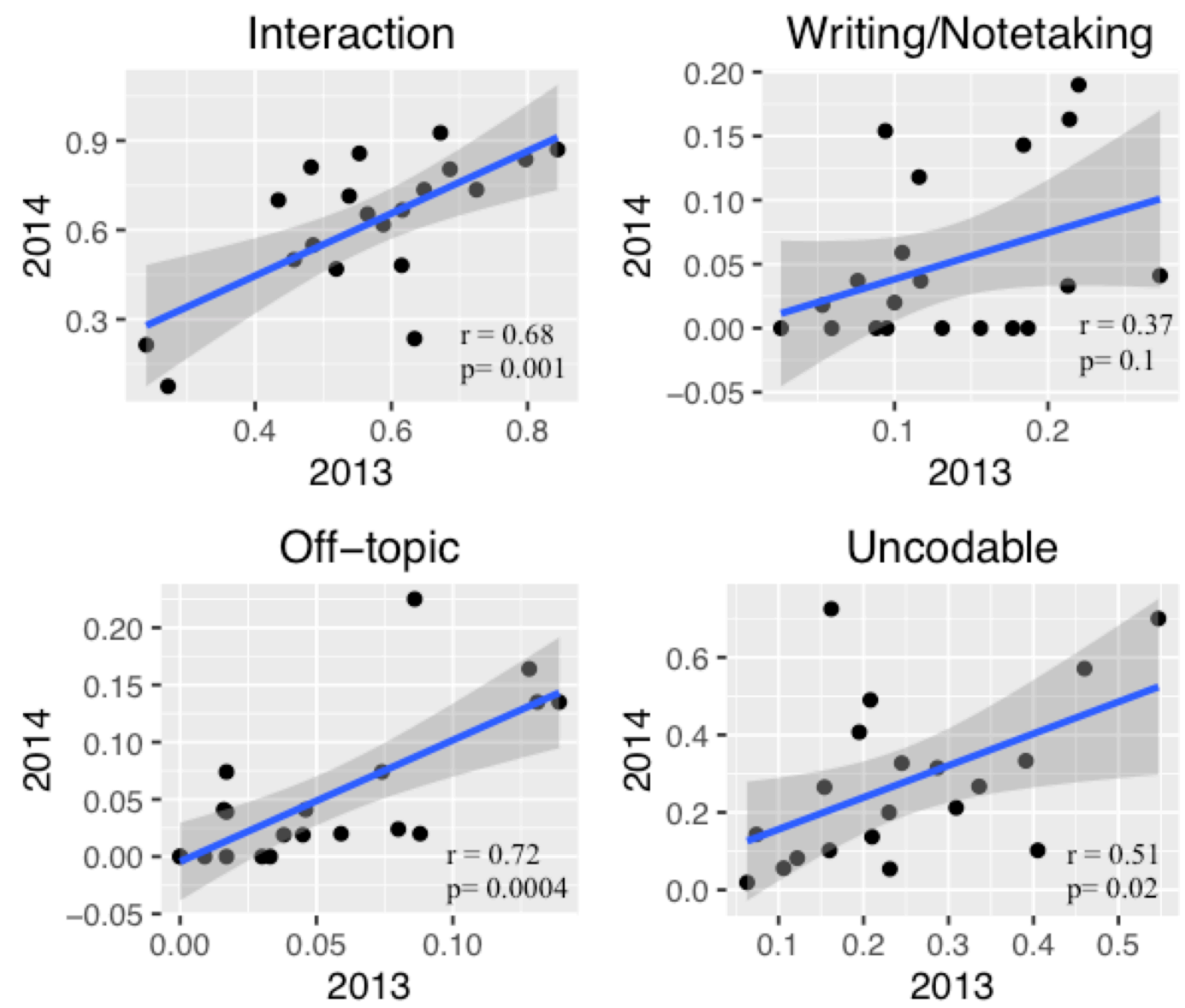

Figure 10. Relation Between Each Category of Coding in the LAct for the Common Students in the Fall and Spring Semesters.

To investigate the pattern of students' participation throughout two semesters, the common students in both semesters were taken into account. The scatterplot in Figure 10 shows the correlation between each category of code of the LAct between the fall and spring semesters. The correlation coefficient between quantity of engagement in each coding category of the LAct in the fall and spring semesters are also presented. The letter 
"r" represents Permutation Correlation coefficient with number of permutation 10,000.

The results indicate that students tended not to change the forms of their participation significantly; those who were regularly interacting during fall tended to interact during spring. Those who were inclined to be off-topic during fall semester also were inclined to be off-topic during spring semester.

The reason behind the not significant correlation in Writing/Notetaking code category between two semesters could be the sharing of more classwork among students through social tools such as WhatsApp, Facebook, etc. As they became more familiar with each other in the second semester, they probably started sharing more classwork through pictures. That might have made them take fewer notes and write less in their notebooks during the LActs in the spring 2014.

\subsubsection{Pattern of Students' Participation in the RS}

How students transformed their participation in the RS is analyzed in this subsection. In order to conduct this analysis, fall semester was divided into three time segments and the participation data in the Interaction code between the three time segments was compared. Data from the Interaction code of the RS were not normally distributed when these data were tested by the Shapiro-Wilk Normality test. Results from normality tests were: for Segment I $(\mathrm{n}=30, \mathrm{M}=0.442, \mathrm{SD}=0.369, \mathrm{~W}=0.867)$, for Segment II $(\mathrm{n}=30, \mathrm{M}=0.47, \mathrm{SD}=0.335, \mathrm{~W}=0.891)$, for Segment III $(\mathrm{n}=30, \mathrm{M}=$ $0.376, \mathrm{SD}=0.349, \mathrm{~W}=0.852$ ). The threshold value of $\mathrm{W}$ for $\mathrm{n}=30$ is 0.927 for $\mathrm{p}=$ 0.05. To test whether the change in participation occurred, the Wilcoxon Signed-Ranks 
Test was utilized. The Wilcoxon Signed-ranks test is a non-parametric test, an alternative to the paired t-test. Results of two-tailed Wilcoxon Rank-Test are presented in Table 16.

Table 16. Wilcoxon Signed-Rank Test Between the Interaction code of RS in Three Time Segments of the Fall Semester

\begin{tabular}{l|c|c|c}
\hline & Segment I II & Segment I III & Segment II III \\
\hline W-value & 155 & 143.5 & 84.5 \\
\hline Mean Difference & -0.62 & -0.5 & -0.69 \\
\hline Sum of pos. Ranks & 155 & 262.5 & 84.5 \\
\hline Sum of neg. Ranks & 223 & 143.5 & 293.5 \\
\hline Z- value & $-0.817(\mathrm{p}=0.41)$ & $-1.354(\mathrm{p}=0.17)$ & $\begin{array}{c}-2.510 \\
(\mathrm{p}=0.01)\end{array}$ \\
\hline Mean (W) & 189 & 203 & 189 \\
\hline Standard Deviation $(\mathrm{W})$ & 41.62 & 43.91 & 41.62 \\
\hline
\end{tabular}

The $z$-value of the test for segments I and II was $Z=-0.817(p=0.41)$, for segments I and III was $Z=-1.35(p=0.17)$ and for segments II and III was $Z=-2.51$ (p $=0.01)$. Therefore, the only significant change happened in interaction between time segments II and III. To visualize the distribution of students' engagement in Interaction code of the RS in three time segments, scatter plots between these segments are presented in Figure 11. The shaded region in the plots is the standard error. Students who were involved in interaction during the first segment continued interacting throughout the rest of the semester. The permutation correlation coefficients between segments I \& II was $r$ $=0.83,(p$-value $=7.847 \mathrm{e}-09)$, segments I \& III was $\mathrm{r}=0.78(\mathrm{p}$-value $=2.49 \mathrm{e}-07)$, segments II \& III was $\mathrm{r}=0.84(\mathrm{p}$-value $=5.8 \mathrm{e}-09)$. The strong correlation between the instances of students' engagement in Interaction code between the different time segments indicates that the same students were involved in the Interaction during the RS. 

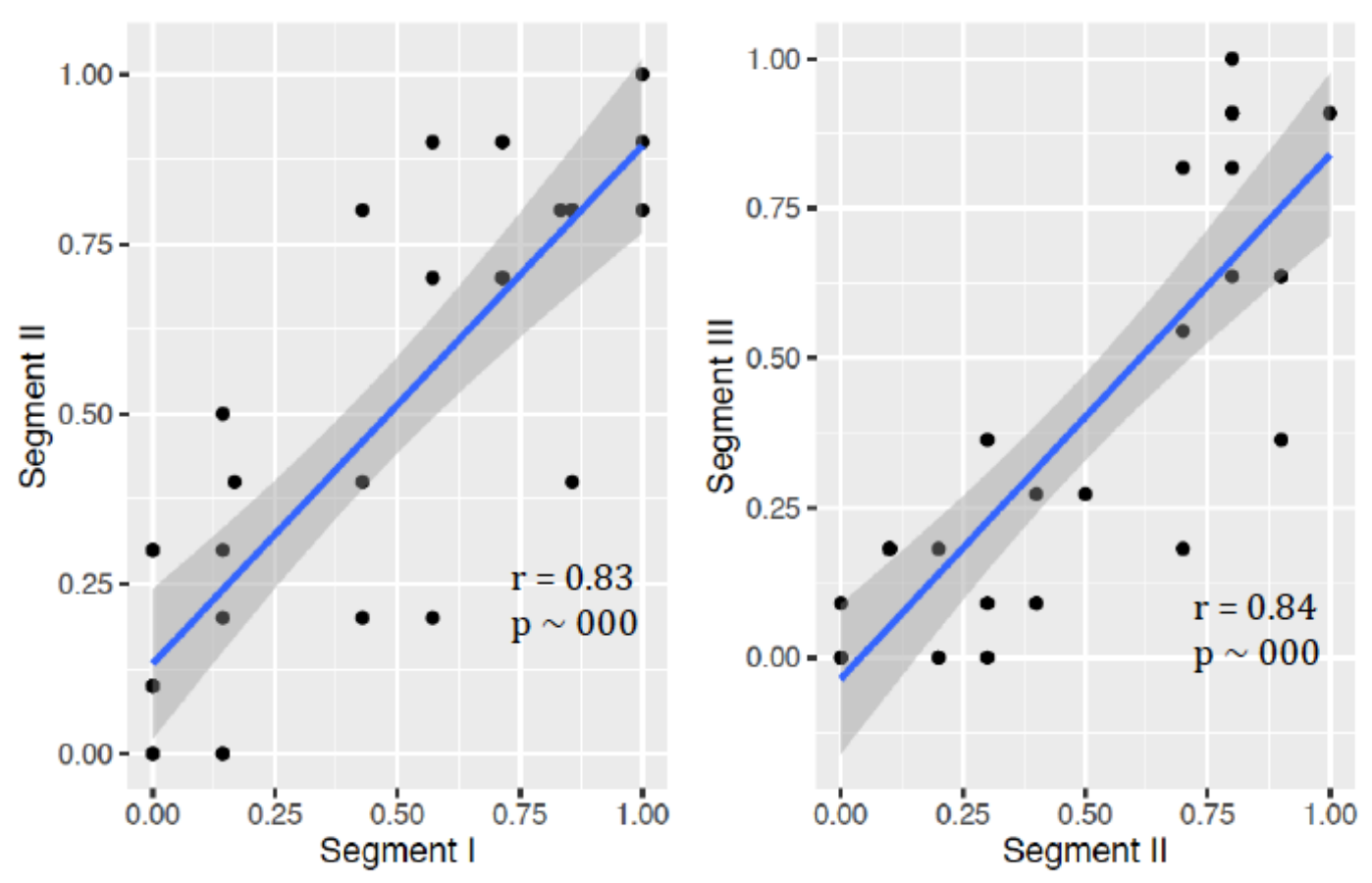

Figure 11. Scatter Plot of the Interaction Code of RS in Three Time Segments of the Fall Semester
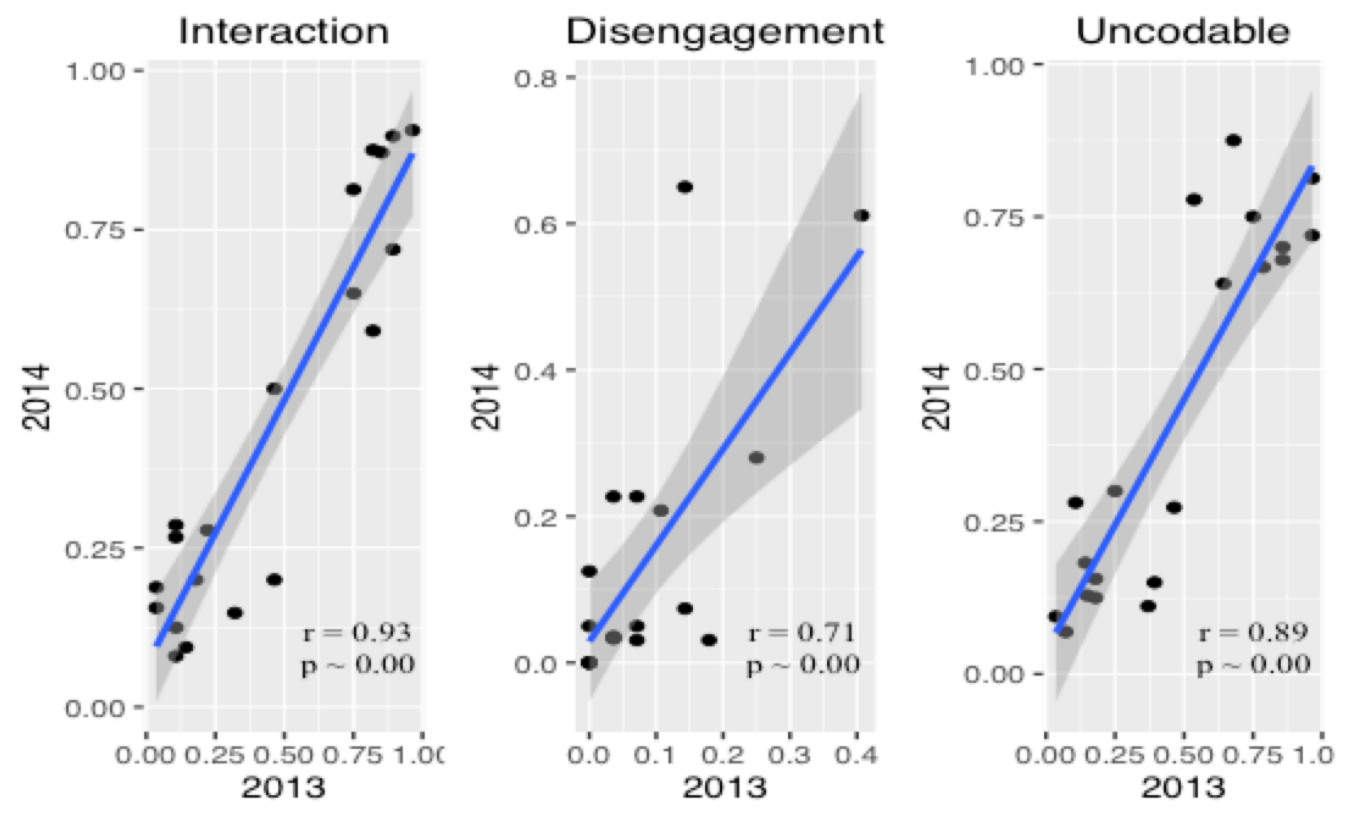

Figure 12. Relation Between Each Category of Coding in the RS for the Common Students in the Fall and Spring Semesters. 
The common students in both semesters were taken into account to investigate the pattern of students' participation throughout two semesters. The scatter plots in Figure 12 show the connection between each category of code of the RS between the fall and spring semesters. The correlation coefficient between quantity of engagement in each coding category of the RS in the fall and spring semesters are also presented in Figure 12. The letter " $r$ " represents Permutation Correlation coefficient with number of permutation 10,000. Just like in LAct, the results indicate that students tend not to change the forms of their participation significantly: those who interacted more during fall tended to interact more during spring as well. The scatter plot between the uncodable code in the fall and spring semesters supported that students do not change their behavior over the semester in an interactive learning environment.

\subsubsection{Comparison of Students' Engagement in the Interaction in LAct, RS, and ILC Between the Fall and Spring Semesters}

The Interaction code in the RS and LAct, and PageRank centrality of the ILC, were the major components of students' participation in an active learning environment of this study. There were strong, significant positive relationships between the students' engagement in various categories of coding of the LAct and RS between Fall 2013 and Spring 2014. Scatter plots in Figure 13 show strong relationships between the Interaction in LAct in the fall and in the spring semesters, the Interaction in the RS in the fall and spring, and participation (quantified by PageRank centrality) in the ILC in the fall and spring semesters.

Permutation correlation coefficients between the Interaction code during LAct in the fall and spring was $r=0.69(p=0.001)$, the Interaction in the RS was $r=0.93(p=$ 
2.07e-09), and participation in the ILC (PageRank centrality) was $r=0.95(p=4.641 \mathrm{e}$ 10). Students had complete freedom of choice with whom they would prefer to collaborate in the ILC. In the RS discussion, whole class met together and discussed what they did in the last class. Therefore, there might not have been enough time for everyone to participate. In the LAct, although the domain of interaction was restricted, there were high chances of being involved in discussion because there were only three students in the discussion group. Therefore, whatever the environment of active learning, it is hard to change students' non-participative behavior.
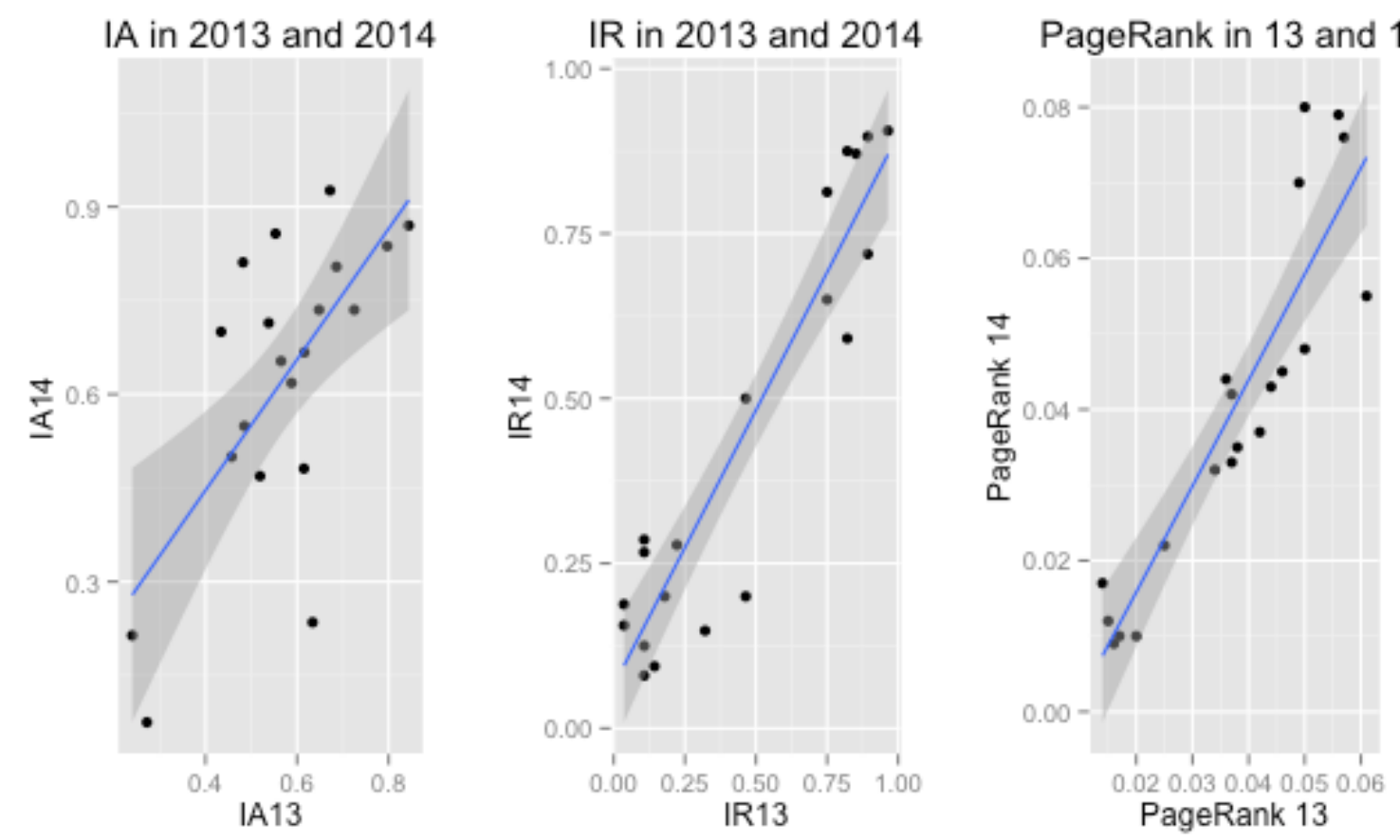

Note: IA- Interacting in LAct, IR- Interaction in RS, PageRank- PageRank Centrality of ILC, '13' Represents Fall and '14' Represents Spring Semester.

Figure 13. Scatter Plot of Students' Participation in LAct, RS and ILC Between the Fall and Spring Semesters 


\subsubsection{Comparison of Students' Participation in LAct, RS, and ILC}

A main goal of active learning environment classrooms is to encourage students to have a greater participation in learning process (Armbruster, Patel, Johnson, \& Weiss, 2009). Since the participation in different aspects of the class played distinct roles in learning, it would be better to look at the connection between students' level of participation in different aspects of the classroom. When a permutation correlation test was run between Interaction in LAct and RS, the result was not significant $(r=0.29, p=$ $0.11)$ in the fall semester. However, there was a significant relation $(\mathrm{r}=0.55$ and $\mathrm{p}=$ 0.003 ) between Interaction in LAct and Interaction in RS in the spring semester.

Students' level of interactions in classroom activities (LAct and RS) and their participation outside the classroom, quantified by PageRank centrality, were also investigated. There were significant relations between PageRank centrality and Interaction in LAct in both semesters: $(r=0.39, p=0.03$ in fall, $r=0.47, p=0.01$ in the spring semester). However, there were not significant associations between PageRank centrality and Interaction in RS in both fall $(\mathrm{r}=.02, \mathrm{p}=0.89)$ and spring semesters $(\mathrm{r}=$ $0.20, p=0.3)$. These results indicate that students preferred different settings for the collaboration. Moreover, the not significant correlations between the 'Uncodable' code in LAct and RS throughout two semesters [fall $(r=0.29, p=0.11)$ and spring $(r=0.31, p=$ 0.12) explain that uncodable students in one setting did not necessarily remain uncodable in another setting of active learning classrooms. Therefore, it would be beneficial if an instructor utilized different approaches of teamwork in running active learning classrooms to ensure students greater participation. 


\subsection{Data Analysis Related to the Sub-Research Questions}

In this section, data analysis related to each sub-problem is presented serially according to the research questions written in the first chapter. To address the sub problems, the Interaction code in both RS and LAct was considered as students' participation in an active learning environment. PageRank centrality was considered as students' participation during the data analysis from the ILC.

\subsubsection{Sub-Research Question 1}

"What is the relation between students' participation in various aspects of an interactive learning physics class and their conceptual understanding?"

Table 17. Model: Role of Participation on Conceptual Understanding

\begin{tabular}{c|c|c|l|c|c}
\hline Models & $\begin{array}{l}\text { Standard } \\
\text { Error }\end{array}$ & $\begin{array}{l}\text { Multiple } \\
\text { R-squared }\end{array}$ & $\begin{array}{l}\text { Adjusted } \\
\text { R-Squared }\end{array}$ & F (3,20) & p-value \\
\hline Fall & 0.147 & 0.360 & 0.261 & 3.709 & .028 \\
\hline
\end{tabular}

\begin{tabular}{c|c|c|c|c|c|c|c}
\hline $\begin{array}{c}\text { FCI } \\
\text { (M1) }\end{array}$ & \multicolumn{3}{|c|}{$\begin{array}{c}\text { Correlation coeff. } \\
\text { between independent } \\
\text { variables }\end{array}$} & & & & \\
\hline $\begin{array}{c}\text { Independent } \\
\text { Variable }\end{array}$ & IR & IA & PR & Estimate & $\begin{array}{c}\text { Std. } \\
\text { Error }\end{array}$ & t-value & p-value \\
\hline PR & & & 1.0 & -0.90 & 1.81 & -0.49 & 0.62 \\
\hline IA & & 1.0 & $0.41^{*}$ & 0.23 & 0.23 & 1.00 & 0.32 \\
\hline IR & 1.0 & $0.41^{*}$ & 0.00 & 0.25 & 0.10 & 2.37 & $0.02^{*}$ \\
\hline
\end{tabular}

$* \mathrm{p}<0.05, * * \mathrm{p}<0.005, \mathrm{~N}=24$, PR: PageRank Centrality of the ILC,

IA: Interaction in the LAct, IR: Interaction in the RS

Multiple linear regression analysis was used to develop a model for predicting conceptual understanding (quantified by FCI Gain) from the Interaction in the RS and 
LAct and PageRank Centrality of the ILC. In order to accomplish this, data from the fall semester was used. Approximately $36 \%$ of variation in conceptual understanding (FCI Gain) was explained by the Interacting in the LAct and RS and PageRank centrality in the ILC. The model summary and details of the model are presented in Table 17.

Within the limited statistical power of our study, only participation in the RS played a significant role in gains in conceptual understanding. It could be suggested that this surprising result is because the RS was a rather unique class activity in which it was observed how students often engaged in intense communal "making-sense-of" ideas explored in the previous class with minimal intervention from the instructor. Students were free and willing to raise the questions that revealed their lack of understanding.

\subsubsection{Sub-Research Question 2}

"Which aspects of the interactive learning class play the greatest role in students' success?”

To answer which aspects of the interactive learning class play the greatest role in students' success, multiple linear regression analysis was utilized to develop a model for predicting students' success quantified by Exam Scores and Effort Scores (score on outof-class assignments) from the Interaction in the RS and LAct and PageRank Centrality of the ILC. Analysis was conducted separately for the fall and spring semesters.

Table 18 shows the summary of two models that predict students' exam scores from the explanatory variables: Interacting in the LAct and RS and PageRank Centrality for the fall and spring semesters. The three predictors model was able to account for $26 \%$

of the variance in Exam Score $\left(F(3,26)=3.05, p=0.04, R^{2}=0.26\right)$ in the fall semester 
and $48 \%$ of the variance $\left(F(3,22)=6.83, p=0.02, R^{2}=0.48\right)$ in the spring semester. Although the models were, overall, significant in both semesters, the Interacting in LAct predictor had significant partial effects with beta $(\beta) 0.512(\mathrm{p}=0.02)$ in the full model in the spring semester only.

Table 18. Model: Role of Participation on Exam Score

\begin{tabular}{c|c|c|c|c|c}
\hline Models & $\begin{array}{c}\text { Standard } \\
\text { Error }\end{array}$ & $\begin{array}{c}\text { Multiple } \\
\text { R-squared }\end{array}$ & $\begin{array}{c}\text { Adjusted } \\
\text { R-Squared }\end{array}$ & $\begin{array}{c}\text { Fall-F(3,26) } \\
\text { Spring-F(3,22) }\end{array}$ & p-value \\
\hline Fall & 0.158 & 0.260 & 0.175 & 3.049 & .046 \\
\hline Spring & 0.081 & 0.482 & 0.411 & 6.828 & .002 \\
\hline
\end{tabular}

\begin{tabular}{|c|c|c|c|c|c|}
\hline Model & \multicolumn{2}{|c|}{ Unstandardized Coefficient } & Standardized & $\mathrm{t}$ & Sig. \\
\hline Spring & $\beta$ & Std. Error & $\beta$ & & \\
\hline Constant & 0.532 & 0.042 & & 12.584 & 0.000 \\
\hline IA & 0.217 & 0.087 & 0.512 & 2.498 & 0.020 \\
\hline IR & 0.053 & 0.066 & 0.150 & 0.814 & 0.424 \\
\hline PageRank & 0.770 & 0.844 & 0.160 & 0.913 & 0.371 \\
\hline
\end{tabular}

Note: Outcome Variable- Exam Score, Predictor Variables: IA- Interaction in the LAct, IR- Interaction in the RS, and PageRank- PageRank Centrality of the ILC,

Table 19 and 20 present the summary of two models that predict students' effort scores (total score on out of class assignments: Homework, Labs, and Journals) from the 
independent variables the Interacting code in the LAct and RS and PageRank centrality for the ILC in the fall and spring semesters. The model with three predictors was able to account for $42 \%$ of the variance $\left(F(3,26)=6.25, p=0.002, R^{2}=0.419\right)$ in the fall semester and $39 \%$ of the variance $\left(F(3,22)=4.742, \mathrm{p}=0.01, R^{2}=0.393\right)$ in the spring semester. Overall, although the models were significant in both semesters, only the PageRank centrality predictor had significant positive partial effects in the full model in both semesters with beta $0.612(\mathrm{p}=0.004)$ in fall and beta $(\beta) 0.384(\mathrm{p}=0.029)$ in the spring semesters.

Table 19. Model: Role of Participation on Effort Score in Fall

\begin{tabular}{|c|c|c|c|c|c|c|c|}
\hline Model & $\begin{array}{c}\text { Standard } \\
\text { Error }\end{array}$ & $\begin{array}{c}\text { Multiple } \\
\text { R-squared }\end{array}$ & & $\begin{array}{l}\text { djusted } \\
\text { Squared }\end{array}$ & $\begin{array}{r}\mathrm{Fa} \\
\mathrm{Spr}\end{array}$ & $\begin{array}{l}-F(3,26) \\
g-F(3,22)\end{array}$ & p-value \\
\hline \multirow[t]{3}{*}{ Fall } & 11.18 & 0.419 & & 0.352 & & .254 & .002 \\
\hline & \multicolumn{3}{|c|}{ Unstandardized Coefficient } & \multicolumn{2}{|c|}{$\begin{array}{l}\text { Standardized } \\
\text { Coefficient }\end{array}$} & \multirow[t]{2}{*}{$\mathrm{t}$} & \multirow[t]{2}{*}{ Sig. } \\
\hline & $\beta$ & Std. Er & & $\beta$ & & & \\
\hline Constant & 68.930 & 7.789 & & & & 8.850 & 0.000 \\
\hline IA & 21.848 & 15.58 & & 0.24 & & 1.402 & 0.173 \\
\hline IR & -20.191 & 6.637 & & -0.47 & & -3.042 & 0.005 \\
\hline PageRank & 355.311 & 154.07 & & 0.38 & & 2.306 & 0.029 \\
\hline
\end{tabular}


Table 20. Model: Role of Participation on Effort Score in Spring

\begin{tabular}{c|c|c|c|c|c}
\hline Model & $\begin{array}{c}\text { Standard } \\
\text { Error }\end{array}$ & $\begin{array}{c}\text { Multiple } \\
\text { R-squared }\end{array}$ & $\begin{array}{c}\text { Adjusted } \\
\text { R-Squared }\end{array}$ & $\begin{array}{c}\text { Fall-F(3,26) } \\
\text { Spring-F(3,22) }\end{array}$ & p-value \\
\hline Spring & 0.116 & 0.393 & 0.310 & 4.742 & .010 \\
\hline
\end{tabular}

\begin{tabular}{c|c|c|c|c|c}
\hline $\begin{array}{c}\text { Spring } \\
\text { Semester }\end{array}$ & \multicolumn{2}{|c|}{ Unstandardized Coefficient } & $\begin{array}{c}\text { Standardized } \\
\text { Coefficient }\end{array}$ & $\mathrm{t}$ & Sig. \\
\hline & $\beta$ & Std. Error & $\beta$ & & \\
\hline Constant & 0.771 & 0.060 & & 12.819 & 0.000 \\
IA & -0.010 & 0.124 & -0.019 & -0.084 & 0.934 \\
IR & -0.149 & 0.094 & -0.317 & -1.590 & 0.126 \\
PageRank & 3.884 & 1.201 & 0.612 & 3.234 & 0.004 \\
\hline
\end{tabular}

PageRank: PageRank Centrality of the ILC, IA: Interaction in the LAct, IR: Interaction in the RS

\subsubsection{Sub-Research Question 3}

Does prior students' physics knowledge of conceptual understanding bias their participation in an interactive learning environment?

Pre-FCI score was considered to measure students' prior physics knowledge or conceptual understanding. To investigate whether prior students' physics knowledge would bias students' participation in an interactive learning environment, the Permutation Correlation coefficients between the Pre-FCI scores and data from the Interaction code of the LAct and RS were utilized. For the ILC, Spearman's correlation coefficient was used between students' PageRank centrality and Pre-FCI. Results are presented in the Table 21. Students' prior conceptual understanding, 
which was quantified by their Pre-FCI, did not have any association in the interaction in the LAct, RS and participation in ILC.

Table 21. Correlation Coefficients Between Pre-FCI and Students' Participation

\begin{tabular}{c|c|c|c}
\hline & 'Interaction' & 'Interaction' & $\begin{array}{c}\text { PageRank } \\
\text { centrality of ILC }\end{array}$ \\
& in LAct & in RS & $\mathbf{r}_{\mathbf{s}}=\mathbf{- 0 . 2 8}$ \\
\hline Pre-FCI & $\mathbf{r}_{\mathbf{p}}=\mathbf{- 0 . 1 2}$ & $\mathbf{r}_{\mathbf{p}}=\mathbf{0 . 0 1}$ & \\
\hline
\end{tabular}

$\mathrm{N}=24 \mathrm{r}_{\mathrm{s}}$ : Spearman's, $\mathrm{r}_{\mathrm{p}}$ : Permutation Correlation Coefficient 


\section{CHAPTER V: RESULTS, DISCUSSIONS, IMPLICATIONS, FUTURE WORKS, LIMITATIONS, AND CONCLUSIONS}

In this chapter, results of the data analysis are presented in reference to the research questions and discussed in the first section. In the second section, implications of these findings will be considered. Finally, limitations and conclusions related to this research will be explored, as well as future research motivated by the findings of this project.

\subsection{Results and Discussions}

\subsubsection{Main Research Question A}

What are the different ways in which students participate both inside and outside of the classroom, and what sort of relationships exist between how they participate and their success in the class?

Students' engagement in Learning Activities (LActs) is classified in four categories: Interaction, Off-topic, Writing/Note Taking, and Uncodable. In Review Sessions (RS), students' engagement is classified in three categories: Interaction, Disengagement, and Uncodable. When students were working in small groups in assigned LActs across two semesters, they engaged in on-topic interaction on an average of $57 \%$ percent within the 30 -second time segment. In RSs, when students were participating in the whole class, an average of $42 \%$ of the students were participating in the on-topic Interaction category daily. On the other hand, on average for two semesters, $28 \%$ of students were Uncodable (which does not necessarily mean that students were not engaged) in LAct and 45\% in RSs. Although this study was conducted in highly student- 
centered active learning classrooms, still a high percentage of students were not engaged in the learning process.

To quantify students' outside of the class participation, students were asked, “who they worked with outside the class every week". Then, social network analysis was used to find the PageRank centralities of each student. The average degrees of the aggregated network of ILC in the fall and spring semester were 18.13 and 18.3, respectively. Similarly, network densities were also around the same in both semesters, 0.625 in fall and 0.732 in the spring semester. Though the average degree in the networks were similar in the fall and spring semester, the standard deviation of PageRank centralities were different in the fall and spring semesters ( 0.015 for fall and 0.022 for spring semester), whereas mean PageRank centrality for fall was 0.033 and for spring was 0.036 . These results suggest that more students were isolated in the spring semester. The reason behind this may be some students found ILC is not worthwhile enough to participate in the second semester.

The results from the comparison of students' participation in different aspects of the active learning classrooms suggest that students' participate differently in different activities. The permutation correlation coefficients between the Interaction code of LAct and RS are inconsistent in the fall and spring semester $(r=0.29, p=0.11$ for fall and $r=$ 0.55 and $\mathrm{p}=0.003$ for spring semester). Similarly, there was not significant association between PageRank centrality and Interaction in RS in both fall $(r=0.2, p=0.89)$ and spring semester $(r=0.2, p=0.3)$. These inconsistent associations between the level of participation in in-class activities (LAct and RS), and in-class activities and out-of-class study group study (ILC), indicate that different students like to be engaged in different 
settings. Therefore, to make the active learning more participative, an instructor may utilize different approaches of teamwork in the active learning classroom to ensure students' greater participation. Though these findings are interesting, the literature does not indicate how students' engagement varies in the different settings of an active learning classroom.

\section{Relating participation to student success.}

As Savory (2012) mentioned, faculty that establish student success in their teaching can be challenged to document which classroom practices are most successful in engaging student learning. The results of this current study found that correlations between students' success throughout the course and their participation in three different aspects of the active learning classroom indicate that various classroom practices have different impacts on students' learning. On-topic interaction in RS played a significant role in gains in conceptual understanding $(r=0.57, \mathrm{p}=0.004)$. Interaction in LAct had a better positive influence on exam score $(r=0.43, p=0.03$ in fall and $r=0.67, p=0.0004$ in the spring semester). Moreover, students who collaborated with their peers out of class (ILC) had better scores in out-of-class assignments. The correlation coefficients between PageRank centrality and score in out-of-class assignment were $(r=0.45, p=0.01$ in fall and $\mathrm{r}=0.54, \mathrm{p}=0.004$ in the spring semester).

One explanation for the positive relation between the Interaction in the LAct and exam scores could be the similarities between some exam questions and the content of the LAct (see an example in Appendix 4). Similarly, it was not surprising to have strong relationships between more collaboration between students outside the classroom and better scores on out-of-class assignments because students are usually looking for help to 
complete their out-of-class assignments. These out-of-class collaborations helped students to succeed through courses. Students were ranked based on their level of participation outside the class, measured by PageRank centrality. The lowest one third ranked students had a significantly lower average course grade than the highest one third ranked students throughout two semesters. However, the middle one third and the highest one third were not significantly different. This implies that students who were highly connected (having higher PageRank centrality) in the ILC formed by themselves outside the class remained less likely to fail in the course. Contrarily, the less connected (having lower PageRank centrality) students in the ILC were more likely to fail in the course.

As anticipated, students' disengaged or off-topic behavior negatively impacted their learning. Off-topic in LAct and Disengagement in RS did not have the same association with the students' success. Disengagement in RS had consistent negative association with the students' success in exams and conceptual understanding. However, the Off-topic behavior in the LAct did not have a consistent, significant, negative association with the exam score and no significant impact in gaining conceptual understanding. Therefore, results of this study match with the Baker et al. (2004) results. They mentioned that "off-task behavior was associated with less learning, but that this was not true of all types of off-task behavior" (Baker et al., 2004, p. 2 ). They only investigated the association between students' performance and off-task behaviors in the classroom. They did not look at students' on-topic engagement and its association with the academic performance. 


\subsubsection{Main Research Question B}

How do students transform or change their participation through the course as they learn how to learn in an interactive student centered learning environment?

Students' participation patterns in three aspects of the active learning classroom (ILC, LAct and RS) show interesting results. Meyers and Jones (1993) mentioned that active learning originates from two fundamental expectations: "(1) that learning is by nature an active endeavor and (2) that different people learn in different ways" (Meyers and Jones, 1993, p. xi). Results of this current study suggest that students' participation in different settings of the active learning classroom play distinct roles in students' academic achievement in the course. The Interaction code in LAct has the highest association with the exam score in fall $(\mathrm{r}=0.43, \mathrm{p}=0.03)$ and in spring $(\mathrm{r}=0.67, \mathrm{p}=$ 0.0004), as shown in Table 7 and 8. The Interaction code in RS has the highest correlation with FCI gain $(r=0.57, p=0.004)$ and PageRank centrality of ILC was found to be the highest correlation with effort score in fall $(\mathrm{r}=0.45, \mathrm{p}=0.01)$ and in spring $(r=0.54, p=0.004)$, as shown in Table 10. Furthermore, the outcome of this study shows that even a highly student-centered learning environment could not change students' participative behavior over time. Therefore, the fundamental assumptions that were identified by Meyers and Jones align with the findings of this research.

\section{Participation in the ILC}

There are strong positive correlations between the PageRank centrality in each segment of the fall semester, and even stronger positive correlations between the fall and 
spring semesters for the students who were common in both semesters. These correlations indicate that students who were working with their peers outside the class in the beginning of the first semester continued working with many friends until the end of the second semester. Students who were isolated from the ILC (not being part of ILC) in the beginning of the first semester remained isolated until the end of the first semester and during the second semester as well. Wilcoxon Rank t-test has shown not significant change in students' participation over the first semester and between the semesters.

\section{Participation in the LAct}

After examining the students' behavior in LAct throughout two semesters, students' pattern of involvement in on-topic interaction did not change significantly across two semesters. However, an interesting difference came out in the participation pattern in LAct between the time segments when the group members kept changing frequently and when the group members were fixed. The correlation between students' involvement in two time segments when they were fixed with the same group members is significantly higher $(\mathrm{r}=0.9, \mathrm{p} \sim 0)$. However, the correlation between the segment of group members who changed frequently versus the other two segments in which group members remained fixed is not significant, as suggested by $(r=0.13, p=0.48)$. This might have happened because level of interactivity remained constant if a student collaborated with the same group members and changed if a student collaborated with the different group members.

Lewin (1947) mentioned that people often take on different roles and behaviors when they engage in group-work with different group members. He defined these roles 
and behaviors by a terminology called "Group dynamics". The nature of group dynamics depends on the characteristics of each group member and on the group as a whole. It is very hard to identify confounding factors, how teams function towards a collective decision, and what makes team members accountable for making things happen. An effective group dynamic increases the creativity of the group outcome (Klug and Bagrow, 2016). Therefore, group dynamics would have changed if an instructor altered group members frequently in an active learning classroom, which could lead to changes in participatory behavior.

\section{Participation in the $R S$}

Students' participation in Review Sessions does not change significantly over time. Almost a perfect correlation $(\mathrm{r}=0.93, \mathrm{p}=2.07 \mathrm{e}-09)$ between the students' participation in the Interaction code across two semesters suggests that the frequency of students' involvement in the review session during the first semester keeps the same level of involvement in the second semester. Instructors who are teaching active learning classroom should impose some classroom strategies so that everyone is motivated to get involved in the learning process.

Additionally, the review session provides students a unique setting for participation. The not significant connection between the students' participation in ILC and RS in both fall $(r=0.02, p=0.89)$ and spring $(r=0.2, p=0.3)$ semesters suggests that students who were interested in working with their peers outside the class were not necessarily interested in participating in the whole class discussion (RS) inside the classroom. Similarly, not significant correlation $(r=0.29, \mathrm{p}=0.11)$ between the 
participation in LAct and RS in the first semester indicates that some students prefer to participate more in whole class discussions and some participate more in small group interactions. This may reflect students having different preferences for participation in different settings of the active learning classroom. The not significant correlations between the 'Uncodable' code in LAct and RS throughout two semesters [fall $(r=0.29, p$ $=0.11)$ and spring $(r=0.31, p=0.12)]$ demonstrate that uncodable students in one setting do not necessarily remain uncodable in another setting of active learning classrooms.

\subsubsection{Sub- Research Question 1}

What is the relation between students' participation in various aspects of an interactive learning physics class and their conceptual understanding?

After examining students' interaction in the LAct and RS, and PageRank centrality in the ILC, only students who were involved in interactions during the RS demonstrate a significant positive relation with conceptual understanding, which is measured by FCI gain. The correlation coefficient between the Interacting code in the RS and FCI gain was $0.57(\mathrm{p}=0.004)$. However, there were no significant correlations between FCI gain and the Interacting code in the LAct and PageRank centrality in the ILC. These results suggest that better conceptual understanding (measured by FCI gain) may be because students themselves facilitated RS and, consequently, may have felt free and willing to raise the questions that revealed their lack of understanding. Those questions were communally debated; students only deferred to the instructor when an impasse was reached. Interestingly, students may have seen the RS as a safe space and used it to build conceptual understanding. However, one might assume that ILC would 
also be a safe space to build conceptual understanding; but this was not the case. This might be because in RS students did not have a fixed assignment to finish, whereas in ILC they had some fixed assignments to finish, such as homework and lab reports. One explanation is that fixed assignments prevent students from exploring ideas that help to build conceptual understanding.

\subsubsection{Sub-Research Question 2}

Which aspects of the interactive learning class play the greatest role in students' success?

The connection between students' ways of engagement in three settings (LAct, RS, and ILC) of an active learning physics class and their success in the course, which was measured by exam score, effort score and FCI gain, was examined. Multiple linear regression analysis was used to develop a model for predicting exam score and effort score from students' engagement in the Interaction code of LAct and RS and PageRank centrality for aggregated network data of ILC. Only the Interaction code in LAct of the second semester had significant partial effects $(\beta=0.52, p=0.02)$ in the full model for exam score and the PageRank centrality had significant partial effects in the full model for effort score in both semesters: with $\beta=0.61(\mathrm{p}=0.004)$ in second semester and $\beta=$ $0.384(p=0.02)$ in the first semester. Similarly, only the Interaction code in the RS had significant partial effect on conceptual understanding with $\beta=0.25(p=0.02)$. Therefore, each of the settings in the active learning classroom has different impacts in students' learning. 


\subsubsection{Sub-Research Question 3}

Does prior students' physics knowledge of conceptual understanding bias their participation in an interactive learning environment?

The Force Concept Inventory (FCI)(Hestenes, Wells, Swackhamer, 1992) is commonly used as a gauge of student understanding of introductory mechanics(Coletta \& Phillips, 2005). Therefore, Pre-FCI scores have been chosen as prior physics knowledge for the mechanics that students took during Fall 2013. Results revealed that there were no significant correlations between students' Pre-FCI score and four coding categories of Learning Activities (LA): Interacting, Off-topic, Writing/note taking, and Uncodable. The correlation coefficient between Interacting and Pre-FCI was $-0.11(p=0.58)$, Offtopic and Pre-FCI was $-0.06(p=0.74)$, Writing/Note taking and Pre-FCI was $0.26(p=$ $0.21)$, and Uncodable and Pre-FCI was $-0.04(\mathrm{p}=0.83)$.

Similarly, in Review Session (RS), correlation coefficient between Interaction and Pre-FCI was $0.12(p=0.74)$. Likewise, in Informal Learning Community (ILC), the correlation between the PageRank Centrality and Pre-FCI is $-0.28(\mathrm{p}=0.18)$. These results indicate that students who came to the class with better content knowledge did not necessarily participate differently in different settings of an active learning classroom. Williams (2015) also found that, in a large active learning classroom, PageRank centrality of students' in-class collaboration was not associated with their prior physics content knowledge, which was measured by pre-score in FMCE test, another diagnostic test for mechanics. Although the common belief is that students' with better understanding of subject matter participate more in class activities, interestingly, this 
study has revealed that a significant relation did not exist between students' prior conceptual understanding and their engagement level in the learning process of active learning environment. The main reason behind this could be that participative behavior in the learning process is more guided by students' personal behavior rather than their content knowledge.

\subsection{Implications of this Research}

\subsubsection{Implications for Instructors}

This study helps educators in many ways. First, it offers information about some aspects and general patterns of students' engagement in each setting of an active learning classroom. Second, once an instructor knows the productive and unproductive behavior of students in interactive learning classes, he/she will try to create a situation that minimizes the chances of unproductive behavior. By maximizing productive behavior, instructors can design a more productive learning environment. Third, as this study found that different aspects of the active learning classroom have different influences on students' learning, instructors can utilize different methods to increase students' participation in the learning process. Different methods such as LAct, RS and ILC will help the instructor to create strategies to make the class more effective and interactive so that every student will have opportunities to share and transfer the knowledge. Finally, as Collins and O'Brien (2003) mentioned, this study guides instructors' implementation of student-centered learning environment, which increases students' motivation to learn, bolsters conceptual understanding, and develops positive mindsets towards courses. 


\subsubsection{Implications for Students}

Results of this research indicate that different aspects of the class have distinct roles in learning. If the instructor utilizes the findings of this study of students' participation when they are engaging in the learning process to accomplish the academic success, students will be benefited from the active learning environment. This is true because in active learning students have opportunities to provide personal understandings and explanations to develop their own response through participation in the learning process. This study has further validated the common notion that active learning strives to engage a greater range of students for effective learning. To do this, active learning cultivates social practices between learners, and between educators and learners. Classroom helps to build the community.

\subsubsection{Implications for Researchers}

Education researchers, who are mainly involved in the curriculum design and practices for active learning environment, will also benefit from this research. So far there have been no detailed studies evaluating the association between students' behaviors in active learning reform classes and their success through courses. If the researchers know the association between the students' behavior in different aspects of an active learning class and their success through the course, they may contribute a different insight on the reform process of teaching, learning and curriculum development. 


\subsection{Directions of Future Research}

Although this study was completed in an active learning physics classroom that implemented the investigative science learning environment philosophy, I am open to investigating students' engagement in other active learning environments with different teaching philosophies Therefore, future research resulting from this endeavor mainly centers on covering this study in active learning classrooms of other subjects, such as Mathematics, Chemistry, Biology etc. To investigate the generalizability of results, I would like to extend this work to various active learning classrooms of other science majors in high schools, community colleges and universities. I will expect to know whether the relation between interaction in the active learning is same across the different majors or not.

In this work, I have developed a model for how to quantify students' engagement while they are involved in different aspects of the active learning classroom, with a focus on how their engaging behaviors impact their leaning outcomes and how they change their participative behavior in the learning process. As this study identified, even in the highly student-centered active learning classroom, there was a significant percentage of Uncodable students who did not have a defined role when they were participating. Therefore, in future work, I will take a closer look at the uncodable category because it was unclear what these students were doing. For example, students who were on their computer or smartphone, but we could not see what they were doing, as well as students who were observed to be staring (apparently at nothing in particular) and may have actually been thinking about the physics subject, were placed in the uncodable category. 
We may only be able to examine these students' participation qualitatively, using a questionnaire to survey them after they have completed the course. This analysis will allow us to make more convincing suggestions for students learning how to interact and collaborate effectively with each other in a highly interactive learning environment.

\subsection{Limitations of this Study}

Although the following points are appropriate for a correlation study, this study failed to consider the dominant factors such as previous physics experience, grades/SAT score, and other measures of preparation in the correlations we observed. This study tried to avoid causality in interpreting the association between students' level of participation and their academic success because interactive traits that students exhibit are not solely a result of classes where the data for this research were collected. Small sample size is another major limitation throughout this research, particularly with the development of linear models.

In addition to small sample size, coding categories of Learning Activities and Review Session are not completely independent. Especially, coding categories of Review Session are more dependent because only one code was assigned for the entire Review Session. Consequently, dependency of coding categories has restricted me to run the multi-linear regression analysis with having more than one code from the Review Sessions and Learning Activities in the same model. Moreover, this study only incorporates two classes with the same instructor. Therefore, I had to take caution to make a generalizable message from the results of what I found in this study. To investigate the generalizability of results, it would be better to have more than one 
instructor's classroom in this study. However, the consistent relationships found across two semesters provided some confidence to the results.

\subsection{Conclusions}

By examining the students' engagement in three different aspects of the active learning physics class, the following conclusions have been made. Students' interaction in the learning process has revealed that three class components (Review Sessions, Learning Activities, and Informal Learning Communities) play distinct roles in learning. Participation in the Review Session plays a significant role in gaining conceptual understanding. Students' participation in the Learning Activities helps them to do better in exams. Informal Learning Community that students form outside the class serves as a "support network" for helping them to get the assignments done. Participation in the Informal Learning Community increases chances of students' success through the course.

Although the common belief is that students with better understanding of subject matter participate more in class activities, interestingly, this study has revealed that a significant relation did not exist between students' prior conceptual understanding, which was quantified by their Pre-FCI score, and their engagement level in the learning process in active learning classes. The main reason behind this could be that participative behavior in the learning process is more guided by students' personal behavior rather than their prior content knowledge. A longitudinal study of students' participation across two semesters reveals that patterns of students' participation do not change significantly over time in the same nature of interactive learning activities. Results indicate that 
students prefer different settings for the collaboration. Therefore, instructors should try to ensure greater participation by incorporating different nature of active learning activities in active learning classes. 


\section{References}

Anderson, T. (2003). Getting the mix right again: An updated and theoretical rationale for interaction. The International Review of Research in Open and Distributed Learning, 4(2).

Armbruster, P., Patel, M., Johnson, E., \& Weiss, M. (2009). Active Learning and Student-centered Pedagogy Imporve Student Attitdues and Performance in Introductory Biology. Life Sciences Education, 8, 203-213.

Armstrong, R. A. (2014). When to use the Bonferroni correction. Ophthalmic and Physiological Optics, 34(5), 502-508.

Baker, R., Koedinger, K. R., Corbett, A. T., Wagner, A. Z., Baker, R., Koedinger, K. R., ... Wagner, A. Z. (2004). Off-task behavior in the cognitive tutor classroom: when students game the system. In SIGCHI conference on Human factors in computing systems, 383-390, Vienna, Austria.

Bandura, A. (1971). Social Learning Theory. General Learning Corporation.

Bandura, A., \& Walters, R. H. (1977). Social learning theory.

Bandura, A. (1986). Social foundations of thought and action: A social cognitive theory. Prentice-Hall, Inc.

Beichner, R. J., Saul, J. M., Abbott, D. S., Morse, J. J., Deardorff, D., Allain, R. J., ... Risley, J. (2007). The Student-Centered Activities for Large Enrollment Undergraduate Programs ( SCALE-UP ) Project Abstract. Research-Based Reform of University Physics, 1(1), 2-39.

Blazer, A. (2014). Student Summaries of Class Sessions. Teaching Theology and Religion, 17(4), 344-344.

Bonwell, C. C., \& Eison, J. a. (1991). Active Learning : Creating Excitement in the Classroom. Learning, 80819(719), 1-6.

Brenneis, L. (2002). Final Cut Pro 3 for Macintosh. Peachpit Press.

Brewe, E. (2008). Modeling theory applied: Modeling Instruction in introductory physics. American Journal of Physics, 76(12), 1155.

Brewe, E., Kramer, L. H., O’Brien, G. E., Singh, C., Sabella, M., \& Rebello, S. (2010). Changing Participation Through Formation of Student Learning Communities, $85-88$. 
Brewe, E., Kramer, L., \& Sawtelle, V. (2012). Investigating student communities with network analysis of interactions in a physics learning center. Physical Review Special Topics - Physics Education Research, 8(1), 010101.

Brin, S., \& Page, L. (1999). The anatomy of a large-scale hypertextual $\{$ Web $\}$ search engine. Computer Networks and ISDN Systems, 30(1--7), 107-117.

Bruun, J., \& Brewe, E. (2013). Talking and learning physics: Predicting future grades from network measures and Force Concept Inventory pretest scores. Physical Review Special Topics - Physics Education Research, 9(2), 020109.

Burrowes, P. A. (2003). A Student-Centered Approach to Teaching General Biology That Really Works : Lord's Constructivist Model Put to a Test. The American Biology Teacher, 65(7), 491-502.

Bybee, R. W. (1997). Achieving Scientific Literacy: From purposes to practices. Heinemann, 88 Post Road West, P.O. Box 5007, Westport, CT.

Cadima, R., Ojeda, J., \& Monguet, J. M. (2012). Social Networks and Performance in Distributed Learning Communities 1. Educational Technology \& Society, 15(4), 296-304.

Čančula, M. P., Planinšič, G., \& Etkina, E. (2015). Analyzing patterns in experts’ approaches to solving experimental problems. American Journal of Physics, 83(4), 366-374.

Cantor, A. B. (1996). Sample-Size Calculations for Cohen's Kappa. Psychological Methods, 1(2), 150-153.

Carrington, P. J., Scott, J., \& Wasserman, S. (2005). Models and methods in social network analysis. New York: Cambridge university press.

Chickering, A. W., \& Gameson, Z. F. (1987). Seven principles for good practice in Undergraduate Education. American Association of Higher Education Bulletin, $39,3-7$.

Coletta, V. P., \& Phillips, J. A. (2005). Interpreting FCI scores: Normalized gain, preinstruction scores, and scientific reasoning ability Vincent P. Coletta and Jeffrey A. Phillips. American Journal of Physics, 73(12), 1172-1182.

Collins, J. W., \& O'Brien, N. P. (2011). The Greenwood dictionary of education. ABCCLIO. 
Csardi, G., \& Nepusz, T. (2006). The igraph software package for complex network research. Complex Systems, 1695

Curtin, F., \& Schulz, P. (1998). Multiple Correlations and Bonferroni' s Correction. Biological Psychiatry, 44, 775-777.

Dancer, D., \& Kamvounias, P. (2005). Student involvement in assessment: a project designed to assess class participation fairly and reliably. Assessment \& Evaluation in Higher Education, 30(4), 445-454.

Demšar, J. (2006). Statistical Comparisons of Classifiers over Multiple Data Sets. The Journal of Machine Learning Research, 7, 1-30.

Eberlein, T., Kampmeier, J., Minderhout, V., Moog, R. S., Platt, T., Varma-Nelson, P., \& White, H. B. (2008). Pedagogies of engagement in science: A comparison of PBL, POGIL, and PLTL. Biochemistry and Molecular Biology Education, 36(4), 262-273.

Etkina, E. (2000). Weekly reports: A two way feedback tool. Science Education, 84(5), 594-605.

Etkina, E., \& Heuvelen, a Van. (2007). Investigative Science Learning Environment - A Science Process Approach to Learning Physics. PER-Based Reforms in CalculusBased Physics, 1-48.

Etkina, E., Karelina, A., Ruibal-Villasenor, M., Rosengrant, D., Jordan, R., \& HmeloSilver, C. E. (2010). Design and Reflection Help Students Develop Scientific Abilities: Learning in Introductory Physics Laboratories. Journal of the Learning Sciences, 19(1), 54-98.

Etkina, E., Van Heuvelen, A., White-Brahmia, S., Brookes, D. T., Gentile, M., Murthy, S., ... Warren, A. (2006). Scientific abilities and their assessment. Physical Review Special Topics - Physics Education Research, 2(2), 1-15.

Favero, T. G. (2011). Active review sessions can advance student learning. Advances in Physiology Education, 35(3), 247-248. http://doi.org/10.1152/advan.00040.2011

Felder, R. M., Felder, G. N., \& Dietz, E. J. (1998). A Longitudinal study of engineering student performance and retention. V. comparisons with traditionally-taught students Journal of Engineering Education, 87(4), 469-480.

Finkel, D. (2010). Teaching with Your Mouth Shut. The Writing Center Journal, 30(1), $45-51$. 
Flower, L. (1994). The Construction of Negotiated Meaning: A Social Cognitive Theory of Writing Language Arts \&Disciplines. Carbondale : Southern Illinois University Press, c1994.

Freeman, S., Eddy, S. L., McDonough, M., Smith, M. K., Okoroafor, N., Jordt, H., \& Wenderoth, M. P. (2014). Active learning increases student performance in science, engineering, and mathematics. Proceedings of the National Academy of Sciences of the United States of America, 111(23), 8410-5.

Fritschner, L. M. (2000). Inside the undergraduate college classroom: Faculty and students differ on the meaning of student participation. Journal of Higher Education, 342-362.

Glaser, B. G., \& Strauss, A. L. (1967). Discovery of grounded theory. Mill Valley.

Gleason, B. L., Peeters, M. J., Resman-Targoff, B. H., Karr, S., McBane, S., Kelley, K., ... Denetclaw, T. H. (2011). An active-learning strategies primer for achieving ability-based educational outcomes. American Journal of Pharmaceutical Education, 75(9), 186.

Goertzen, R. M., Brewe, E., \& Kramer, L. (2012). Introductory University Physics Expanded Markers of Success in Introductory University Physics, (September).

Gosser, D. K., \& Roth, V. (1998). The workshop chemistry project: Peer-led teamlearning. J. Chem. Educ, 75(2), 185.

Grady, M. E. (2014). Inverted Review Session for Problem-Based Courses. College Teaching, 62(4), 150-150.

Granovetter, M. (1983). The Strength of Weak Ties: A Network Theory Revisited. Sociological Theory, 1(1983), 201-233.

Griffiths, Y., \& Ursick, K. (2004). Using active learning to shift the habits of learning in health care education. Internet Journal of Allied Health Sciences and Practice, 2(2), 5.

Grunspan, D. Z., Wiggins, B. L., \& Goodreau, S. M. (2014). Understanding Classrooms through Social Network Analysis: A Primer for Social Network Analysis in Education Research. Cell Biology Education, 13(2), 167-178.

Gulati, S. (2008). Compulsory participation in online discussions: is this constructivism or normalisation of learning? Innovations in Education and Teaching International, 45(2), 183-192. 
Hake, R. R. (1998). Interactive-engagement versus traditional methods: A six-thousandstudent survey of mechanics test data for introductory physics courses. American Journal of Physics, 66(1), 64.

Handelsman, M. M., Briggs, W. L., Sullivan, N., \& Towler, A. (2005). A Measure of College Student Course Engagement. The Journal of Educational Research, 98(3), 184-192.

Hanneman, R. a, Riddle, M., \& Robert, A. (2005). Introduction to social network methods.

Hanson, D. M. (2006). Instructor's guide to process-oriented guided-inquiry learning. Lisle, IL: Pacific Crest.

Harper, K. A., Etkina, E., \& Lin, Y. (2003). Encouraging and Analyzing Student Questions in a Large Physics Course: Meaningful Patterns for Instructors. Journal of Research in Science Teaching, 40(8), 776-791

Hestenes, D. (1987). Toward a modeling theory of physics instruction. American Journal of Physics, 55(5), 440.

Hestenes, M. Wells, G. Swackhamer, D. (1992). Force Concept Inventory. Phys. Teach.

Heymann, S. (2013). Gephi. Paris. Retrieved from http://sebastien.pro/gephi-esnam.pdf

Hmelo-Silver, C. E. (2004). Problem-based learning: What and how do students learn? Educational Psychology Review, 16(3), 235-266.

Hoellwarth, C., Moelter, M. J., \& Knight, R. D. (2005). A direct comparison of conceptual learning and problem solving ability in traditional and studio style classrooms. American Journal of Physics, 73(5), 459.

Howard, J. R., \& Henney, A. L. (1998). Student Participation and Instructor Gender in the Mixed-Age College Classroom. Journal of Higher Education, 69(4), 384-405.

Jackson, J., Dukerich, L., \& Hestenes, D. (2005). Modeling Instruction : An Effective Model for Science Education.

Jensen, P. A., \& Moore, R. (2009). What do help sessions accomplish in introductory science courses. J Coll Sci Teach, 38, 60-64.

Jung, I., \& Choi, S. (2002). Effects of Different Types of Interaction on Learning Achievement, Satisfaction and Participation in Web-Based, 153-163. 
Kapucu, N., Yuldashev, F., Demiroz, F., \& Arslan, T. (2010). Social Network Analysis (SNA) Applications in Evaluating MPA Classes. Journal of Public Affairs

Karelina, A., \& Etkina, E. (2007). Acting like a physicist: Student approach study to experimental design. Physical Review Special Topics - Physics Education Research, 3(2), 020106.

Karp, D. A., \& Yoels, W. C. (1976). The college classroom: Some observations on the meanings of student participation. Sociology \& Social Research.

Klug, M., \& Bagrow, J. P. (2016). Understanding the group dynamics and success of teams. arXiv preprint arXiv: 1407.2893

Knight, J. K., \& Wood, W. B. (2005). Teaching More by Lecturing Less. Cell Biology Education, 4(4), 298-310. http://doi.org/10.1187/05

Knoke, D., Yang, S. (2008). Social Network Analysis. (T. F. Liao, Ed.) (Second). Sara Miller McCune, SAGE Publication, Inc.

Kolb, S. M. (2012). Grounded Theory and the Constant Comparative Method : Valid Research Strategies for Educators. Journal of Emerging Trends in Educational Research and Policy Studies, 3(1), 83-86.

Kuh, G. D. (1996). Guiding Principles for Creating Seamless Learning Environments for Undergraduates. Journal of college student development, 37(2), 135-48.

Kuh, G. D., Kinzie, J., Schuh, J. H., \& Whitt, E. J. (2005). Assessing conditions to enhance educational effectiveness. San Francisco: Jossey-Bass.

Kuh, G. D., Bridges, B. K., \& Hayek, J. C. (2006). What Matters to Student Success : A Review of the Literature Spearheading a Dialog on Student Success. Commissioned Report for the National Symposium on Postsecondary Student Success Spearheading a Dialog on Student Success, 18(July), 156.

Lave, J., \& Wenger, E. (1991). Situated learning: Legitimate peripheral participation. Learning in doing (Vol. 95).

Lewin, K. (1947). Frontiers in group dynamics II. Channels of group life; social planning and action research. Human relations, 1(2), 143-153.

Lin, Y., \& Brookes, D. T. (2013). Using collaborative group exams to investigate students' ability to learn. AIP Conference Proceedings, 1513(1), 254-257. 
Lucas, L. L. (2014). Supporting Representation-Rich Problem-Solving in High School Physics.

Lundy, K. G. (2007). Leap into literacy : teaching the tough stuff so it sticks! Markham, Ont.: Pembroke Publishers.

Lunt, C., Galbreath, N., \& Winner, J. (2015). U.S. Patent No. 8,949,261. Washington, DC: U.S. Patent and Trademark Office.

Machemer, P. L., \& Crawford, P. (2007). Student perceptions of active learning in a large cross-disciplinary classroom. Active Learning in Higher Education, 8, 9-30.

Maloney, D. P., O'Kuma, T. L., Hieggelke, C. J., \& Van Heuvelen, A. (2001). Surveying students' conceptual knowledge of electricity and magnetism. American Journal of Physics, 69(S1), S12.

Marcey, D., \& Brint, M. (2012). Transforming an undergraduate introductory biology course through cinematic lectures and inverted classes: A preliminary assessment of the clic model of the. NABT Biology Education Research Symposium, 1-9.

May, D. B., \& Etkina, E. (2002). College physics students' epistemological selfreflection and its relationship to conceptual learning. American Journal of Physics, 70(12), 1249.

Mazur, E. (1997, March). Peer instruction: getting students to think in class. In AIP Conference Proceedings (pp. 981-988). Institute of Physics Publishing Ltd.

Mayer, R. E. (2004). Should there be a three-strikes rule against pure discovery learning?. American psychologist, 59(1), 14.

Mccray, R. a, Dehaan, R. L., \& Anne, J. (2003). Undergraduate Instruction. Social Sciences.

McHugh, M. L. (2012). Interrater reliability: the kappa statistic. Biochemia medica, 22(3), 276-282.

McKeachie, W. J., \& Others, A. (1986). Teaching and Learning in the College Classroom. A Review of the Research Literature (1986) and November 1987 Supplement. National Center for Research to Improve Postseconotoxy Teaching and Learning.

Meyers, C., \& Jones, T. B. (1993). Promoting Active Learning. Strategies for the College Classroom. Jossey-Bass Inc., Publishers, 350 Sansome Street, San Francisco, CA 94104. 
Michael, J. (2006). Where's the evidence that active learning works? Advances in Physiology Education, 30(4), 159-167.

Mikropoulos, T., Chalkidis, a, Katsikis, a, \& Kossivaki, P. (1997). Virtual realities in environmental education: The project LAKE. Education and Information Technologies, 2(2), 131-142.

Modell, H. I., \& Michael, J. a. (1993). Promoting Active Learning in the Life Science Classroom : Defining the Issues. Annals of the New York Academy of Sciences, 701, 1-7.

Moler, C. B. (2011). Experiments with MATLAB. Society for Industrial and Applied Mathematics.

Nainabasti, B., Brookes, D. T., \& Yang, Y. (2015). Students' Participation And Its Relationship To Success In An Interactive Learning Environment. 2014 Physics Education Research Conference Proceedings, 195-198.

Newman, M. E. (2001). The structure of scientific collaboration networks. Proceedings of the National Academy of Sciences of the United States of America, 98(2), 404-9.

Olson, S., \& Riordan, D. G. (2012). Engage to Excel: Producing One Million Additional College Graduates with Degrees in Science, Technology, Engineering, and Mathematics. Report to the President. Executive Office of the President.

Otte, E., \& Rousseau, R. (2002). Social network analysis: a powerful strategy, also for the information sciences. Journal of information Science, 28(6), 441-453.

Page, L., Brin, S., Motwani, R., \& Winograd, T. (1999). The PageRank citation ranking: bringing order to the web.

Perneger, T. V. (1998). What's wrong with Bonferroni adjustments. Bmj, 316(7139), 1236-1238.

Prince, M. (2004). Does Active Learning Work? A Review of the Research. Journal of Engineering Education, (July).

Rabourn, K. E., Shoup, R., \& Brckalorenz, A. (2015). Barriers in Returning to Learning: Engagement and Support of Adult Learners, 1-32.

Rashidi, N., \& Naderi, S. (2012). The Effect of Gender on the Patterns of Classroom Interaction. Education, 2(3), 30-36. 
Rice, E., \& Yoshioka-Maxwell, A. (2015). Social Network Analysis as a Toolkit for the Science of Social Work. Journal of the Society for Social Work and Research, 6(3), 369-383.

Rocca, K. A. (2010). Student participation in the college classroom: An extended multidisciplinary literature review. Communication Education, 59(2), 185-213

Rogoff, Barbara (1990). Models of Teaching and Learning : Participation in a Community of Learners.

Rogoff, B., Matusov, E., \& White, C. (1996). Models of teaching and learning: Participation in a community of learners. The handbook of education and human development, 388-414.

Rollnick, M., \& Mahooana, P. P. (1999). A quick and effective way of diagnosing student difficulties: two tier from simple multiple choice questions. South African Journal of Chemistry, 52(4).

Savory, P. (2012). Measuring Classroom Engagement by Comparing Instructor Expectations with Students' Perceptions. Mountain Rise, 1-21.

Scardamalia, M., \& Bereiter, C. (1991). Higher levels of agency for children in knowledge building: A challenge for the design of new knowledge media. The Journal of the learning sciences, 1(1), 37-68

Schunk, D. H., \& Zimmerman, B. J. (Eds.). (1998). Self-regulated learning: From teaching to self-reflective practice. Guilford Press.

Scott, J., Tallia, A., Crosson, J. C., Orzano, a. J., Stroebel, C., DiCicco-Bloom, B., ... Crabtree, B. (2005). Social Network Analysis as an Analytic Tool for Interaction Patterns in Primary Care Practice. Annals of Family Medicine, 3, 443-448.

Seymour, E., DeWelde, K., \& Fry, C. (2011). Determining progress in improving undergraduate STEM education: The reformer's tale. ... Diffusion of Transformative Engineering Education ..., 1-30.

Smith, B. (2001). The Challenge of Learning Communities as a Growing National Movement. AAC \&UC on Learning Communities. Rhode Island.

Smith, D. G. (1977). College classroom interactions and critical thinking. Journal of Educational Psychology, 69(2), 180-190. 
Sokoloff, D. R. (1996). Teaching electric circuit concepts using microcomputer-based current/voltage probes. In Microcomputer-Based Labs: Educational Research and Standards (pp. 129-146). Springer Berlin Heidelberg.

Svinicki, M. (2013). Active Learning Classroom (ALC). Ten Benefits of Active Learning Drawn From Theory.

Swing, S. R., \& Peterson, P. L. (1982). The Relationship of Student Ability and SmallGroup Interaction to Student Achievement. American Educational Research Journal, 19(2), 259-274.

Thornton, R. K., \& Sokoloff, D. R. (1998). Assessing student learning of Newton 's laws : The Force and Motion Conceptual Evaluation and the Evaluation of Active Learning Laboratory and Lecture Curricula, 338-352.

Traxler, A. (2015). Community structure in introductory physics course networks. Paper presented at Physics Education Research Conference 2015, July 29-30, College Park, MD

Van Heuvelen, A. (2005). Active Learning Guide. Addison-Wesley.

Vygotsky, L. S. (1962). Thought and language. (E. Hanfmann and G. Vakar, Trans.) Cambridge. MA: MIT \& Wiley.

Vygotsky S., L. (1978). Mind in Society, 151.

Wade, R. C. (1994). Teacher education students' views on class discussion: Implications for fostering critical reflection. Teaching and Teacher Education, 10(2), 231-243.

Webb, N. M. (1982). Peer interaction and learning in cooperative small groups. Journal of Educational Psychology, 74(5), 642-655.

Webb, N. M. (1984). Microcomputer learning in small groups: Cognitive requirements and group processes. Journal of Educational Psychology, 76(6), 1076-1088.

Webb, N. M. (1991). Task-Related Verbal Interaction and Mathematics Learning in Small Groups. Journal for Research in Mathematics Education, 22(5), 366-389.

Webb, N. M., \& Mastergeorge, A. M. (2010). Directed Small Groups The Development of Students 'Helping Behavior and Learning in Peer-Directed Small Groups. Cognition, (907688116).

Webb, N. M., \& Mastergeorge, A. M. (2013). The Development of Students ' Helping Behavior and Learning in Peer-Directed Small Groups, 21(4), 361-428. 
Wells, M., Hestenes, D., \& Swackhamer, G. (1995). A modeling method, 63(July), 606619.

Wertsch, J. V. (1991). Voices of the Mind, 169.

Wieman, C., \& Gilbert, S. (2015). Taking a scientific approach to science education, Part II-Changing teaching. Microbe, 10(15), 203-207.

Williams, E., Brewe, E., Zwolak, J., \& Dou, R. (2015, July 29-30). Understanding Centrality: Investigating Student Outcomes within a Classroom Social Network. Paper presented at Physics Education Research Conference 2015, College Park, MD

Winkler, A. M., Ridgway, G. R., Webster, M. A., Smith, S. M., \& Nichols, T. E. (2014). Permutation inference for the general linear model. Neuroimage, 92, 381-397.

Yang, S. J. H., \& Chen, I. Y. L. (2008). A social network-based system for supporting interactive collaboration in knowledge sharing over peer-to-peer network. International Journal of Human-Computer Studies, 66(1), 36-50.

Zhao, C.-M., \& Kuh, G. D. (2004). Adding Value: Learning Communities and Student Engagement. Research in Higher Education, 45(2), 115-138.

Zhu, E., \& Baylen, D. M. (2005). From learning community to community learning: pedagogy, technology and interactivity. Educational Media International, 42(3), 251-268.

Ziegler, S. G. (2007). The (mis)education of Generation M. Learning, Media and Technology, 32(1), 69-81.

Zimmerman, B. J. (1989). A social cognitive view of self-regulated academic learning. Journal of Educational Psychology, 81(3), 329-339. 
Appendices

Appendix 1: Example of class lesson plan

\begin{tabular}{|c|l|c|c|}
\hline Time & Description & Students doing & $\begin{array}{l}\text { Instructor } \\
\text { doing }\end{array}$ \\
\hline 15 & Review & Talking & $\begin{array}{l}\text { Keeping out } \\
\text { of the way }\end{array}$ \\
\hline 40 & $\begin{array}{l}\text { 8.1.6 and 8.2.4. These are to develop the } \\
\text { flux concept. 8.1.6 is collecting rain, 8.2.4 } \\
\text { is about the field lines passing through a } \\
\text { wire loop. They should put both on } \\
\text { whiteboards and present. }\end{array}$ & Working together & Facilitating \\
\hline 10 & $\begin{array}{l}\text { Summary lecture. Discuss flux. Point out } \\
\text { that we're measuring field in lines per unit } \\
\text { area. Summarize Faraday's law at the end } \\
\text { of it. Connect to experiments done on } \\
\text { Tuesday. Remember, induced EMF } \\
\text { (electromotive force) is Iind } \mathrm{x} \text { R, where R } \\
\text { is the resistance of the loop. }\end{array}$ & Listening, asking & Taestions \\
\hline 15 & $\begin{array}{l}\text { 8.4.1 - Flux practice. Push them to be } \\
\text { quick }\end{array}$ & $\begin{array}{l}\text { Working together } \\
\text { 8.1.5 - Observations to develop Lenz's } \\
\text { rule. They must put the pattern on the } \\
\text { whiteboard and present. I will summarize } \\
\text { at the end if they struggle with it. }\end{array}$ & Working together \\
\hline 15 & $\begin{array}{l}\text { Give them a problem not directly } \\
\text { addressed in the worksheets: Put on the } \\
\text { board and have them work quickly on } \\
\text { whiteboards and present: A loop of wire } \\
\text { passes through a region of magnetic field. } \\
\text { Show three points: Entering the field, in } \\
\text { field, and leaving field. Ask: What is the } \\
\text { direction of the induced current in the } \\
\text { wire loop at the three points shown? They } \\
\text { should present their work. }\end{array}$ & Forkilitating \\
\hline 30 & & Facilitating \\
\hline
\end{tabular}




\section{Appendix 2: Sample of worksheet For LAct}

An elevator starts at rest on the ground floor of a building and stops at the top floor. The elevator then returns to the bottom floor. Complete the table that follows to determine the relative magnitude of the force that the supporting cable exerts on the elevator $\mathrm{F}_{\mathrm{C}}$ on $\mathrm{El}$, compared to the force that the Earth exerts on the elevator $F_{E}$ on El. The motion description and the force description should be consistent with each other and with the rule you've established relating motion and forces. (i.e., is $F_{\mathrm{C} \text { on El }}>F_{\mathrm{E} \text { on El}}, F_{\mathrm{C} \text { on El }}=F_{\mathrm{E} \text { on El }}$, or $F_{\mathrm{C} \text { on }}$ El $<F_{\text {E on El}}$ ?)
(A) Elevator hangs at rest at the first floor.
(B) The elevator starts moving upwards going faster and faster.
(C) The elevator moves upward with a constant speed.
(D) The elevator slows down as it approaches the top floor.
(E) The elevator starts moving downwards going faster and faster.
(F) The elevator moves downwards with a constant speed.
(G) The elevator slows down as it approaches the first floor and comes to a stop.

\begin{tabular}{|c|c|c|c|c|c|c|c|}
\hline & (A) & (B) & (C) & (D) & (E) & (F) & (G) \\
\hline 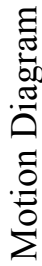 & & & & & & & \\
\hline 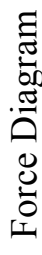 & & & & & & & \\
\hline & & & & & & & \\
\hline
\end{tabular}

Check for consistency between your force and motion diagrams.

Source: Active Learning Guide, Van Heuvelen, A. (2005) 
Appendix 3: One-Week Network Matrix of "who worked with whom"

\begin{tabular}{|c|c|c|c|c|c|c|c|c|c|c|c|c|c|c|c|c|c|c|c|c|c|c|c|c|c|c|c|c|c|c|}
\hline Students & 1 & 2 & 3 & 4 & 5 & 6 & 7 & 8 & 9 & 10 & 11 & 12 & 13 & 14 & 15 & 16 & 17 & \begin{tabular}{|l|}
18 \\
\end{tabular} & \begin{tabular}{|l|}
19 \\
\end{tabular} & 20 & \begin{tabular}{|l|l|}
21 \\
\end{tabular} & \begin{tabular}{|l|}
22 \\
\end{tabular} & 23 & \begin{tabular}{|l|l|}
24 & \\
\end{tabular} & 25 & \begin{tabular}{l|l}
26 \\
\end{tabular} & \begin{tabular}{|l|l}
27 \\
\end{tabular} & \begin{tabular}{|l|l|}
28 \\
\end{tabular} & \begin{tabular}{l|l|}
29 & \\
\end{tabular} & 30 \\
\hline 1 & 0 & 1 & 1 & 1 & 0 & 0 & 0 & 0 & 0 & 0 & 0 & 0 & 0 & 0 & 0 & 1 & 0 & 0 & 1 & 1 & 0 & 0 & 0 & 0 & 0 & 1 & 1 & 0 & 0 & 0 \\
\hline 2 & 1 & 0 & 1 & 1 & 0 & 1 & 1 & 0 & 0 & 0 & 1 & 0 & 1 & 0 & 1 & 0 & 0 & 1 & 0 & 0 & 0 & 0 & 0 & 0 & 0 & 0 & 0 & 0 & 1 & 1 \\
\hline 3 & 1 & 0 & 0 & 1 & 0 & 1 & 0 & 0 & 0 & 1 & 0 & 0 & 0 & 0 & 0 & 0 & 0 & 0 & 0 & 0 & 0 & 0 & 0 & 0 & 0 & 0 & 1 & 1 & 1 & 1 \\
\hline 4 & 1 & 0 & 1 & 0 & 0 & 0 & 0 & 0 & 0 & 8 & 0 & 0 & 0 & 0 & 0 & 1 & 0 & 0 & 1 & 0 & 0 & 0 & 1 & 0 & 0 & 1 & 1 & 0 & 0 & $\overline{0}$ \\
\hline 5 & 0 & 0 & 0 & 0 & 0 & 1 & 0 & 0 & 0 & 0 & 1 & 0 & 1 & 1 & 0 & 0 & 0 & 0 & 0 & 0 & 0 & 0 & 0 & 0 & 0 & 1 & 0 & 1 & 0 & 0 \\
\hline 6 & 0 & 1 & 1 & 0 & 1 & 0 & 0 & 0 & 0 & 1 & 0 & 0 & 1 & 0 & 1 & 1 & 1 & 1 & 1 & 1 & 0 & 0 & 0 & 0 & 1 & 1 & 0 & 1 & 0 & 1 \\
\hline 7 & 0 & 0 & 0 & 0 & 0 & 0 & 0 & 0 & 0 & 0 & 0 & 0 & 0 & 0 & 0 & 0 & 0 & 0 & 0 & 0 & 0 & 0 & 0 & 0 & 0 & 0 & 0 & 0 & 0 & 0 \\
\hline 8 & 0 & 0 & 0 & 0 & 0 & 0 & 0 & 0 & 0 & 0 & 0 & 0 & 0 & 0 & 0 & 0 & 0 & 0 & 0 & 0 & 0 & 0 & 0 & 0 & 0 & 0 & 0 & 0 & 0 & 0 \\
\hline 9 & 0 & 0 & 0 & 0 & 0 & 0 & 0 & 0 & 0 & 0 & 0 & 0 & 0 & 1 & 0 & 0 & 0 & 0 & 0 & 0 & 0 & 0 & 0 & 0 & 0 & 1 & 1 & 0 & 1 & 1 \\
\hline 10 & 0 & 1 & 1 & 0 & 1 & 1 & 0 & 0 & 1 & 4 & 0 & 0 & 1 & 0 & 0 & 0 & 0 & 0 & 0 & 0 & 1 & 0 & 1 & 0 & 0 & 1 & 1 & 0 & 1 & 1 \\
\hline 11 & 1 & 0 & 0 & 1 & 0 & 0 & 0 & 0 & 0 & 0 & 0 & 0 & 0 & 0 & 0 & 1 & 0 & 0 & 1 & 0 & 0 & 0 & 0 & 0 & 0 & $\begin{array}{ll}0 \\
\end{array}$ & 1 & 0 & 0 & $\overline{0}$ \\
\hline 12 & 0 & 0 & 0 & 0 & 0 & 0 & 0 & 0 & 0 & 0 & 0 & 0 & 0 & 0 & 0 & 0 & 0 & 0 & 0 & 0 & $\begin{array}{ll}0 \\
\end{array}$ & 0 & 0 & 0 & 0 & 0 & 0 & 0 & 0 & 0 \\
\hline 13 & 0 & 0 & 0 & 0 & 1 & 1 & 0 & 0 & 0 & 0 & 0 & 0 & 0 & 0 & 0 & 0 & 0 & 0 & 0 & 0 & 0 & 0 & 0 & 0 & 0 & 0 & 0 & 0 & 0 & 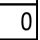 \\
\hline 14 & 0 & 0 & 0 & 0 & 0 & 0 & 0 & 0 & 1 & 0 & 0 & 0 & 0 & 0 & 0 & 0 & 0 & 0 & 0 & 0 & 0 & 0 & 0 & 0 & 0 & 1 & \begin{tabular}{l|}
0 \\
\end{tabular} & 0 & 1 & 1 \\
\hline 15 & 0 & 1 & 1 & 1 & 0 & 0 & 0 & 1 & 0 & 0 & 0 & 0 & 0 & 0 & 0 & 0 & 0 & 0 & 0 & 0 & 0 & 0 & 0 & 0 & 0 & 0 & 0 & 0 & 0 & 0 \\
\hline 16 & 1 & 0 & 0 & 1 & 0 & 1 & 0 & 0 & 0 & 0 & 1 & 0 & 1 & 0 & 0 & 0 & 1 & 0 & 1 & 0 & 0 & 0 & 0 & 0 & 0 & 0 & 1 & 0 & 0 & 0 \\
\hline 17 & 0 & 0 & 0 & 0 & 0 & 1 & 0 & 0 & 1 & 0 & 0 & 0 & 0 & 0 & 0 & 1 & 0 & 0 & 0 & 0 & 0 & 0 & 0 & 1 & 0 & 1 & 0 & 1 & 0 & $\overline{0}$ \\
\hline 18 & 0 & 0 & 0 & 0 & 0 & 0 & 0 & 0 & 0 & 0 & 0 & 0 & 0 & 0 & 0 & 0 & 0 & 0 & 0 & 0 & 0 & 0 & 0 & 0 & 0 & 0 & 0 & 0 & 0 & 0 \\
\hline 19 & 1 & 0 & 0 & 1 & 0 & 0 & 0 & 0 & 0 & 0 & 0 & 0 & 0 & 0 & 0 & 1 & 1 & 0 & 0 & 0 & 0 & 0 & 0 & 0 & 0 & 1 & 1 & 0 & 0 & 1 \\
\hline 20 & 1 & 1 & 1 & 1 & 1 & 1 & 0 & 0 & 0 & 1 & 0 & 0 & 0 & 1 & 0 & 0 & 0 & 0 & 0 & 0 & 0 & 0 & 0 & 1 & 0 & 1 & 1 & 0 & 1 & 1 \\
\hline 21 & 1 & 0 & 0 & 0 & 0 & 0 & 0 & 0 & 0 & 0 & 0 & 0 & 0 & 0 & 0 & 0 & 0 & 1 & 0 & 0 & 0 & 0 & 0 & 0 & 0 & 0 & 0 & 0 & 0 & 0 \\
\hline 22 & 0 & 0 & 0 & 0 & 0 & 0 & 0 & 0 & 0 & 0 & 0 & 0 & 0 & 0 & 0 & 0 & 0 & 0 & 0 & 0 & 0 & 0 & 0 & 0 & 0 & 0 & 0 & 0 & 0 & 0 \\
\hline 23 & 0 & 0 & 0 & 0 & 1 & 0 & 1 & 0 & 1 & 1 & 0 & 1 & 0 & 0 & 0 & 0 & 0 & 0 & 0 & 0 & 0 & 0 & 0 & 0 & 0 & 0 & 0 & 0 & 0 & 0 \\
\hline 24 & 0 & 0 & 0 & 0 & 0 & 0 & 0 & 0 & 0 & 0 & 0 & 0 & 0 & 0 & 0 & 0 & 0 & 0 & 0 & 0 & 0 & 0 & 0 & 0 & 0 & 0 & 0 & 0 & 0 & $\overline{0}$ \\
\hline 25 & 0 & 0 & 0 & 0 & 1 & 1 & 0 & 0 & 0 & 0 & 0 & 1 & 1 & 0 & 0 & 0 & 0 & 0 & 0 & 0 & 0 & 0 & 0 & 0 & 0 & 0 & 0 & 0 & 0 & 0 \\
\hline 26 & 1 & 1 & 0 & 1 & 0 & 0 & 0 & 0 & 0 & 0 & 0 & 0 & 0 & 1 & 0 & 0 & 0 & 0 & 1 & 0 & 0 & 0 & 0 & 0 & 0 & 0 & 1 & 0 & 1 & 1 \\
\hline 27 & 1 & 0 & 0 & 1 & 0 & 0 & 0 & 0 & 0 & 0 & 0 & 0 & 0 & 0 & 0 & 1 & 0 & 0 & 1 & 0 & 0 & 0 & 0 & 0 & 0 & 0 & \begin{tabular}{l|l}
0 \\
\end{tabular} & 0 & 0 & 0 \\
\hline 28 & 0 & 0 & 1 & 1 & 1 & 0 & 0 & 0 & 0 & 0 & 0 & 0 & 1 & 0 & 0 & 0 & 1 & 1 & 0 & 0 & 0 & 0 & 0 & 1 & 0 & 1 & 0 & 0 & 0 & 1 \\
\hline 29 & 0 & 1 & 0 & 0 & 1 & 1 & 0 & 0 & 1 & 0 & 0 & 0 & 0 & 1 & 0 & 0 & 0 & 0 & 0 & 1 & 0 & 0 & 0 & 0 & 0 & 1 & 1 & 0 & 0 & 1 \\
\hline 30 & 0 & 1 & 1 & 0 & 0 & 1 & 0 & 0 & 1 & 1 & 0 & 0 & 0 & 1 & 0 & 0 & 0 & 0 & 1 & 1 & 0 & 0 & 0 & 0 & 0 & 1 & 0 & 0 & 1 & 0 \\
\hline
\end{tabular}

Note: Serial Numbers 1-30 in the first row and first column represent name of each

student. "1" in the first row represents number one student reported with whom he/she worked with during this particular week. In this matrix students, "1" worked with students "2", “3”, “4”,"16”, “19”, “20”, “26” and "27” in that particular week. 


\section{Appendix 4: Example of one Learning Activity and Related Exam Question}

\section{Learning Activity:}

Place an object on the scale, note the reading, then tilt the scale 10 degree or so. Make sure the object does not slide. Note what happens to the reading on the scale, and then draw a force diagram for the situation.

\section{Exam Question:}

A street vendor in the market is using a scale to weigh produce. Unfortunately the street has a slope of $5^{\circ}$, which means his scale is tilted $5^{\circ}$ from horizontal. Suppose he buys 15 $\mathrm{kg}$ apples from wholesale (there the seller has a level scale) and has sold 10kg of apples to his customers from his tilted scale. Therefore he thinks he has $5 \mathrm{~kg}$ of apples left. What mass of apples does he really have left? Is he losing money or is he stealing from his customers because of the tilted scale? 
VITA

BINOD NAINABASTI

Born, Ramgha, Lamjung, Nepal

Education

Bachelor of Science, (Majors: Physics, Mathematic and Statistics)

Tribhuvan University, Kathmandu, Nepal, January 1996

Masters of Science, Physics

Tribhuvan University, Kathmandu, Nepal, November 1999

Masters of Arts and Science, JICA Scholar

Waseda University, Tokyo, Japan, March 2007

Masters of Science, Physics

Florida Atlantic University, Florida, USA, 2011

Publications

Binod Nainabasti, David T. Brookes, Yuehai Yang, and Yuhfen Lin, "Connection Between Participation in Interactive Learning Environment and Learning through Teamwork", Peer Reviewed and edited by Paula V. Engelhardt, Alice Churukian, and Dyan L. Jones, AIP Conference Proceeding, College Park, Maryland, 2015, pp 231-234.

Binod Nainabasti, David T. Brookes, and Yuehai Yang, "Students' Participation And Its Relationship To Success In An Interactive Learning Environment”, Peer Reviewed and edited by Paula V. Engelhardt, Alice Churukian, and Dyan L. Jones, AIP Conference Proceedings, Minneapolis, MN, 2014, pp. 195-198.

Yuehai Yang, Binod Nainabasti, David T. Brookes, and Eric Brewe, A Study of Informal Learning Communities: a Tale of Two Physics Courses, Peer Reviewed and edited by Paula V. Engelhardt, Alice Churukian, and Dyan L. Jones, AIP Conference Proceedings, Minneapolis, MN, 2014, pp. 283-186.

David T. Brookes, Binod Nainabasti, and Yuehai Yang "Characterizing Student Participation in an ISLE Physics Class", Peer Reviewed and edited by Paula V. Engelhardt, Alice D. Churukian, and Dyan L. Jones, AIP Conference Proceedings, Portland, OR, 2013, 77-80. 